\title{
PROTOTY PICALITY, DISTINCTIVENESS, AND INTERCORRELATION: ANALYSES OF THE SEMANTIC ATTRIBUTES OF LIVING AND NONLIVING CONCEPTS
}

\author{
Peter Garrard \\ University of Cambridge Neurology Unit, Addenbrooke's Hospital, Cambridge, UK \\ Matthew A. Lambon Ralph \\ $M R C$ Cognition and Brain Sciences Unit, Cambridge, UK. \\ John R. Hodges \\ University of Cambridge Neurology Unit, Addenbrooke's Hospital, Cambridge, UK and MRC Cognition and Brain Sciences Unit, \\ Cambridge, UK. \\ Karalyn Patterson \\ MRC Cognition and Brain Sciences Unit, Cambridge, UK.
}

\begin{abstract}
Many cognitive psychological, computational, and neuropsychological approaches to the organisation of semantic memory have incorporated the idea that concepts are, at least partly, represented in terms of their fine-grained features. We asked 20 normal volunteers to provide properties of 64 concrete items, drawn from living and nonliving categories, by completing simple sentence stems (e.g., an owl is _., has $\ldots$, can__. At a later date, the same participants rated the same concepts for prototypicality and familiarity. The features generated were classified as to type of knowledge (sensory, functional, or encyclopaedic), and also quantified with regard to both dominance (the number of participants specifying that property for that concept) and distinctiveness (the proportion of exemplars within a conceptual category of which that feature was considered characteristic). The results demonstrate that rated prototypicality is related to both the familiarity of the concept and its distance from the average of the exemplars within the same category (the category centroid). The feature database was also used to replicate, resolve, and extend a variety of previous observations on the structure of semantic representations. Specifically, the results of our analyses (1) resolve two conflicting claims regarding the relative ratio of sensory to other kinds of attributes in living vs. nonliving concepts; (2) offer new information regarding the types of features - across different domains - that distinguish concepts from their category coordinates; and (3) corroborate some previous claims of higher intercorrelations between features of living things than those of artefacts.
\end{abstract}

\section{INTRODUCTION}

The neuropsychological study of brain-damaged individuals can provide insights into the nature of normal, intact cognitive systems, and studies of patients in whom semantic knowledge has been disrupted have made a number of important observations that bear on aspects of its underlying archi-

Requests for reprints should be addressed to Dr Peter Garrard, University of Cambridge Neurology Unit, Box 165, Addenbrooke's Hospital, Cambridge, CB2 2QQ, UK. (Email: garrard@cnbc.cmu.edu).

This research was supported by means of Medical Research Council grants to JRH and a Medical Research Council clinical training fellowship to PG. 
tecture. In cases with progressive disintegration of semantic memory (such as occurs in some patients with dementia of Alzheimer's type [DAT; Hodges, Salmon, \& Butters, 1992a; Chertkow \& Bub, 1990] and, by definition, in those with the syndrome of semantic dementia [SD; Hodges, Patterson, Oxbury, \& Funnell, 1992b] the course is typically gradual such that, in the early stages, knowledge is only partially disrupted (Warrington, 1975). With progression of the disease, the patient's performance changes in a characteristic fashion. For example, the ability to assign concepts to their superordinate categories invariably outlasts the ability to draw distinctions based on more specific criteria (e.g., to distinguish between fierce and nonfierce animals). Furthermore, in picture naming the tendency towards generic responses (i.e., the category label or the name of a highly prototypical category member) has been shown to increase with disease progression (Hodges, Graham, \& Patterson, 1995).

Such phenomena have been interpreted as suggesting that semantic memory is organised according to a nested hierarchy, with superordinate distinctions (such as that between natural kinds and artefacts), categories (such as animals, birds, and tools), and individual exemplars (such as chimpanzees, flamingos, and sledgehammers) represented at different levels (Warrington, 1975). Despite the appeal of this view, a number of empirical observations about the nature of concepts and categories are somewhat difficult to reconcile with it. In the first place, category membership is often unclear (are tomatoes fruit or vegetables?), multiple (a horse could be categorised as both animal and vehicle), or simply unnatural (to what category of objects do traffic lights and railway platforms belong?). It is unclear how the rigid classification implied by a hierarchical model could incorporate such conceptual imprecisions. A similar argument applies to the fact that some categories seem much more internally coherent than others-compare the category of "birds" with that of "household items."

An alternative view holds that knowledge of higher-order (categorical and superordinate) structure is an emergent property of a distributed network of more fine-grained components. The underlying cognitive structure of such a network may thus be reducible to the overlapping organisation of discrete featural elements. This idea has much in common with theories which regard conceptual representations as equivalent to "some sort of measure of central tendency of the instances' properties or patterns" (Smith \& Medin, 1981, p. 61). According to this view, categories do not have independent ontological status; rather, they are products of a collection of individual conceptual representations that share a partially common set of features. The "coherence" of the "category" is then directly related to the quantity, or proportion, of shared features.

A neuropsychological phenomenon that has been interpreted in this context is category-specific impairment of semantic memory. Cases exhibiting this phenomenon show disproportionate impairment of concepts belonging to one of two superordinate domains, broadly defined as biological kinds (such as animals, birds, and fruits/vegetables) or man-made artefacts (such as vehicles and tools). The majority of such cases have shown a disproportionate impairment of knowledge in the domain of natural kinds (e.g., Sartori, Job, Miozzo, Zago, \& Marchiori, 1993; Warrington \& Shallice, 1984) but the reverse dissociation has also been observed (e.g., Hillis \& Caramazza, 1991; Sacchett \& Humphreys, 1992; Warrington \& McCarthy, 1987).

The basis of category specificity remains controversial: One influential view is that the natural kinds/artefacts dichotomy captures a fundamental difference in the nature of the representations underlying different semantic categories, rather than simply reflecting the presence of two distinct knowledge systems. Knowledge about one class of objects (dominated by natural kinds) is thought to be encoded principally in terms of perceptual features (size, shape, colour, etc.), whereas functional attributes (such as how we interact with or use the object) are more salient for another class of objects (predominantly artefacts). Thus, damage to the neural systems critical for the representation of perceptual attributes will result in disproportionate loss of knowledge about natural kinds. This explanation appeared to make more sense of findings in 
the experimental literature that could not easily be accommodated into purely taxonomic accounts. For example, knowledge of body parts (a biological category with highly salient functional properties) tends to be preserved along with artefacts, whereas certain inanimate subgroups, whose members are perceptually distinct but share a canonical function (e.g., fabrics, precious stones, and musical instruments) behave more like natural kinds (Warrington \& McCarthy, 1987). The idea that category-specific deficits reflect disproportionate damage to an information type rather than to a category per se has come to be known as the sensoryfunctional theory (SFT). The possibility of emergent category effects appearing with damage to a noncategorically organised system has been established using a connectionist model (Farah \& McClelland, 1991).

Two fundamentally different explanations have been proposed to account for the independent disruption of distinct types of knowledge. One idea is that representations of different knowledge types are located in separate regions of the brain, and that the location of brain damage is therefore critical in determining which domain of knowledge is preferentially disrupted. To the extent that many cases with a category-specific pattern appear to follow characteristic distributions of well-circumscribed brain damage (Gainotti, 1990; Garrard, Patterson, Watson, \& Hodges, 1998), this account appears plausible. It also has parallels in neurophysiological models of the visual system, which distinguish between two functionally and anatomically separable pathways: an inferior temporal pathway specialised for item recognition and an inferior parietal pathway for visually guided hand movements (Goodale, Milner, Jakobson, \& Carey, 1991). The richness of inferior parietal lobe projections to and from other cortical areas has led to the hypothesis that the latter region serves a supramodal sensory function by which visuospatial, tactile, and kinaesthetic information is integrated. It would therefore be a likely substrate for the representation of functional information, in contrast to more directly perceptual features such as colour and shape, which might be separately represented in the temporal lobes.
This model has been criticised, however, for a variety of reasons. First, although some patients with a disproportionate deficit for living categories have also been found to show the expected difference in their knowledge of sensory and functional attributes (Silveri \& Gainotti, 1988), both deficits have also been described in isolation (Laiacona, Capitani, \& Barbarotto, 1993), arguing strongly against a causal link. Equally problematic are cases SE (Laws, Evans, Hodges, \& McCarthy, 1995), whose sizeable deficit for living things was accompanied by poor associative rather than visual knowledge, and IW (Lambon Ralph, Howard, Nightingale, \& Ellis, 1998) who showed selective loss of visual knowledge together with relative preservation of living kinds. Finally, the SFT has not been considered adequate to account for the occurrence of category-specific deficits in the context of degenerative conditions in which the pathological lesion is less clearly localised, such as dementia of Alzheimer's type (DAT). Alternative accounts have therefore been proposed, which place greater importance on the statistical regularities-originally pointed out by Keil $(1987,1989)$ and Rosch (1978) — that exist between groups of elements in a feature network (Devlin, Gonnerman, Anderson, \& Seidenberg, 1998; Durrant-Peatfield, Tyler, Moss, \& Levy, 1997; Gonnerman, Andersen, Devlin, Kempler, \& Seidenberg, 1997). These accounts suggest that statistical correlations identify mutually reinforcing groups of features, and that the presence of such feature coalitions within a concept's representation results in a greater degree of robustness in the face of mild degrees of diffuse damage. The same coalitional factor will, however, render such concepts vulnerable in the presence of more severe disruption, because the groups of features on which they jointly depend will tend to drop out en masse.

There are two variants of this hypothesis: One account (that of Devlin et al., 1998) proposes that feature intercorrelation is primarily a property of concepts in the living domain, whereas Durrant Peatfield et al. (1997) argue that groups of sensory and functional features, particularly those of artefacts ("form-function" correlations), tend to be the most highly correlated. These two models make 
opposing predictions about the relative robustness of living and nonliving categories in the face of mild semantic disruption, but there is still little empirical evidence, either from patients or feature norming studies, that would allow one to choose between them.

A third explanation for category-specific deficits has been provided by the organised unitary content hypothesis (OUCH; Hillis, Rapp, \& Caramazza, 1995; Caramazza, Hillis, Rapp, \& Romani, 1990). According to this formulation, the representation of conceptual knowledge depends on a single system, in which similar concepts tend to cluster together by virtue of their shared attribute structure. Localised cortical insults may therefore produce disproportionate impairments of concepts in similar regions of semantic space, leading to category-specific impairments. Among the advantages of this model is the fact that it can account for combinations of spared and affected categories that are not predicted by the SFT. For instance, Hillis and Caramazza (1991) described a patient with preserved knowledge of animals but impaired knowledge of fruits/vegetables and inanimate objects.

A problem for OUCH, however, is that while it appears to predict the possibility of selective impairment to a wide selection of individual categories, the patterns that are observed in brain-damaged patients are largely limited to the broad domains of animals, fruit/vegetables, and inanimate objects. To overcome this objection, Caramazza and Shelton (1998) have proposed that there may, in addition, be a categorical level of semantic organisation. They argue that separate areas of neural tissue may have become specialised, under evolutionary pressures, to represent items belonging to three broad domains-animals, plant life, and artefacts-and that category-specific semantic impairments result from damage to "categorically organised knowledge system[s] that represent all types of information relevant to that domain" (p.9). They thus challenge the reductionist notion that knowledge of items in each category depends on different types of property. They also suggest that some attempts (such as that of Farah and McClelland, 1991) to determine empirically the featural components of individual concepts have been subject to a major experimental bias: To define functional information as describing "what something is for" may have deterred subjects from associating such information with certain living categories. Caramazza and Shelton also point out that many of the case reports arguing for a complementary dissociation between feature types based on subjects' ability to answer different types of question (e.g., Farah, Hammond, Mehta, \& Ratcliff, 1989; Basso, Capitani, \& Laiacona, 1988; Silveri \& Gainotti, 1988) have failed to control for the relative difficulty of visual and functional attribute judgements. Moreover, individual categories whose meanings are hypothesised to depend on the same feature modality (e.g., animals and fruits, which are both weighted heavily for perceptual attributes) may be independently damaged (Farah \& Wallace, 1992; Hart, Berndt, \& Caramazza, 1985; Hart \& Gordon, 1992; Hillis \& Caramazza, 1991), and some appropriately controlled studies of attribute knowledge in cases with an established category-specific impairment have reported equal difficulty with sensory and functional information (Barbarotto, Capitani, Spinnler, \& Trivelli, 1995; Lambon Ralph et al., 1998). In addition, there are a number of studies in which patients have been found to exhibit relatively poor sensory over functional knowledge, without the occurrence of a category-specific deficit for living things (Coltheart et al., 1998; Lambon Ralph et al., 1999; Moss, Tyler, Durranta-Peatfield, \& Bunn, 1998).

Some of these formulations have been implemented in connectionist networks, in which category-specific conceptual loss results from either differential "lesioning" of the units representing perceptual and functional features, or from global lesioning in which domain effects are a by-product of differential intercorrelations between the component features. In the model of Farah and McClelland (1991), the semantic features were derived from a series of dictionary definitions, components of which were judged by a panel of undergraduate students to be examples of either sensory or functional knowledge. It is questionable whether an attribute set assembled on this basis accurately reflects the featural composition of concepts within any individual human's semantic memory, and the 
potential for biases favouring the hypothesis to be tested has been noted by Caramazza and Shelton (1998). McRae, de Sa, and Seidenberg (1997) used a rather more natural method to collect a large set of attributes for living and manmade concepts, and examined their database for evidence of some of the correlational properties referred to earlier. Neither of these studies has, however, presented sets of features corresponding to items in a semantic test battery that can be used to investigate potential differences in knowledge of specific categories in brain-damaged patients (though for a thorough analysis of these issues using a very large feature database, see McRae \& Cree, in press).

The motivations for collecting a set of attribute norms, therefore, are threefold: first, to examine the relationship between category structure and feature knowledge; second, to evaluate the assumptions of cognitive models that attempt to explain categoryspecific semantic impairments in terms of disruption to feature knowledge in the light of an empirically derived corpus of semantic features; and third, to provide a set of living and nonliving concepts that, together with a sample of semantic features varying over theoretically important dimensions such as type of knowledge and distinctiveness, can be used for fine-grained investigations of subjects with semantic memory impairments (see Appendix A).

\section{SUBJECTS, MATERIALS, AND METHODS}

\section{Generation of semantic features}

The subjects were 20 volunteers from the MRC Cognition and Brain Sciences Unit subject panel. Eleven were female and nine male. Mean age was 67.4 years (SD 3.9), and mean years of education 11.4 (SD 2.0). A payment of $£ 25$ was made to each subject on completion of testing.
Subjects were tested in 2 groups of 10 each group attending for 2 sessions, 1 week apart. Data were collected using booklets containing 64 sheets with a standardised format as illustrated in Figure 1, but with a different item heading each sheet. The items had been selected from the Snodgrass and Vanderwart (1980) corpus as stimuli for a battery of tests of semantic memory, and consisted of eight animals native to Britain, eight foreign animals, eight birds, six fruits, two vegetables, eight small manipulable items, eight large non-manipulable items, eight tools, and eight vehicles.

Subjects were given folders containing all 64 sheets, arranged in random order, and asked to work through the folder filling in the blank spaces, beginning with the "Category" field". In order to avoid excessive constraints on the subjects' responses, instructions were minimised, but the following principles were explained, with examples where appropriate:

1. The object of the test was to determine the content of mental representations of familiar items of knowledge.

2. The category chosen for each item should be neither very broad nor very narrow.

3. The attributes should consist of single words or short phrases that could be connected to the word at the top of each page by the word adjoining each blank space.

4. "Is" attributes would tend to be descriptive words (not necessarily of a perceptual kind), "has" attributes to refer to parts of the item, and "can" attributes to the abilities, activities and uses of the item.

5. Attributes should not be pieces of specialised, technical information, nor judgements about the value or aesthetic qualities of an item, but examples of factual knowledge.

6. All the category spaces, and as many as possible of the attribute spaces were to be filled in, with a minimum of two or three per section ${ }^{2}$.

\footnotetext{
${ }^{1}$ The purpose of using a sentence-stem completion method rather than an attribute-listing procedure (favoured by McRae et al., (1997), was to standardise the task as far as possible, both between items and between subjects, without producing excessive constraints on the range of acceptable responses.

${ }^{2}$ Points 4 and 6 were designed to overcome the bias towards sensory attributes inherent in the fact that only one of the three sentence stems ("can...") is more likely to elicit functional than perceptual features.
} 


\section{Elephant}

\section{Category..............}

is $\ldots . \ldots \ldots \ldots$.

is $\ldots . . . \ldots \ldots$.

is $\ldots . . . . . . .$.

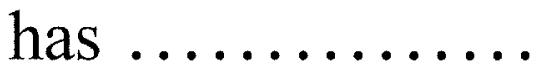

has .............

has .............

can ...............

can.........

can ...............

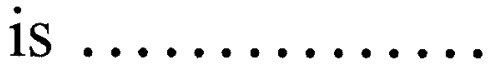
is $\ldots . . . \ldots \ldots$. is $\ldots . . . \ldots \ldots$.

has ............. has ............. has .............

can .............. can .............. can .............. 
7. When a page had been completed it should not be returned to later.

8. Two potentially ambiguous items ("glass" and "plug") referred to a container for drinking and an electrical plug, respectively.

Two practice sheets were given, and these were collected and examined to ensure that all subjects had understood the instructions before beginning the test proper. If the responses on any practice sheet indicated that the instructions had not been correctly followed, the errors were explained to the group as a whole without attributing them to any individual. To minimise fatigue, items were presented in 4 blocks of 16 , and the subjects were allowed to work for half an hour at a time. Although no formal time limits were set for the task, all subjects completed 12 to 16 sheets per half-hour period. Any unfinished sheets at the end of each block were inserted into an extra block, which was completed at the end.

Nineteen subjects completed the test, while one subject dropped out after the first session and therefore completed just under half of the sheets. The results were collated and entered into a database. Data entry took place in three stages: in the first, responses were divided into individual components of information (e.g., "an apple is red or green" was recoded as "an apple is red" and "an apple is green"). Composite attributes (such as "a horse has four legs") were coded as "a horse has legs" and "a horse has four legs", on the grounds that they contained two separate pieces of information. Responses to a given concept that were identical or had similar meanings were grouped together (e.g., "a lion is ferocious", "a lion is dangerous," and "a lion can kill"). In the second stage a standardised wording was assigned to each such grouping, and a dominance value (the proportion of subjects who generated the attribute for that concept) was calculated.
Finally, attribute wordings were standardised across the entire stimulus set (e.g., "an axe can be used to kill someone," "a lorry can run someone over," and "a hammer can be used as a weapon" were all recoded as instances of "....is dangerous").

As far as possible, all the information found on the sheets was preserved in the database, but the following kinds of response were changed: (1) "can" responses indicating attributes that may or may nor be true (e.g., "an apple can be green") were entered as "is" attributes ${ }^{4}$; (2) responses that identified subordinate instances of the item (e.g., "a saw is a fretsaw," or "an aeroplane is a Jumbo jet") were excluded; (3) qualifying expressions were omitted, so that, for instance, "a bicycle is quite fast" became an instance of "a bicycle is fast"; (4) the small number of responses that were highly idiosyncratic or otherwise difficult to classify, such as "a train can evoke happy memories," were excluded.

When data entry was complete, each attribute was designated as an instance of sensory, functional, encyclopaedic, or categorising information, according to the following criteria: attributes classified as sensory were those which could be appreciated in some sensory modality (e.g., "an eagle is large" or "a saw is sharp"); attributes categorised as functional were those which described an action, activity, or use of an item (e.g., "a cat can catch mice," "an owl can fly," or "a suitcase can be carried"); encyclopaedic attributes were considered to be those describing some other type of associative relationship (e.g., "a tiger is found in India"; or "a toaster is kept in the kitchen"); features classed as categorising were those that placed the item in a superordinate category (e.g., "a dog is an animal").

\section{Judgements of prototypicality and familiarity}

The 19 subjects who returned complete sets of attribute data in the initial part of the study were

\footnotetext{
${ }^{3}$ This process of "top-down" standardisation may ultimately have resulted in an underestimate of the distinctive properties, but was necessary because the feature set would otherwise have been dominated by distinctive features with a dominance of .05, making the quantity of usable data very small indeed. Moreover, many of these apparently distinctive features are not distinctive at all (a lorry is not the only vehicle that can run somebody over), and re-wording them to stand for some genuinely shared element that captures most of the sense behind them was felt to be an appropriate intervention.

${ }^{4}$ This manoeuvre runs counter to "classical" theories which assume that concepts are represented only in terms of their necessary and sufficient features (for a discussion, see Smith, \& Medin, 1981, pp. 22-60).
} 
contacted 12 months later, and asked to fill in a questionnaire with ratings of their assessments of the familiarity and typicality (considered as members of the 6 basic level categories) of the same 64 items. The format of the questionnaire required typicality judgements to be given on each member of the 6 categories, by assigning it to one of four typicality bands, which ranged from "highly typical" to "very atypical" of its category. Full written instructions, incorporating two completed examples (for categories of sea creatures and items of clothing) were given. Completed forms were received from 18 subjects, and average values of familiarity and prototypicality for each concept were calculated.

\section{DATA ANALYSES}

\section{Overall database characteristics}

The two vegetables in the category of fruit and vegetables were subsequently removed in order to make this category more homogeneous. The fruit category considered here therefore has only 6 exemplars, and subsequent analyses are based on a set of 62 items, 30 from living and 32 from nonliving categories. In total, 869 unique features were generated to the 62 stimulus words. Many of these responses were associated with more than $1 \mathrm{item}$, so the total number of concept-feature pairs was rather larger (2969).

The distribution of feature dominance is displayed in Figure 2, where it can be seen that a large number (approaching 300) of the attributes were generated by only one respondent (dominance <.1). In common with McRae et al. (1997), we chose to include in the analysis only those features that had been generated by two or more subjects. In this reduced set of 618 unique features, there were 1656 item-feature pairs, of which $5.5 \%$ were sensory, $27.6 \%$ functional, $14.7 \%$ encyclopaedic, and $7.2 \%$ categorising. Table 1 displays the distribution of feature types among each of the six basic level categories.

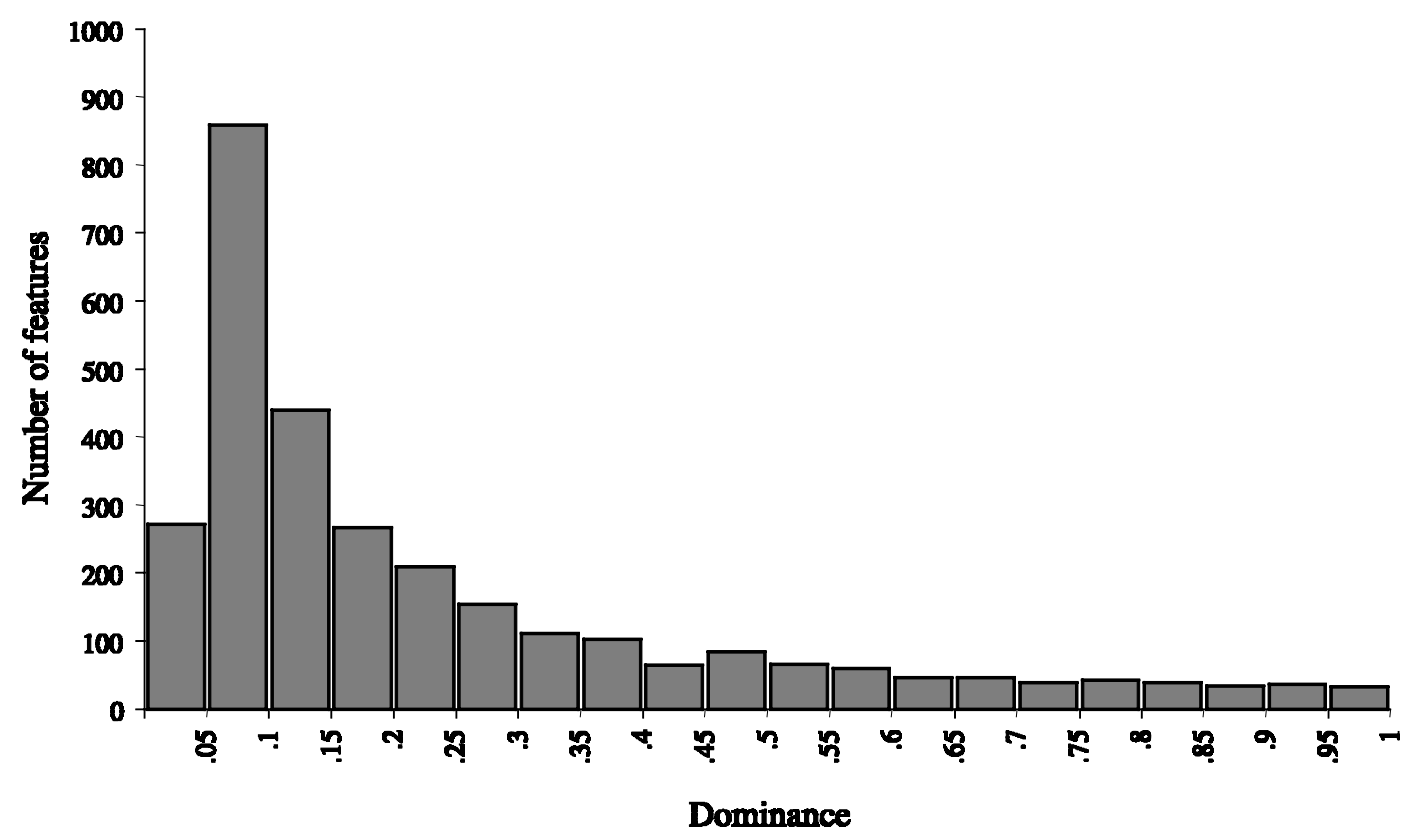

Figure 2. Distribution of dominance (production frequency) values in the original set of 2969 features. 
Table 1. Total number of features of each type associated with each of the six basic level categories.

\begin{tabular}{|c|c|c|c|c|c|c|c|c|c|}
\hline \multirow[b]{2}{*}{ Feature type } & \multicolumn{4}{|c|}{ Living } & \multicolumn{4}{|c|}{ Nonliving } & \multirow{2}{*}{$\frac{\text { Overall }}{\text { Total }}$} \\
\hline & Animals & Birds & Fruit & Total & H'hold & Tools & Vehicles & Total & \\
\hline Categorising & 40 & 12 & 7 & 59 & 38 & 10 & 12 & 60 & 119 \\
\hline Encyclopaedic & 106 & 40 & 17 & 163 & 23 & 16 & 43 & 82 & 245 \\
\hline Functional & 152 & 49 & 26 & 227 & 111 & 45 & 74 & 230 & 457 \\
\hline Sensory & 275 & 110 & 77 & 462 & 205 & 69 & 100 & 374 & 836 \\
\hline Total & 573 & 211 & 127 & 911 & 377 & 140 & 229 & 746 & 1657 \\
\hline
\end{tabular}

\section{Validity of the feature approach as a model of category and concept representation}

\section{Hierarchical cluster analysis of semantic features}

To assess categorical structure within the feature data and compare this with the categories assigned a priori, a hierarchical cluster analysis was performed, using the presence or absence of each feature (excluding categorising features) as the variable of interest.

Three observations can be made from the dendrogram presented in Figure 3. First, the degree of similarity based on these features alone was sufficient to produce clusters of items that corresponded very closely to the a priori category structure without any information about category membership being specified. Second, the earliest clusters to emerge are equivalent to the three broad domains suggested by Caramazza and Shelton (1998)fruit, animate beings, and inanimate objects - and these quickly divide to produce the most intuitively coherent categories of land-animals, birds, fruit, and vehicles. Third, the biological kinds are generally much more tightly clustered together than are any of the inanimate items except for those in the category of vehicles.

\section{Correlation between rated and computed measures of typicality}

Using the available data, it is possible to consider not only the differentiation of categories one from another, but also comparisons of items within individual categories. This suggests an alternative method of examining the validity of the featural approach, namely a comparison of the values of a semantic variable obtained directly from subjects' intuitions, with values derived from a theoretically motivated analysis of the feature data. According to Rosch and Mervis (1975), the typicality of a concept within its category is correlated with a measure of family resemblance, which is based on the degree to which its features are shared with those of other members of its category. The family resemblance metric used in these earlier studies was equivalent to the weighted sum of a concept's features, with the weights denoting the degree to which a feature was shared by other members of the same category. These measures were found to be highly correlated both with independently derived prototypicality ratings and with reaction times in category-concept verification tasks (Rosch, 1973). The present feature data allow this idea to be generalised to a different group of concepts, and across a selection of semantic categories.

In line with the distributed models of semantic organisation outlined in the Introduction, each concept's featural description was considered as a binary vector in a 618-dimensional feature space. The family resemblance measure used by Rosch and Mervis was implemented in the present study by calculating vector centroids for each of the six semantic categories. These were derived by calculating the average values of each element of all the vectors within a category, and were taken to be representative of the average, or most typical, category member. The angle between this vector centroid and each concept vector was assumed, therefore, to reflect its prototypicality within the category. Although the procedure for deriving prototypicality differed from that of Rosch and Mervis, the values obtained were influenced by the same factors: The greater the number of concepts sharing a particular feature, the higher the value of the corresponding element of the vector centroid. 


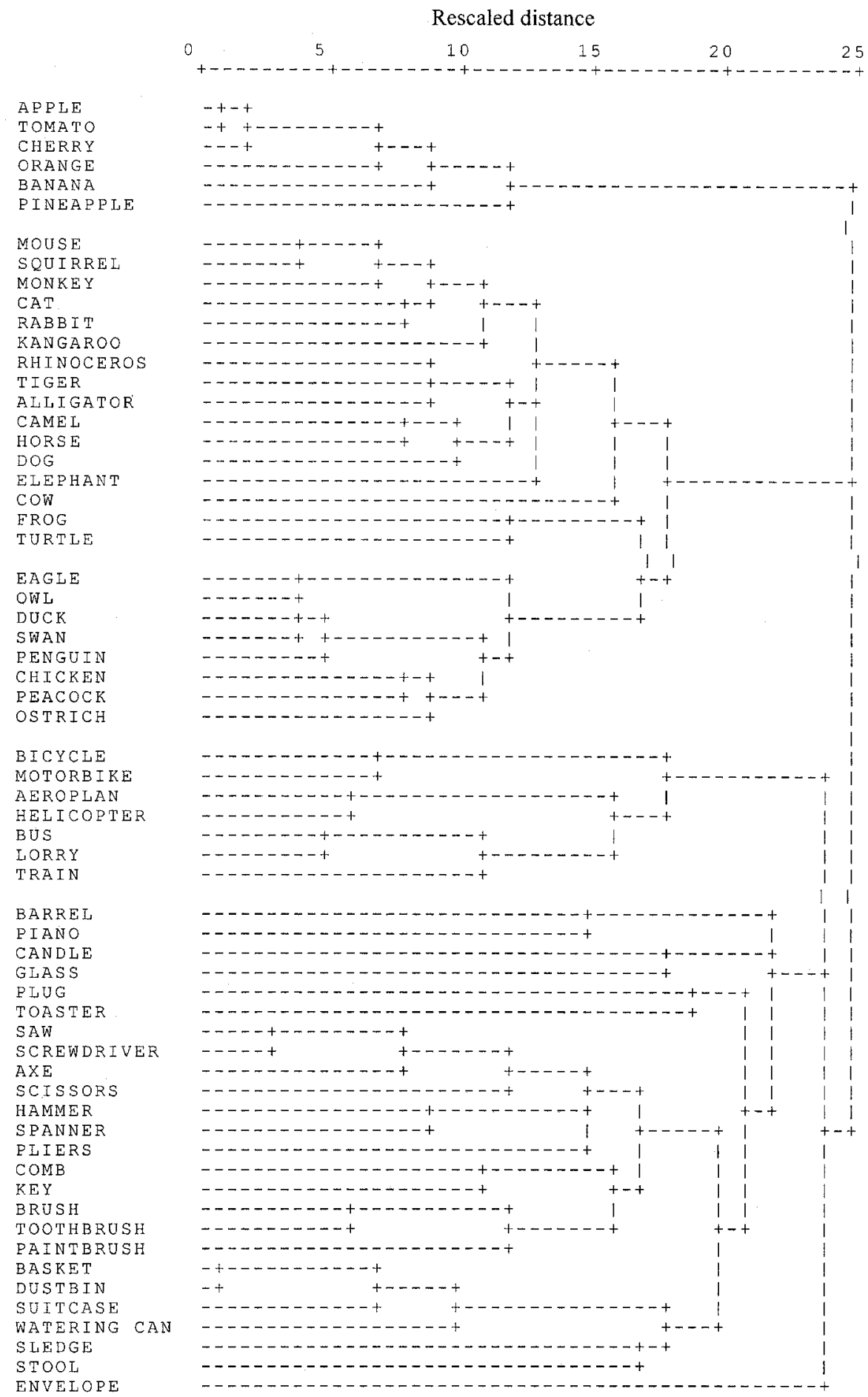

Figure 3. Dendrogram resulting from hierarchical cluster analysis of binary feature data from the reduced set of 1656 features. 
The angle (or normalised dot product) between each concept vector and its category centroid was calculated for all six semantic categories, and compared in a correlation analysis to the subjects' prototypicality and familiarity ratings. Dot product was significantly correlated with subjects' ratings of familiarity, $r=-.49, p<.01$, and typicality, $r=-.38$, $p<.01$. The relationship between typicality and dot product was also examined in a partial correlation analysis (with familiarity entered as covariate) and found to remain significantly negatively correlated, $r=-.41, p<.01$. This is consistent with the Rosch model (since smaller values of the dot product indicated greater vector similarity). A correlation of similar magnitude was obtained when the Euclidean distance between the concept vectors and their category centroids were considered, $r=.44, p<.01$.

\section{Comment}

These preliminary analyses have suggested that concepts can be organised into categories and categories into broader domains of knowledge, based purely on their similarities in terms of attribute structure, a conclusion that was also reached in an earlier, related study (Small, Hart, Nguyen, \& Gordon, 1995). Consideration of the similarities alone produced a broad differentiation of concepts into three domains (fruit, animate beings, and artefacts) together with more specific coherent categories (e.g., vehicles). This outcome accords with the idea that, rather than being explicitly encoded, concepts' membership of semantic categories and higher-order domains may "emerge" from the patterns of overlap among the features of their component concepts.

Our results also provide some independent support for the feature approach to semantic memory, insofar as they have endorsed the findings of Rosch and Mervis (1975) concerning the relationship between shared features and rated typicality. The possession of shared features (such as "has wings," "has legs," "lays eggs," etc.) yields a coherent category structure, and the specificity of these shared features (e.g., "is sweet" vs. "has legs" vs. "is made of metal") promotes the subdivision into three superordinate domains (fruits, animate beings, and inanimate objects).

\section{Do living and nonliving domains differ with respect to sensory and functional features?}

Neuropsychological studies that have demonstrated dissociations between living and nonliving domains in brain-damaged patients have motivated a number of competing theories regarding the key organising principles within semantic memory. We now examine each of these theories in the context of the present feature database.

Warrington and Shallice (1984) proposed that differential performance on living and nonliving items occurs because of the varying importance of sensory and functional knowledge in the cognitive representations of these two domains. This idea can be operationalised in two ways. Like Farah and McClelland (1991), one can consider how the proportions of features of each type may differ between the two domains. Alternatively, one can look at the distinctiveness of individual features. A feature's distinctiveness can be understood as the extent to which it allows a particular concept to be distinguished from other members of the same category. Thus, "has a trunk" is a highly distinctive feature of an elephant, whereas "has a tail" is very nondistinctive; similarly "can be used to knock in nails" is a distinctive, and "has a handle" a nondistinctive feature of a hammer.

It should also be noted that distinctiveness need not be regarded as all-or-nothing; according to the definition just given, it can vary continuously from being diagnostic of a single concept to being shared across an entire category. Critical to the Warrington and Shallice position is the suggestion that the type of feature that enables category coordinate exemplars to be distinguished from one another varies between semantic domains. It is therefore necessary to separate features on the basis of distinctiveness before the distribution of different feature types between semantic domains can be interpreted. To our knowledge, no previous analysis of semantic feature data has given full consideration to this critical factor. The scope of the present data allowed us to consider the distribution of fea- 
ture types across domains before and after distinctiveness was taken into account.

\section{Do the numbers of sensory and functional features differ between domains?}

Farah and McClelland (1991) based their connectionist network on a set of semantic features that had been selected from dictionary definitions of living and manmade items. Although sensory features outnumbered functional in both knowledge domains, the proportions were different in each case: for living items the ratio of sensory to functional features was 7.7:1, whereas for nonliving items it was 1.4:1. The numbers of features of each type contributing to the distributed concept representations were therefore critical to the behaviour of the network when damage was introduced. Caramazza and Shelton (1998) criticised this approach on the grounds that the subjects who performed the selection of features were biased by the instructions against selecting many functional features for living items, since the idea of "function" (in the sense of "what it is for") as applied to living things is counterintuitive. They went on to argue that if the subjects had been instructed instead to identify sensory and nonsensory information (i.e., including "encyclopaedic" features), then the ratios of these two types of knowledge in each domain would have been equivalent, and the network would have failed to produce the emergent category-specific pattern. These two alternative proposals were considered further by analysing the present feature database, in which nonsensory features had already been classified separately as either "functional" or "encyclopaedic."

The mean numbers of sensory and functional features per item in the living and nonliving subsets are displayed in Figure 4a, and the mean numbers of sensory and nonsensory (i.e., functional + encyclopaedic) features per item are shown in Figure $4 \mathrm{~b}$. Adopting a rigorous definition of "functional", which excluded the encyclopaedic properties, the ratio of sensory to functional features for the living set was 2.03:1 and for the nonliving set 1.62:1. A two-way analysis of variance on the raw number of attributes generated yielded significant main effects of feature type, $F(1,60)=$
$154.4, p<.001$, and domain, $F(1,60)=1.3, p<.01$, together with an interaction, $F(1,60)=11.72, p<$ .01. Using the Caramazza and Shelton definition of "nonsensory," which collapses across functional and encyclopaedic features, the main effects of feature type, $F(1,60)=13.1, p<.01$, and domain, $F(1,60)=$ $16.64, p<.001$, persisted, but the interaction disappeared, $F(1,60)<1$, due to the larger numbers of encyclopaedic features contributing to the living domain.

\section{Comment}

This empirically derived set of semantic attributes has revealed contrasting numbers of sensory and functional features associated with the two conceptual domains, a pattern that is broadly similar to the distribution found by Farah and McClelland, though by no means as striking. This failure to demonstrate a sizeable interaction between domain and feature type is thus more in keeping with the findings of Caramazza and Shelton and, moreover, corroborated the objection levelled by these authors against Farah and McClelland's classification of feature types. In our analysis, inclusion of encyclopaedic features in the set of nonsensory attributes increased the number of functional features in the living domain, and thus largely equated the proportions of each type between the two domains. For a parallel analysis and very similar results, see McRae and Cree (in press).

The claim of Warrington and Shallice, however, was not based entirely on the numbers of features, but on the nature of the distinguishing features in each domain, which they claimed would tend to be sensory in the case of living things, and functional in the case of man-made artefacts (Warrington \& Shallice, 1984).

\section{Do the numbers of distinctive semantic features vary by knowledge type and by domain?}

For the present analysis, the distinctiveness of a feature was considered as a continuous variable, which was simply equal to the proportion of concepts within a category for which the feature in question was generated. Distinctiveness could take a range of values between .125 (characteristic of only one of the eight concepts in the category and thus highly 
(a)

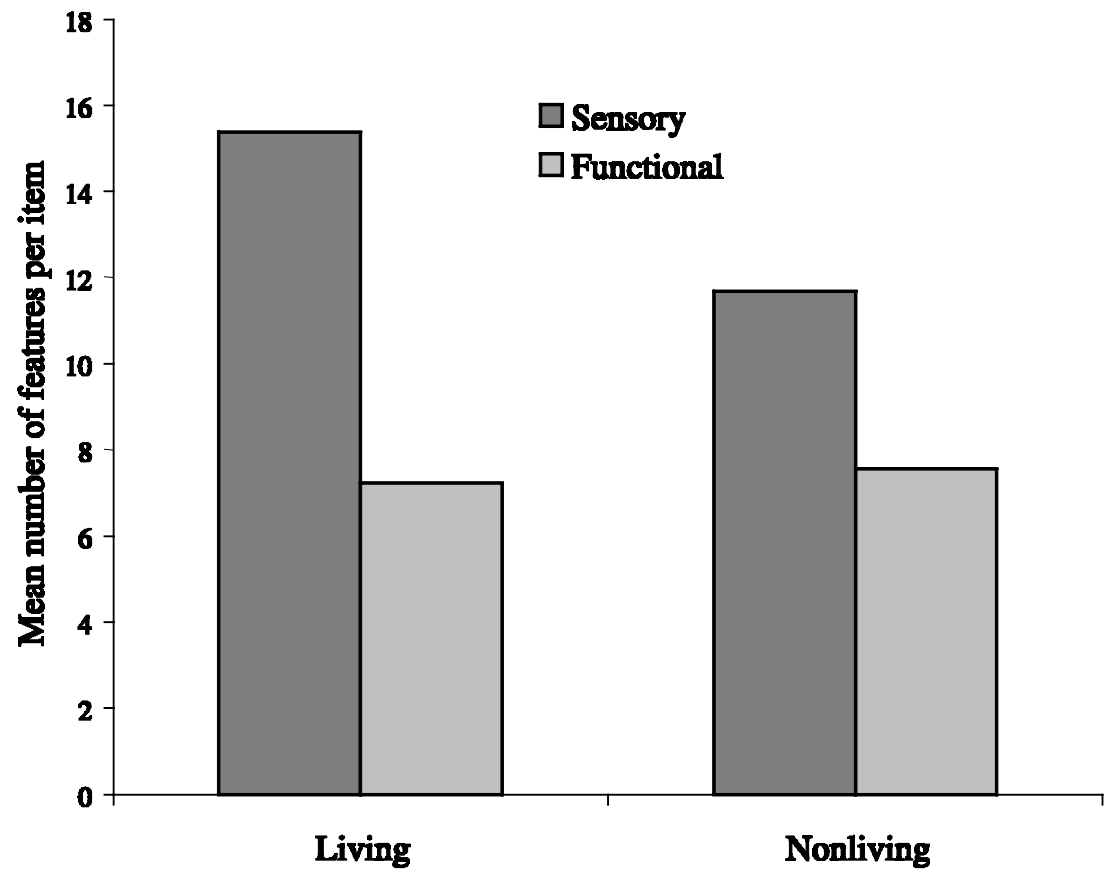

(b)

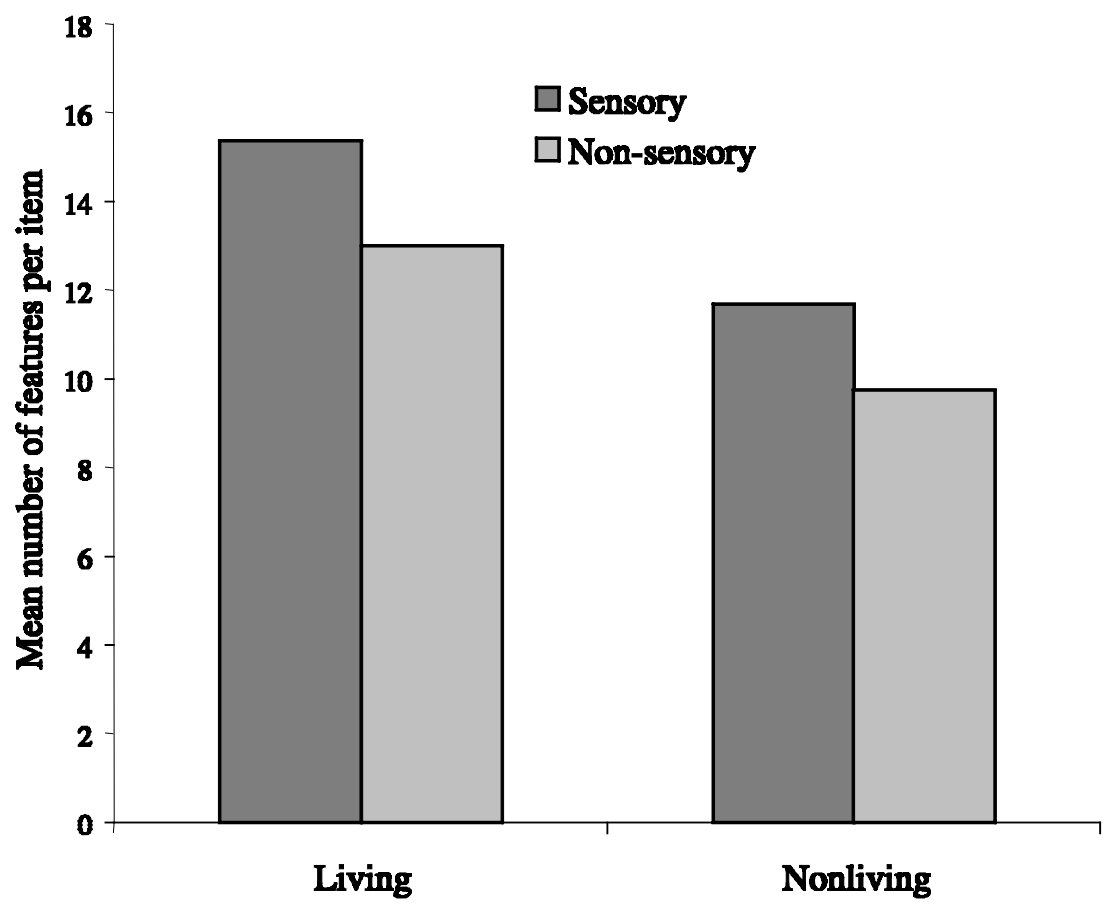

Figure 4. Mean numbers of features per item in the living and nonliving subsets, split by feature type. Sensory features are compared (a) with functional features, following Farah and McClelland, and (b) with nonsensory features, following Caramazza and Shelton. 
distinctive) and 1.0 (shared by all category members $)^{5}$. For instance, within the category of animals the features "has four legs" and "can walk" are relatively non-distinctive, whereas the features "has a trunk" and "can bark" are so distinctive that they could almost stand alone as descriptive expressions for the exemplars to which they apply. Between these two extremes lie a group of features- such as "has hooves" or "can be used to carry loads"-which pick out smaller subsets without being distinctive of any one exemplar. In its original formulation, the Warrington and Shallice hypothesis would predict that, among the distinctive features, those associated with living things would be predominantly sensory, whereas those associated with artefacts would be predominantly functional.

Figures $5(\mathrm{a})-5(\mathrm{c})$ show the distributions of distinctiveness values associated with the sensory, functional, and encyclopaedic features, respectively, of the living and nonliving subgroups. It can be seen that among nonliving things there were more distinctive than nondistinctive features of all types. For concepts from the living categories, on the other hand, this same pattern (i.e., more distinctive than shared features) was only true of the encyclopaedic features, whereas the distribution of distinctiveness in the sensory and functional features was U-shaped.

To allow a more formal examination of the distribution of features among types, domains, and levels of distinctiveness, the features were assigned to one of two subgroups: a relatively distinctive subgroup consisted of those features occurring in the descriptions of half or fewer of the category exemplars (i.e., associated with a distinctiveness value of .5 or less), and a relatively shared subgroup consisted of features occurring in the descriptions of more than half of the exemplars within their categories (i.e., associated with a distinctiveness value above .5$)^{6}$. Using this definition of distinctiveness, the mean numbers of distinctive and shared features of each type generated for living and nonliving concepts were examined (see Figure 6).
A three (sensory vs. functional vs. encyclopaedic) by two (distinctive vs. shared) by two (living vs. nonliving) analysis of variance revealed that there were significantly more distinctive than shared features, $F(1,27)=30.4, p<.001$, in addition to significant main effects of feature type: sensory $>$ functional $>$ encyclopaedic; $F(2,54)$ $=193.1, p<.001$, and domain: living $>$ nonliving; $F(1,27)=6.7, p<.05$, already observed. In addition, there were significant interactions between feature type and domain, $F(2,54)=11.3, p<.01$, and feature type and distinctiveness, $F(2,54)=$ $6.13, p<.01$. The interaction between distinctiveness and domain, and the three-way interaction, however, both fell short of statistical significance.

The distinctive and shared features were examined individually using separate three (feature type) by two (domain) analyses of variance. These revealed that the domain by feature type interaction was significant in both subsets: distinctive; $F(2$, $120)=6.8, p<.01$; shared; $F(2,120)=46.03, p<$ .001. Post hoc pairwise comparisons showed that, among the shared features (right side of Figure 6), all feature types were significantly more numerous in the living things: sensory; $t(60)=9.02, p<.001$; functional; $t(60)=8.69, p<.001$; encyclopaedic; $t(60)=5.2, p<.001$. By contrast, among the distinctive features (left side of Figure 6) the excess of functional features associated with the nonliving items, and the reverse pattern for the encyclopaedic features, were both significant, $t(60)=2.04, p<.05$ and $t(60)=3.41, p<.01$, respectively, but the number of sensory features did not differ significantly between domains, $t(60)=.51, p=.62$.

The differences between conceptual domains with respect to the associated overall proportions of different feature types were found earlier to be influenced by the interpretation chosen to distinguish sensory from functional information. A similar approach was therefore taken using the distinctive and shared feature subsets, with definitions of the sensory-functional distinction based on the same criteria as before (i.e., with and without

\footnotetext{
${ }^{5}$ Between .17 and 1.0 in the case of fruits, for which there were only six category members.

${ }^{6}$ When a feature is true of exemplars in more than one category, it may be distinctive in one but shared in the other. An example of this is "has wings," which is true of all birds, but of only one vehicle.
} 
encyclopaedic features included in the definition of "functional"). Figure 7(a) displays the mean number of distinctive sensory and functional features generated for living and nonliving categories using the former of these definitions, and Figure 7(b) the same information using the latter definition. Separate two (feature type) by two (domain) analyses of variance were performed for each of these data sets. In the set based on Farah and McClelland (Figure $7(\mathrm{a})$ ), there was a significant overall excess of distinctive sensory over functional features, $F(1,60)=$ $35.02, p<.001$, with no main effect of domain, $F(1$, $60)=2.21, p=.14$, and no interaction, $F(1,60)=$ $6.04, p=.42$. Using the Caramazza and Shelton definition of sensory and non-sensory features, as reflected in Figure 7(b), there were no significant main effects or interactions, all $\mathrm{Fs}_{\mathrm{s}}<1$.

\section{Comment}

These analyses have confirmed that, as suggested by Warrington and Shallice (1984), statistically reliable differences exist between the proportions of different feature types associated with concepts in the living and nonliving domains, and that these differences are influenced by feature distinctiveness. Of the individual comparisons, however, the only finding that is predicted by the Warrington and Shallice hypothesis is the greater number of distinctive functional features in the nonliving subset; the expected complementary difference (i.e., an excess of distinctive sensory features associated with concepts in the living domain) was not found, though there was an excess of shared sensory features associated with concepts in the living domain. In general, however, the prediction of Warrington and McCarthy (1987) that visual features are crucial for distinguishing among living things, and therefore that damage to "visual semantics" should result in a category-specific deficit, has not been upheld. In fact, the interaction observed in the distinctive feature subset, between feature type and conceptual domain, was critically dependent on the distribution of encyclopaedic features, and was not apparent when these features were excluded from the analysis, nor when they were combined with the functional features (following Caramazza and Shelton). The significantly greater number of dis- tinctive encyclopaedic features associated with concepts in the living domain is a finding that is not predicted by any theoretical model known to us.

\section{Are there differences in the degree to which the features of living and nonliving things are intercorrelated?}

A number of recent papers have emphasised the potential influence of another factor within featurebased approaches to semantic memory, namely the intercorrelation of feature-pairs across concepts (Devlin et al., 1998; Durrant-Peatfield et al., 1997; Gonnerman et al., 1997; Moss, Tyler, \& Jennings, 1997). The principal notion underlying such approaches is that if two or more features tend to co-occur in the description of various concepts then this statistical fact will have significant consequences for the semantic system under both normal and impaired circumstances (McRae et al., 1997). Several investigators have demonstrated the effect of different degrees of feature-intercorrelation on the performance of computational models of semantic memory. Typically, if a concept includes a large number of intercorrelated features then (1) under normal circumstances, the full conceptual representation is more readily activated (McRae et al., 1997), and (2) under mild degrees of damage, the intercorrelated features are less vulnerable than those lacking intercorrelational "support" (Devlin et al., 1998).

McRae et al. noted that within their feature database for 190 different concepts, intercorrelations were generally low (i.e., the distribution of correlation coefficients for all the possible feature-pairings was strongly skewed) but that in general the intercorrelations were higher for the living than nonliving concepts. Figure 8 shows the distribution of intercorrelations between pairs of attributes generated for the living and nonliving concepts in the present database. Despite its smaller size, this database produces a pattern similar to that described by McRae et al. First of all, the absolute value of Spearman's correlation across concepts (a formal measure of the number of concepts in which pairs of features are either both present or both 
GARRARD ET AL.

(a)

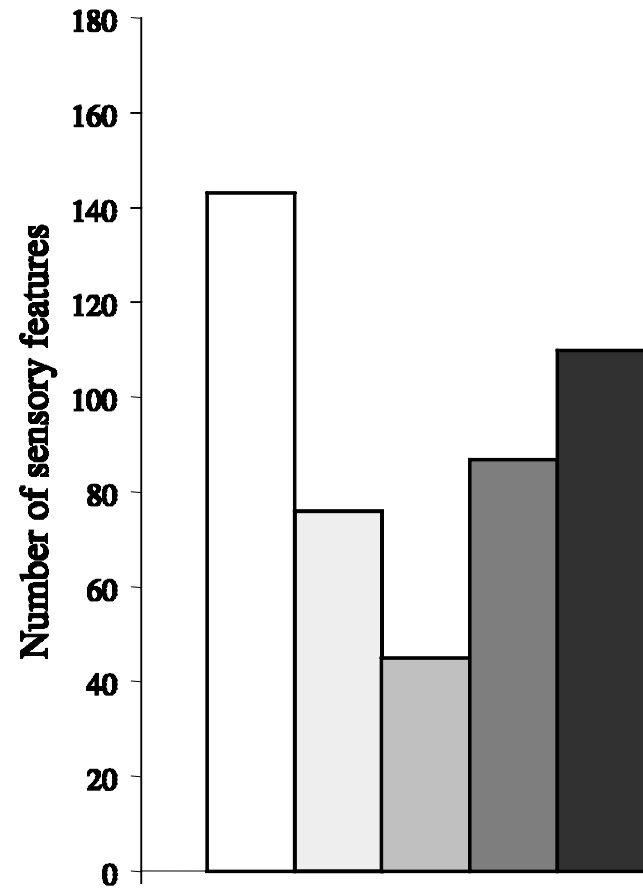

Living
Distinctiveness

$\square \quad 0-19$

口 $\quad 2-.39$

$\square \quad$.4-.59

$\square \quad .6-.79$

$\square \quad$.8-1.0

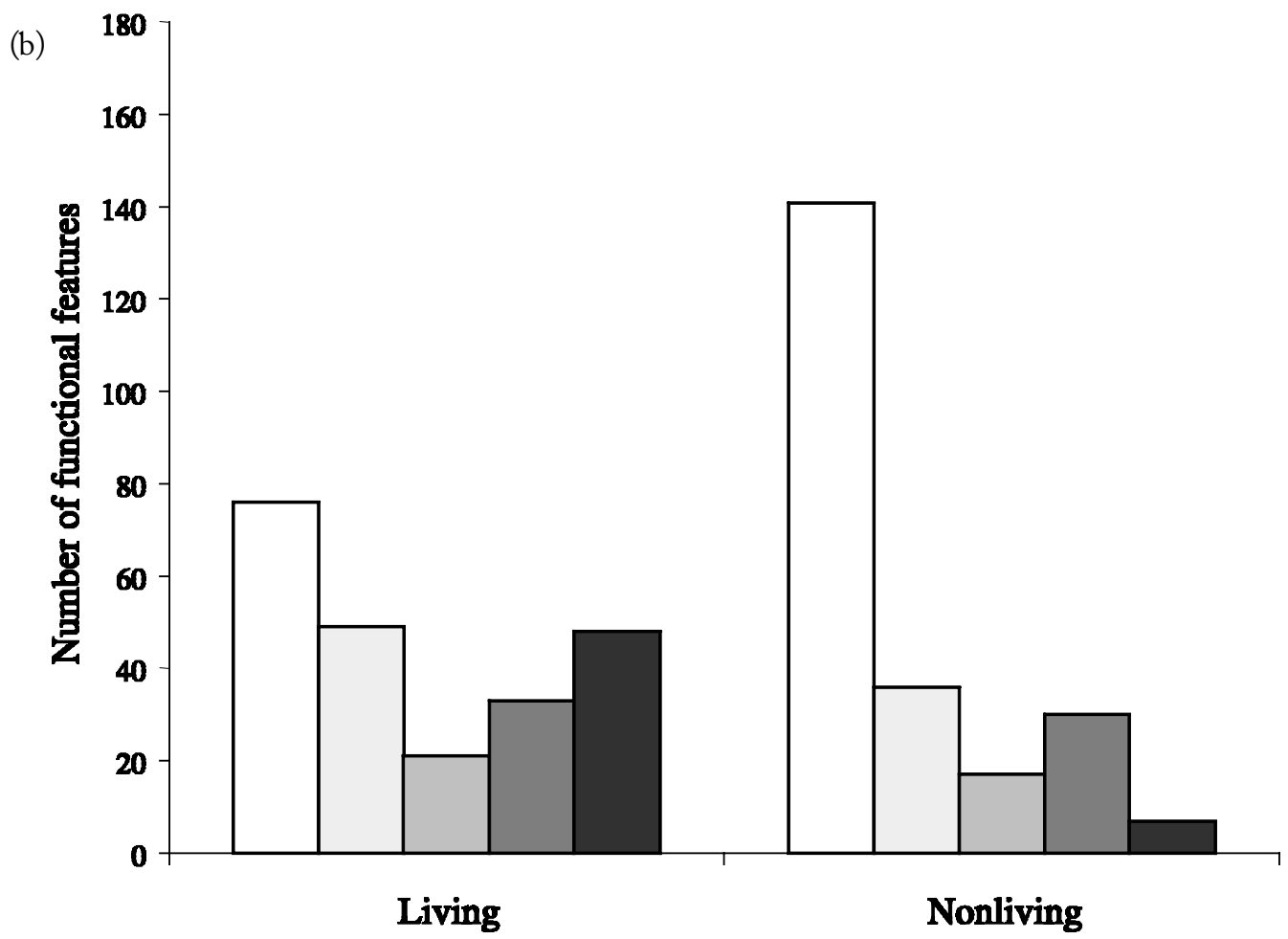

140 COGNITIVE NEUROPSYCHOLOGY, 2001, 18 (2) 


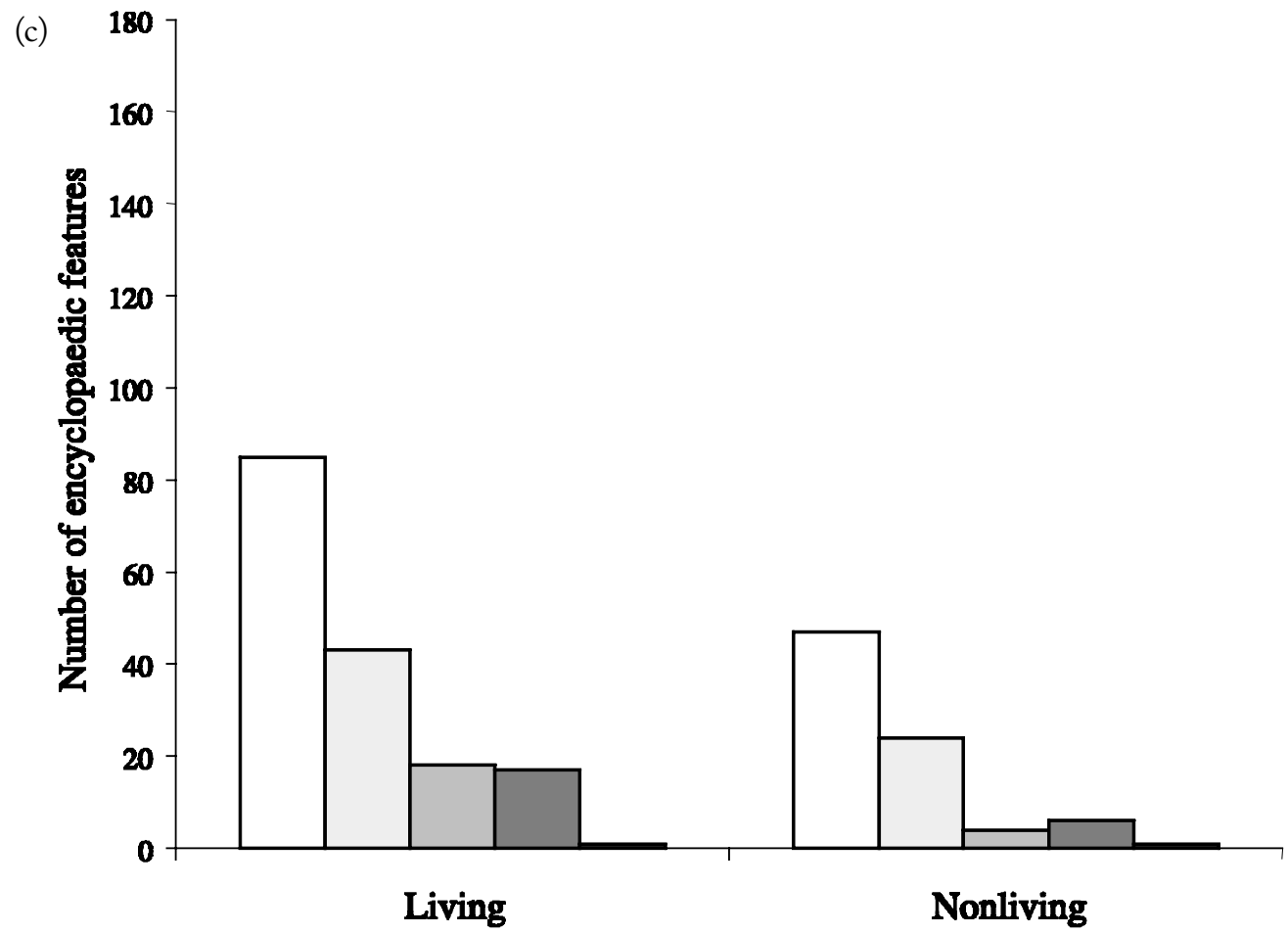

Figure 5. Distribution of distinctiveness values in the subsets of (a) sensory, (b) functional, and (c) encyclopaedic features.

absent) for the vast majority of feature pairs was extremely small. Second, the values for the features of living things were slightly higher than those of nonliving: the mean correlation coefficient for living feature pairs was $.13(\mathrm{SD}=.16)$, and for nonliving feature pairs it was $.10(\mathrm{SD}=.17)$, a difference that was statistically significant given the large number of possible feature pairings (Mann-Whitney, $p<.001)$. It is important, however, to view this significant difference between intercorrelations for the two domains in terms of the critical values for the correlation coefficient $\left(\mathrm{R}_{\text {critical }}\right)$. For the features of living items, $N=30, \mathrm{R}_{\text {critical }}=.36$, whereas for features of nonliving items, $N=32, \mathrm{R}_{\text {critical }}=.35(\alpha=.05$ in both cases). It is clear, therefore, that the vast majority (90\%) of these intercorrelations are not statistically significant.

Two approaches have utilised this apparently different degree of intercorrelation for features of living and nonliving concepts to explain patterns of category-specific semantic deficits. These two approaches differ in terms of the feature types that are presumed to participate in intercorrelations, and make contrasting predictions about the emergence and progression of category-specific effects.

\section{Feature intercorrelation is more characteristic of living things}

Devlin et al. (1998) reported results from a computational model of conceptual knowledge in which, with mild degrees of simulated generalised damage, the greater number of intercorrelated features for living things resulted in a relatively better performance on living than on nonliving items. As the level of damage was increased, however, the intercorrelated features showed a tendency to "drop out" together, resulting in relatively better performance for the nonliving items (see Devlin et al., 1998, Figure 4, p. 87). This cross-over in the relationship between severity and the direction of the category advantage has also been observed in a group of 


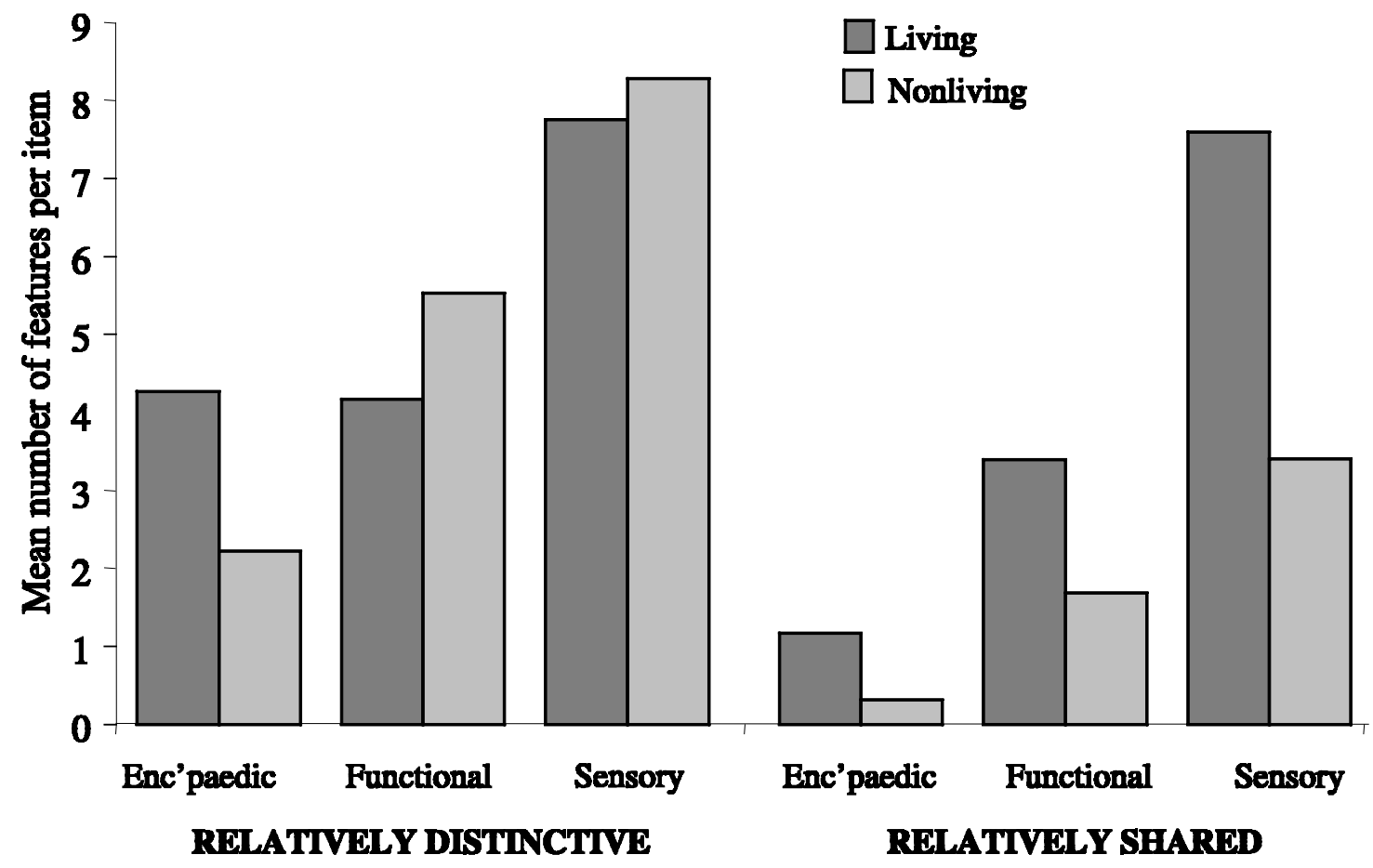

Figure 6. Comparative distributions of the relatively distinctive and relatively shared features split by feature type and by semantic domain.

patients with DAT (Gonnerman et al., 1997), though the pattern could not be replicated in a larger cross-sectional study (Garrard et al., 1998).

Detailed neuropsychological investigation has provided little support for this approach (for details see Garrard et al., 1998; Lambon Ralph et al., 1998) and it is further challenged by reports of category effects persisting in the same direction in patients who recover from acute brain injury (e.g., Hillis \& Caramazza, 1991). Analysis of our feature database, however, is relevant to its empirical foundations. It was noted earlier that there were more shared features for living than for nonliving things. Shared features will tend to be highly intercorrelated with each other. For example the features can see, can hear, has eyes, has ears are not only shared across many of the concepts within a category, they also tend to co-occur within representations of each of these concepts. This raises the possibility that the higher number of intercorrelated features for living concepts may be a by- product of the larger number of shared features in that domain.

Given that the majority of feature pairs were not significantly intercorrelated, the following dependent measure was used. For each feature we calculated the proportion of all possible pairings that resulted in statistically significant values of Spearman's correlation coefficient. The mean of these proportions, split by domain and distinctiveness, is shown in Figure 9. A two (shared vs. distinctive) by two (living vs. nonliving) analysis of variance revealed significant main effects of feature distinctiveness, $F(1,1534)=16.9, p<.001$, and of semantic domain, $F(1,1534)=125.9, p<.001$, and a significant interaction, $F(1,1534)=33.4, p<.001$. The interaction clearly results from a higher proportion of significant intercorrelations among the shared than the distinctive features associated with living concepts, $t=8.73, p<.001$, a difference that was not present in the nonliving domain, $t=-.78$, n.s. 
(a)
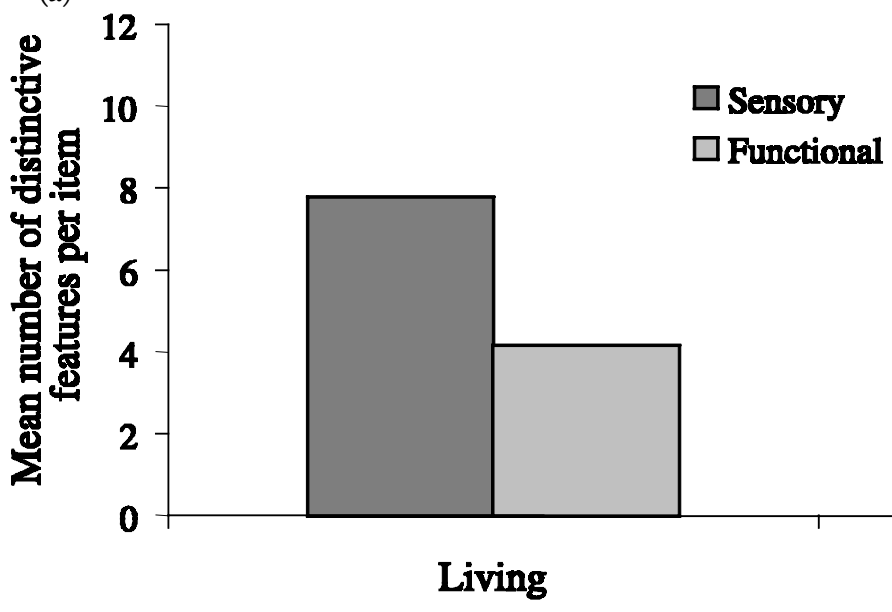

(b)
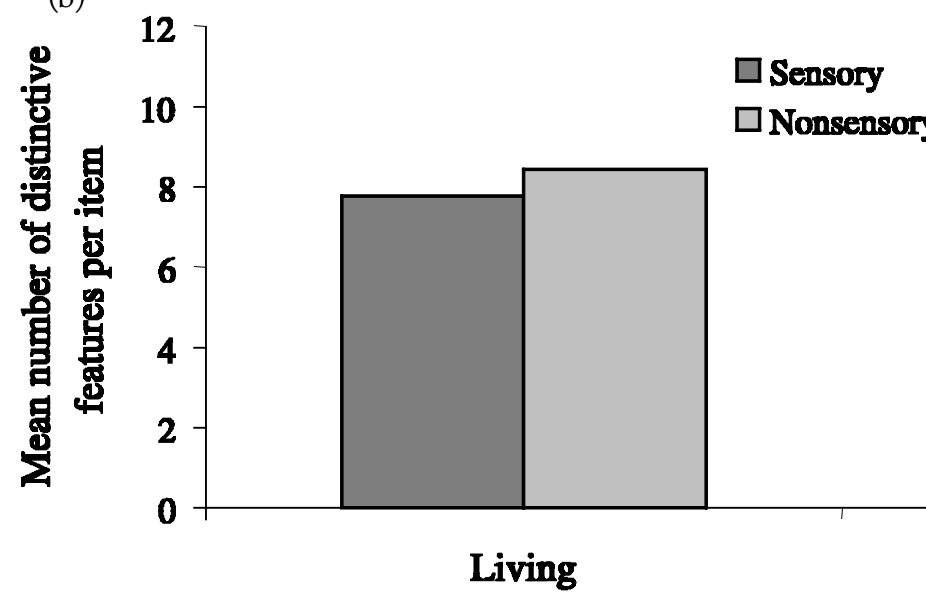

Nonliving

Living

Nonliving

Figure 7. Mean numbers of distinctive features per item in the living and nonliving subsets, split by feature type. Sensory features are compared (a) with functional features, following Farah and McClelland, and (b) with nonsensory features, following Caramazza and Shelton.

\section{Intercorrelations exist between the structural and} functional features of nonliving things, and among the shared features of living things

Moss, Tyler, and colleagues have suggested an alternative role for intercorrelations in the production of category-specific deficits (DurrantPeatfield et al., 1997; Moss et al., 1998; Moss \& Tyler, in press). Unlike Devlin et al. (1998) and McRae et al. (1997), Moss and Tyler have emphasised the importance of two specific types of intercorrelation. For living things the shared functional features (e.g., can see, can hear, can run, etc.) and shared perceptual features (e.g., has eyes, has ears, has legs) are highly intercorrelated, but the distinctive features are much less so. For artefacts, the pattern is reversed: Building upon previous notions of form-function relationships (Caramazza et al., 1990; De Renzi \& Lucchelli, 1994), Moss et al. (1998) suggested that artefact concepts have strong correlations between pairs of individual, distinctive perceptual and functional properties (e.g., the properties of being sharp and being used for cutting), but fewer, and more weakly intercorrelated, shared features. 


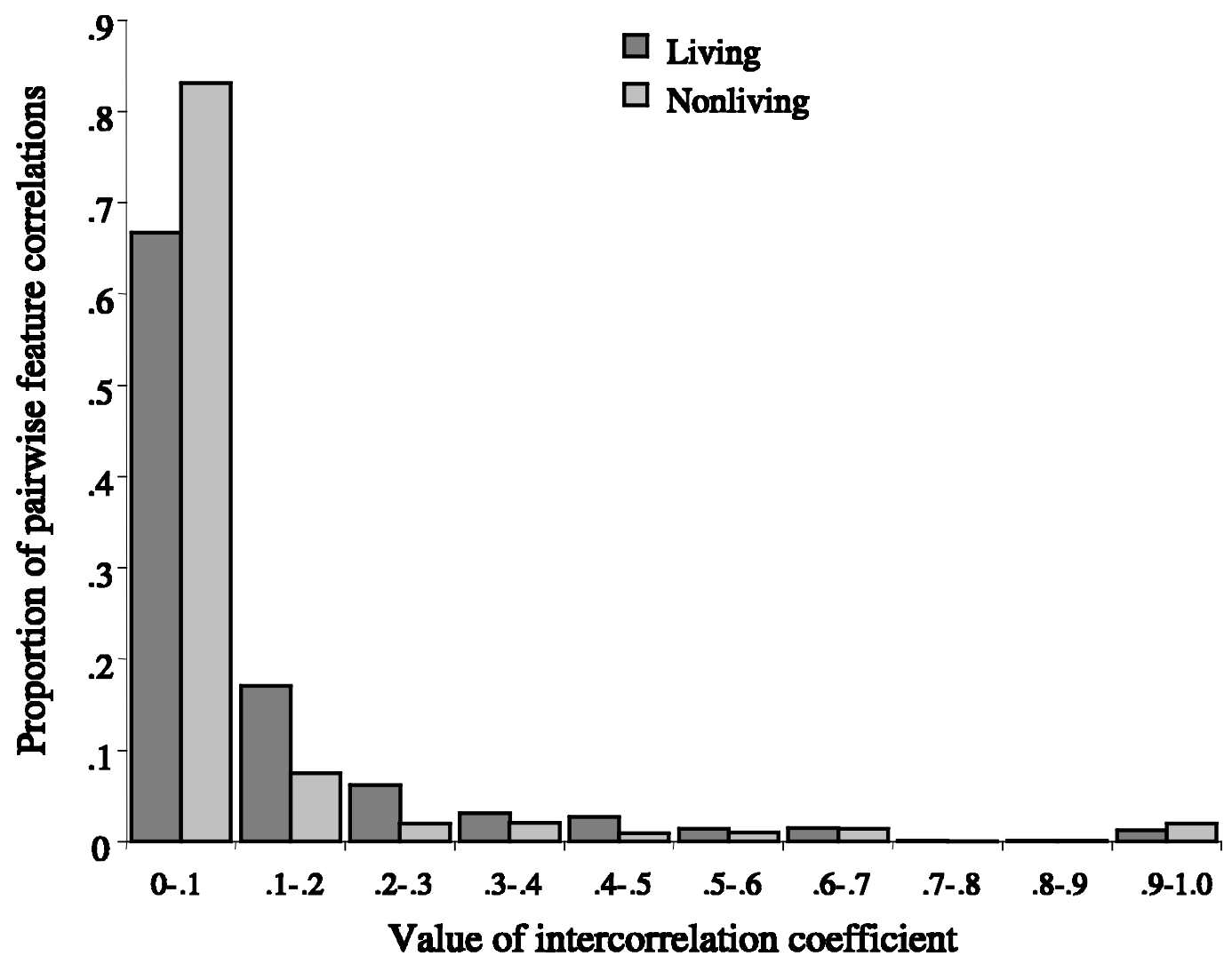

Figure 8. Distribution of values of Spearman's correlation coefficient for all pairwise combinations of features, excluding categorising features, in the reduced set.

Although this account, like that of Devlin et al., (1998), predicts a relationship between severity and category advantage, the direction of the predicted relationship is in fact reversed: With mild degrees of damage, unique identification will be best preserved for nonliving concepts due to the presence of the strong form-function intercorrelations among the distinctive features of these items. With more severe impairments, however, the category advantage reverses because the living concepts are supported to a greater degree by the shared, intercorrelated attributes.

We have already reported the distribution of shared and distinctive sensory and functional features in the present feature database for living and nonliving domains. These analyses of feature intercorrelations can now be extended to address the stated hypothesis. As this proposal does not make any predictions with regard to "encyclopaedic" knowledge, these features were excluded from the analyses. Figure 10 shows the proportion of feature correlations that reached significance, split by domain, distinctiveness, and correlation type-i.e., between feature types (sensory with functional) or within feature type (sensory with sensory and functional with functional). We shall refer to the former as "intercorrelations" and to the latter as "intracorrelations".

A two (living vs. nonliving) by two (distinctive vs. shared) by two (intracorrelation vs. intercorrelation) analysis of variance revealed a significant three-way interaction, $F(1,1290)=14.4, p<$ .001 , which was analysed further using separate two-way analyses of variance for the living and nonliving domains. For living concepts, the proportion of significant intercorrelations was greater for 


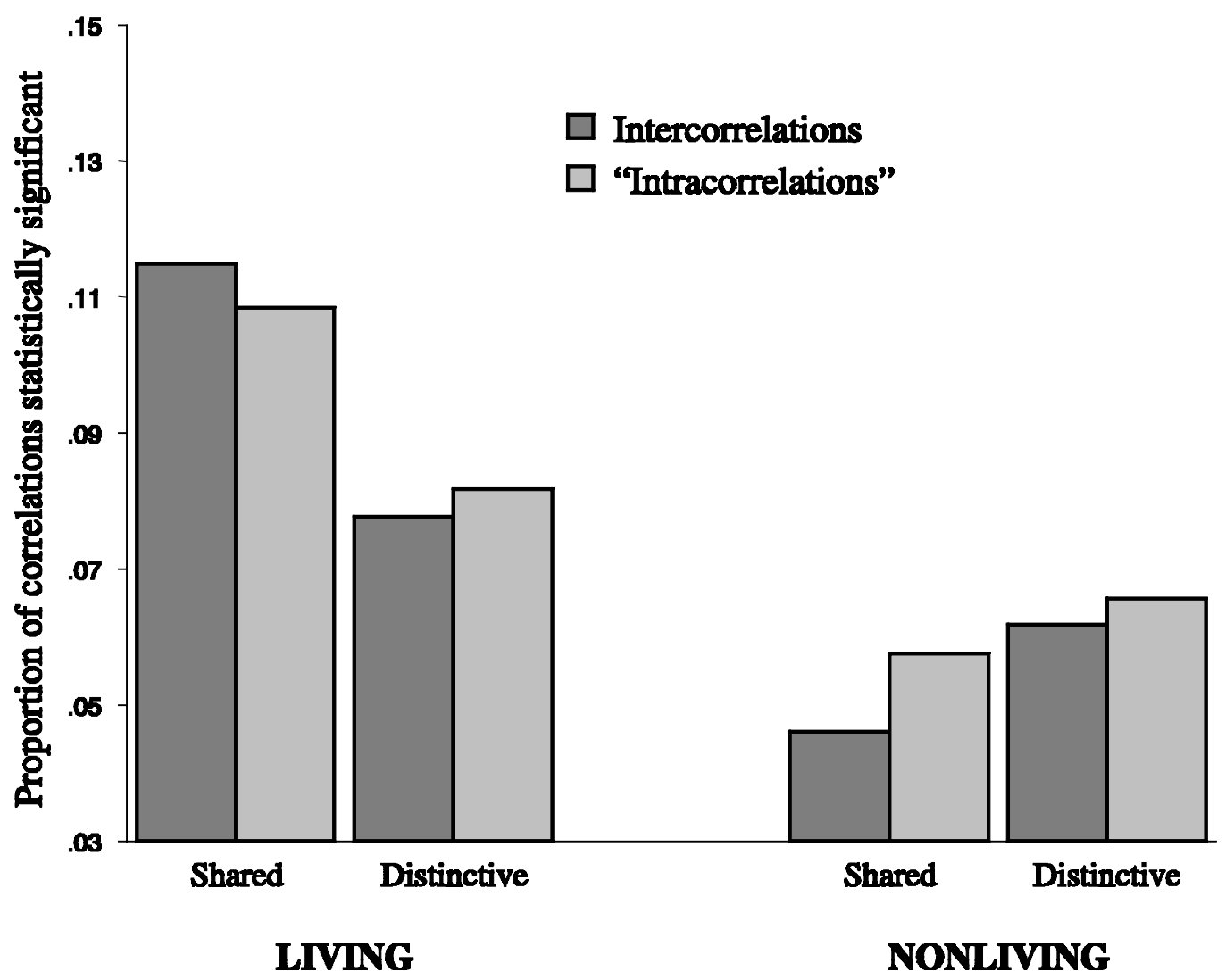

Figure 9. Mean proportions of the shared and distinctive features of living and nonliving items associated with statistically significant correlations.

shared than distinctive features, $F(1,687)=89.7, p$ $<.001$, but there was no effect of correlation type, $F(1,687)<1$. There was a small but significant interaction between distinctiveness and correlation type, $F(1,687)=9.7, p=.002$. For nonliving concepts, the overall proportion of significant intercorrelations was higher for the distinctive than for the shared features, $F(1,603)=1.0, p=.02$, and for the intracorrelations than for the intercorrelations $F(1,603)=23.2, p<.001$. The interaction was also significant, $F(1,603)=5.7, p=.02$.

\section{Comment}

These results indicate that, even in the absence of encyclopaedic attributes, the overall proportion of significant feature correlations was very small. Although the model proposed by Moss et al. predicted that the shared features of living concepts should be more highly correlated, other details of their hypothesis are not supported by the present data. For living things, it is true that the shared features are more likely to be correlated with other features, but the distinctive features of living things are also more correlated than any of the features of the nonliving concepts. Finally, although there is a slight excess of correlation among the distinctive features in the nonliving domain, the intracorrelations are more, rather than less, numerous than the putatively more important (perceptualfunctional) intercorrelations.

\section{GENERAL DISCUSSION}

The data reported here consist of a set of concept properties collected from a group of normal volun- 


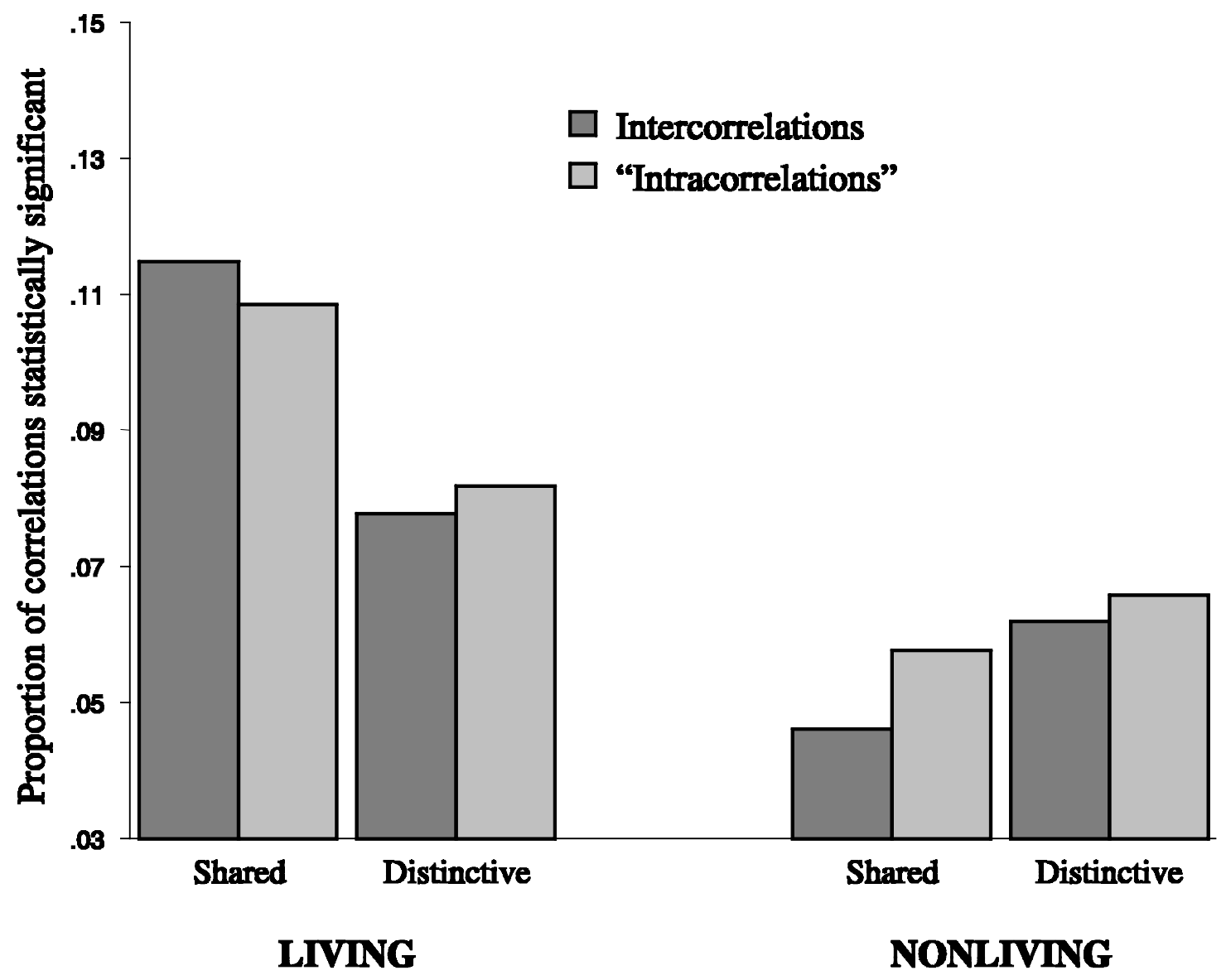

Figure 10. Mean proportions of the shared and distinctive features of living and nonliving items associated with statistically significant correlations, split by domain and by intercorrelation type: intercorrelations refer to pairings between features of different types (i.e., sensory with functional), and intracorrelations to pairings between features of the same type (i.e., sensory with sensory or functional with functional).

teers in a manner that was designed to permit examination of claims about the structure of semantic knowledge. Analyses of these properties have upheld the usefulness of the feature-based approach to semantic knowledge, as well as the idea that broad conceptual domains may emerge simply from the similarity in feature structure among groups of concepts. Our results support the notion that such emergent domains may manifest as a distinction between living and nonliving items - an idea that is central to distributed theories of semantic knowledge. It therefore seems unnecessary, on theoretical grounds alone, to assume that a separate coding mechanism is required for category and domain membership, whether this coding reflects learning or evolutionary, neural adaptations. Theoretical redundancy, however, does not preclude the existence of an organising principle in the brain, and Caramazza and Shelton (1998) have made a convincing case, on empirical grounds, for the existence of regional neural systems specialised for the recognition of three broad semantic domains - animals, plant life, and artefacts. Nevertheless, to assume on the basis of one case that this mechanism explains all category-specific phenomena would be premature. This note of caution is emphasised by the results of our analyses. 
Another interesting aspect of the feature database was the degree of accordance it showed with more intuitive assessments of category and concept structure. Not only was there a familiar variation in coherence for different collections of exemplars (for example, living things were more tightly clustered than most nonliving entities), but the rated typicality of each exemplar was also significantly correlated with the angle-or distance-between the featural representation of the exemplar and the category centroid, or "average exemplar".

The data were also analysed along the lines of contemporary theoretical models of semantic organisation that have been proposed to explain patterns of category-specific semantic impairments. Such models have variously emphasised the role of feature type (perceptual, functional, and encyclopaedic), feature distinctiveness, and feature intercorrelation in the representations of living and nonliving concepts.

The raw numbers of features of each type were found to be distributed between the two conceptual domains in rather different proportions: Although sensory features were the most numerous in both, the disparity was relatively greater for living than for nonliving concepts. This pattern of results loosely resembles that described by Farah and McClelland (1991), though the contrast between the two sensory:functional ratios was less marked, and would probably not have been large enough to produce category-specific deficits if incorporated into a similar connectionist network. Moreover, the observed difference was highly dependent on the role assigned to features that had been classified as encyclopaedic, as pointed out by Caramazza and Shelton (1998).

When distinctiveness was taken into account, a striking asymmetry appeared between the shared and distinctive features: Although more distinctive features of all types were associated with nonliving concepts (see also McRae \& Cree, in press), this pattern was evident only among the encyclopaedic features of living things; for the sensory and functional subsets the numbers of shared and distinctive features were approximately equal. This is an important result, as it apparently runs counter to the hypothesis (never previously tested directly) that visual features are crucial for distinguishing among living things (Warrington \& McCarthy, 1987).

The analyses relating to feature intercorrelation showed that few feature combinations participated in statistically significant intercorrelations, and that these were largely made up of intercorrelations among shared features. This finding also characterises the semantic feature data reported by McRae et al. (1997). Even allowing for the possibility that these empirically derived data are unrepresentative of semantic feature knowledge in its entirety (an issue that is given more detailed consideration later), it is difficult to see how the influence of this subset of features alone could produce category dissociations of the magnitude of those described in the neuropsychological literature. The critical observation in the studies of both DurrantPeatfield et al. (1997) and Devlin et al. (1998) was that the advantage evinced by the system switched from one domain to the other when a substantial overall level of damage had accumulated. This pattern has rarely been observed in longitudinal or cross-sectional studies of patients with progressive neurodegenerative disorders; and category advantages persisting after resolution of an acute lesion and overall improvement in the linguistic deficit have also been reported (Hillis \& Caramazza, 1991). The relative paucity of these internal relationships in the present sample of semantic feature knowledge might go some way to explaining the rather unimpressive evidence, both computational and neuropsychological, for predictable patterns in the relationship between severity of damage and direction of category advantage.

Consideration of the distinctiveness of features in living and nonliving domains may be relevant to explaining certain aspects of the category-specific behavioural data. First, the cases reported as showing a significant advantage for nonliving categories are much more numerous than those with the reverse dissociation, but the origin of this inequality has never been satisfactorily explained: It is certainly not due to the relative incidences of the causative lesion, since left middle cerebral artery (MCA) territory infarction (the commonest reported underlying pathology in cases with an 
advantage for living items) is much more common than Herpes simplex virus encephalitis (HSVE), which is the modal aetiology in cases with an advantage for artefacts. The present data suggest a possible explanation in the much higher proportion of distinctive relative to shared features of all attribute types associated with artefacts (see Figure 6); since partial, nonselective loss of knowledge would tend to maintain a balance favouring distinctive information about nonliving items, performance on tasks such as object naming-which presumably relies on the appreciation of distinctive information - should be relatively more robust to damage for artefact than for natural kinds.

A recent finding that is difficult to accommodate within the Warrington and Shallice hypothesis is that patients with progressive focal temporal lobe atrophy and the syndrome of semantic dementia suffer a disproportionately severe loss of knowledge of visual attributes, yet the majority of these patients exhibit little, if any, cross-domain difference in their performance on semantic tests (Lambon Ralph, Graham, Patterson, \& Hodges, 1999). It remains to be seen whether those semantic dementia patients who do manifest a nonliving advantage can also be shown to have a disproportionate deficit in encyclopaedic knowledge - a pattern that, according to the results presented in this paper, could contribute to such a dissociation.

We were also able to analyse our feature database in respect of three recent claims about the importance of intercorrelations between different types of semantic attribute (Devlin et al., 1998; McRae et al., 1997; Moss et al., 1998). Like McRae et al. we found (1) that most intercorrelations are extremely small (and nonsignificant) and (2) that the intercorrelations were somewhat higher for living than nonliving domains. Once the features are split by distinctiveness, it is clear that the main difference between domains is carried by the presence of a greater proportion of significant intercorrelations for the shared features of living things. This would appear to agree with the obvious intuition that features such as "has eyes," "has ears," "can see," and "can hear" are not only shared across concepts but also intercorrelated. In contrast to the hypothetical structure proposed by Moss, Tyler, and colleagues, however, the degree of intercorrelation among the distinctive features of living things is no less than among any of the features of nonliving things. Moreover, nonliving concepts do not appear to be dominated by a large proportion of significant distinctive, form-function correlations.

One difficulty with the present data is that they do not suggest a means of explaining the origin of advantages for natural kinds over artefacts. That such patterns have their origin in the nature of semantic organisation is no longer widely questioned, though insufficiently stringent control of the contribution of the age of acquisition and imageability of the compared concepts may produce an exaggerated difference favouring living categories (as children tend to learn animal names before those of artefacts; McKenna \& Parry, 1994). If this is the case, then the size of the advantages in some reported cases might in reality be even smaller than the data suggest. This raises the possibility that contributions from the small but statistically significant domain differences in intercorrelational properties that were observed in the present data might be important in causing an advantage for the domain of living things when there is widespread damage to the semantic system. The feature norms provided in Appendix A constitute a corpus of attribute knowledge that will allow these and similar issues to be addressed directly in studies of both normal and brain-damaged individuals.

Any interpretation of these results must, of course, be viewed in the context of a relative paucity of data. With respect to the sum total of semantic knowledge acquired over an average lifetime, a sample of 62 concrete items is somewhat trifling. Moreover, the analyses described here have been based on a limited corpus of semantic features, while the true extent of attribute knowledge associated with even one of these items is potentially almost infinite. The items were, however, chosen to represent a distinction that is known to be important in the organisation of semantic knowledge, and to allow a series of specific theoretical claims to be examined. These limitations are perhaps most important when considering the properties of features that are shared among a large number of category members, since it is within this subset of 
features that correlational structure is most likely to exist. In this regard it is important to note that the subjects in the present study were not explicitly instructed to generate either distinctive or shared information. Although in the absence of such instructions, subjects would probably tend to produce relatively distinctive information, the present results show that shared information was also generated, suggesting a more even sampling across a range of distinctiveness values. This lends some justification to the generalisation of the trends observed in these data to the domain of semantic knowledge as a whole.

Manuscript received 26 July 1999 Revised manuscript received 5 May 2000 Revised manuscript accepted 8 May 2000

\section{REFERENCES}

Barbarotto, R., Capitani, E., Spinnler, H., \& Trivelli, C. (1995). Slowly progressive semantic impairment with category specificity. Neurocase, 1, 107-119.

Basso, A., Capitani, E., \& Laiacona, M. (1988).Progressive language impairment without dementia: A case with isolated category specific semantic defect. Journal of Neurology, Neurosurgery and Psychiatry, 51, 1201-1207.

Caramazza, A., Hillis, A.E., Rapp, B.C., \& Romani, C. (1990). The multiple semantics hypothesis: Multiple confusions. Cognitive Neuropsychology, 7, 161-189.

Caramazza, A., \& Shelton, J.R. (1998). Domain-specific knowledge systems in the brain: The animate-inanimate distinction. Journal of Cognitive Neuroscience, 10, 1-34.

Chertkow, H., \& Bub, D. (1990). Semantic memory loss in dementia of Alzheimer's type. Brain, 113, 397417.

Coltheart, M., Inglis, L., Cupples, L., Michie, P., Bates, A., \& Budd, W. (1998). A semantic subsystem of visual attributes. Neurocase, 4, 353-37.

De Renzi, E., \& Lucchelli, F. (1994). Are semantic systems separately represented in the brain? The case of living category impairment. Cortex, 30, 3-25.

Devlin, J.T., Gonnerman, L.M., Andersen, E.S., \& Seidenberg, M.S. (1998). Category-specific semantic deficits in focal and widespread brain damage: A computational account. Journal of Cognitive Neuroscience, 10, 77-94.
Durrant-Peatfield, M.R., Tyler, L.K., Moss, H.E., \& Levy, J.P. (1997). The distinctiveness of form and function in category structure: A connectionist model. In Proceedings of the Nineteenth Annual Conference of the Cognitive Science Society. (pp. 193-198) Mahwah, NJ: Lawrence Erlbaum Associates Inc.

Farah, M., Hammond, K., Mehta, Z., \& Ratcliffe, G. (1989). Category-specificity and modality-specificity in semantic memory. Neuropsychologia, 27, 193-20.

Farah, M.J., \& McClelland, J.L. (1991). A computational model of semantic memory impairment: Modality specificity and emergent category specificity. Journal of Experimental Psychology: General, 120, 339-357.

Farah, M.J., \& Wallace, M.A. (1992). Semantically bounded anomia: Implications for the neural implementation of naming. Neuropsychologia, 30, 609-621.

Gainotti, G. (1990). The categorical organisation of semantic and lexical knowledge in the brain. Behavioural Neurology, 3, 109-115.

Garrard, P., Patterson, K., Watson, P.C., \& Hodges, J.R. (1998). Category specific semantic loss in dementia of Alzheimer's type: Functional-anatomical correlations from cross-sectional analyses. Brain, 121, 633-646.

Gonnerman, L.M., Andersen, E.S., Devlin, J.T., Kempler, D., \& Seidenberg, M.S. (1997). Double dissociation of semantic categories in Alzheimer's disease. Brain and Language, 57, 254-279.

Goodale, M.A., Milner, A.D., Jakobson, L.S., \& Carey, D.P. (1991). A neurological dissociation between perceiving objects and grasping them. Nature, 349, 154-156.

Hart, J., Berndt, R., \& Caramazza, A. (1985). Category specific naming deficit following cerebral infarction. Nature, 316, 439-44.

Hart, J., \& Gordon, B. (1992). Neural subsystems for object knowledge. Nature, 359, 60-64.

Hillis, A., \& Caramazza, A. (1991). Category specific naming and comprehension impairment: A double dissociation. Brain, 114, 2081-2094.

Hillis, A.E., Rapp, B., \& Caramazza, A. (1995). Constraining claims about theories of semantic memory: More on unitary versus multiple semantics. Cognitive Neuropsychology, 12, 175-186.

Hodges, J.R., Graham, N., \& Patterson, K. (1995). Charting the progression in semantic dementia: Implications for the organisation of semantic memory. Memory, 3, 463-495.

Hodges, J.R., Salmon, D.P., \& Butters, N. (1992a). Semantic memory impairment in Alzheimer's dis- 
ease: Failure of access or degraded knowledge? Neuropsychologia, 30, 301-314.

Hodges, J.R., Patterson, K., Oxbury, S., \& Funnell, E. (1992b). Semantic dementia: Progressive fluent aphasia with temporal lobe atrophy. Brain, 115, 1783-1806.

Keil, F. (1987). Conceptual development and category structure. In U. Neisser (Ed.), Concepts and conceptual development (pp. 175-200). Cambridge: Cambridge University Press.

Keil, F. (1989). Concepts, kinds and cognitive development. Cambridge, MA: MIT Press.

Laiacona, M., Capitani, E., \& Barbarotto, R. (1993). Perceptual and associative knowledge in category specific impairment of semantic memory: A study of two cases. Cortex, 29, 727-74.

Lambon Ralph, M.A., Graham, K.S., Patterson, K., \& Hodges, J.R. (1999). Is a picture worth a thousand words? Evidence from conceptual definitions by patients with semantic dementia. Brain and Language, 70, 309-335.

Lambon Ralph, M.A., Howard, D., Nightingale, G., \& Ellis, A.W. (1998). Are living and non-living category-specific deficits causally linked to impaired perceptual or associative knowledge? Evidence from a category-specific double dissociation. Neurocase, 4, 311-338.

Laws, K.R., Evans, J.J., Hodges, J.R., \&McCarthy, R.A. (1995). Naming without knowing and appearance without associations: Evidence for constructive processes in semantic memory? Memory, 3, 409-433.

McKenna, P., \& Parry, R. (1994). Category specificity in the naming of natural and man-made objects: Normative data from adults and children. Neuropsychological Rehabilitation, 4, 225-281.

McRae, K., \& Cree, G.S. (in press). Factors underlying category-specific semantic deficits. In: E.M.E. Forde \& G. Humphreys (Eds.), Category-specificity in brain and mind. Hove, UK: Psychology Press.

McRae, K., de Sa, V.R., \& Seidenberg, M.S. (1997). On the nature and scope of featural representations of word meaning. Journal of Experimental Psychology: General, 126, 99-13.

Morrison, C.M., Chappell, T.D., \& Ellis, A.W. (1997). Age of acquisition norms for a large set of object names and their relation to adult estimates and other variables. Quarterly Journal of Experimental Psychology, 50, 528-559.

Moss, H.E., \& Tyler, L.K. (in press). A progressive category-specific semantic deficit for non-living things. Neuropsychologia.
Moss, H.E., Tyler, L.K., Durrant-Peatfield, M., \& Bunn, E.M. (1998). "Two eyes of a see-through": Impaired and intact semantic knowledge in a case of selective deficit for living things. Neurocase, 4, 339352.

Moss, H.E., Tyler, L.K., \& Jennings, F. (1997). When leopards lose their spots: Knowledge of visual properties in category-specific deficits for living things. Neuropsychology, 14, 901-95.

Rosch, E. (1973). On the internal structure of perceptual and semantic categories. In T.E. Moore (Ed.), Cognitive develeopment and the acquisition of language. New York: Academic Press.

Rosch, E.H. (1978). Principles of categorization. In E. Rosch \& B.B. Lloyd (Eds.), Cognition and categorization. Hillsdale, NJ: Lawrence Erlbaum Associates Inc.

Rosch, E.H., \& Mervis, C.B. (1975). Family resemblance studies in the internal structure of categories. Cognitive Psychology, 7, 573-605.

Sacchett, C., \& Humphreys, G.W. (1992). Calling a squirrel a squirrel but a canoe a wigwam: A categoryspecific deficit for artifactual objects and body parts. Cognitive Neuropsychology, 9, 73-86.

Sartori, G., Job, R., Miozzo, M., Zago, S., \& Marchiori, G. (1993). Category specific form-knowledge deficit in a patient with Herpes Simplex virus encephalitis. Journal of Clinical and Experimental Neuropsychology, 15, 280-299.

Shallice, T. (1988). From neuropsychology to mental structure. Cambridge: Cambridge University Press.

Silveri, M., \& Gainotti, G. (1988). Interaction between vision and language in category-specific semantic impairment. Cognitive Neuropsychology, 5, 677-709.

Small, S.L., Hart, J., Nguyen, T., \& Gordon, B. (1995). Distributed representations of semantic knowledge in the brain. Brain, 118, 441-453.

Smith, E.E., \& Medin, D.L. (1981). Categories and concepts. Cambridge, MA: Harvard University Press.

Snodgrass, J.G., \& Vanderwart, M.A. (1980). A standardised set of 260 pictures: Norms for name agreement, familiarity and visual complexity. Journal of Experimental Psychology: General, 6, 174-215.

Warrington, E.K. (1975). Selective impairment of semantic memory. Quarterly Journal of Experimental Psychology, 27, 635-657.

Warrington, E.K., \& McCarthy, R.A. (1987). Categories of knowledge: Further fractionations and an attempted integration. Brain, 110, 1273-1296.

Warrington, E.K., \& Shallice, T. (1984). Category specific semantic impairments. Brain, 107, 829-853. 


\section{APPENDIX A}

Feature norms

\begin{tabular}{|c|c|c|c|c|c|c|c|c|c|}
\hline \multicolumn{10}{|l|}{ Aeroplane } \\
\hline is a aircraft & c & .28 & .25 & & is a reptile & c & .32 & .19 & \\
\hline is large & $\mathrm{s}$ & .53 & .63 & .07 & is a animal & $\mathrm{c}$ & .58 & .88 & \\
\hline \multirow{4}{*}{$\begin{array}{l}\text { is made of metal } \\
\text { is fast } \\
\text { can make a noise } \\
\text { has cockpit } \\
\text { has fuselage }\end{array}$} & s & .42 & .88 & .04 & has tail & $\mathrm{s}$ & .84 & .81 & .11 \\
\hline & $\mathrm{s}$ & .33 & .88 & .08 & has teeth & $\mathrm{s}$ & .79 & .56 & .10 \\
\hline & $\mathrm{s}$ & .32 & .75 & .08 & has skin & $\mathrm{s}$ & .63 & .44 & .10 \\
\hline & $\mathrm{s}$ & .32 & .25 & .09 & has large mouth & $\mathrm{s}$ & .47 & .13 & .08 \\
\hline has rudder & $\mathrm{s}$ & .21 & .13 & .06 & has eyes & s & .32 & 1.00 & .13 \\
\hline has controls & s & .11 & .25 & .12 & has long tail & $\mathrm{s}$ & .26 & .25 & .11 \\
\hline has flap & $\mathrm{s}$ & .11 & .13 & .09 & has sharp teeth & $\mathrm{s}$ & .21 & .38 & .19 \\
\hline can fly & $\mathrm{f}$ & .94 & .25 & .09 & has four legs & $\mathrm{s}$ & .21 & .13 & .08 \\
\hline carry passengers & $\mathrm{f}$ & .67 & .50 & .17 & is large & s & .21 & .63 & .06 \\
\hline can land & $\mathrm{f}$ & .47 & .25 & .09 & has feet & $\mathrm{s}$ & .16 & .44 & .06 \\
\hline can taxi & $\mathrm{f}$ & .32 & .13 & .06 & is long & $\mathrm{s}$ & .16 & .06 & .06 \\
\hline can crash & $\mathrm{f}$ & .28 & .13 & .06 & has head & $\mathrm{s}$ & .11 & .38 & .04 \\
\hline can take off & $f$ & .26 & .13 & .06 & has large teeth & $\mathrm{s}$ & .11 & .06 & .07 \\
\hline is useful & $\mathrm{f}$ & .26 & .75 & .01 & has powerful tail & $\mathrm{s}$ & .11 & .13 & .07 \\
\hline & & & & & can lay eggs & $\mathrm{f}$ & .16 & .19 & .05 \\
\hline & & & & & can dive & $\mathrm{f}$ & .11 & .06 & .10 \\
\hline & & & & & can hide & $f$ & .11 & .19 & .08 \\
\hline & & & & & can run & $\mathrm{f}$ & .11 & .88 & .12 \\
\hline & & & & & is dangerous & $\mathrm{e}$ & .79 & .25 & .05 \\
\hline & & & & & is carnivorous & $\mathrm{e}$ & .32 & .19 & .14 \\
\hline & & & & & is found near water & $\mathrm{e}$ & .26 & .25 & .04 \\
\hline & & & & & is wild & $\mathrm{e}$ & .26 & .75 & .09 \\
\hline & & & & & can eat people & $\mathrm{e}$ & .16 & .06 & .07 \\
\hline & & & & & has tough skin & $\mathrm{e}$ & .16 & .13 & .09 \\
\hline & & & & & can eat fish & $\mathrm{e}$ & .11 & .06 & .06 \\
\hline & & & & & is found in America & $\mathrm{e}$ & .11 & .06 & .07 \\
\hline & & & & & is strong & $\mathrm{e}$ & .11 & .31 & .21 \\
\hline
\end{tabular}




\begin{tabular}{|c|c|c|c|c|c|c|c|c|c|}
\hline & $\begin{array}{c}\text { Feature } \\
\text { type }\end{array}$ & $\begin{array}{l}\text { Domi- } \\
\text { nance }\end{array}$ & $\begin{array}{l}\text { P } \\
\text { Distinc- } \\
\text { tiveness }\end{array}$ & $\begin{array}{l}\text { Proportion of } \\
\text { all inter- } \\
\text { correlations } \\
\text { significant }\end{array}$ & & $\begin{array}{c}\text { Feature } \\
\text { type }\end{array}$ & $\begin{array}{l}\text { Domi- } \\
\text { nance }\end{array}$ & $\begin{array}{l}\text { Distinc- } \\
\text { tiveness }\end{array}$ & $\begin{array}{l}\text { Proportion of } \\
\text { all inter- } \\
\text { correlations } \\
\text { significant }\end{array}$ \\
\hline \multicolumn{5}{|l|}{ Apple } & \multicolumn{5}{|l|}{ Banana } \\
\hline is a fruit & $\mathrm{c}$ & 1.00 & 1.00 & & is a fruit & $c$ & 1.00 & 1.00 & \\
\hline has pips & $\mathrm{s}$ & .95 & .67 & .15 & has skin & $\mathrm{s}$ & .95 & 1.00 & .10 \\
\hline has skin & $\mathrm{s}$ & .74 & 1.00 & .10 & is yellow & $\mathrm{s}$ & .95 & .33 & .08 \\
\hline is round & $\mathrm{s}$ & .74 & .67 & .13 & has flesh & $\mathrm{s}$ & .63 & 1.00 & .22 \\
\hline has stalk & s & .68 & .67 & .15 & is curved & $\mathrm{s}$ & .42 & .17 & .06 \\
\hline has flesh & $\mathrm{s}$ & .63 & 1.00 & .22 & is soft & $\mathrm{s}$ & .42 & .33 & .10 \\
\hline has core & $\mathrm{s}$ & .53 & .33 & .10 & has taste & $\mathrm{s}$ & .26 & .17 & .06 \\
\hline is red & $\mathrm{s}$ & .37 & .50 & .10 & is long & $\mathrm{s}$ & .26 & .17 & .06 \\
\hline is green & $\mathrm{s}$ & .37 & .33 & .11 & has pips & $\mathrm{s}$ & .21 & .67 & .15 \\
\hline is sweet & s & .37 & 1.00 & .22 & has smell & s & .21 & .17 & .06 \\
\hline has leaves & $\mathrm{s}$ & .32 & .83 & .19 & is green & $\mathrm{s}$ & .21 & .33 & .11 \\
\hline is hard & $\mathrm{s}$ & .32 & .33 & .09 & has leaves & $\mathrm{s}$ & .16 & .83 & .19 \\
\hline is juicy & $\mathrm{s}$ & .32 & .83 & .18 & has stalk & $\mathrm{s}$ & .16 & .67 & .15 \\
\hline is coloured & $\mathrm{s}$ & .16 & .17 & .09 & is sweet & $\mathrm{s}$ & .16 & 1.00 & .22 \\
\hline is sour & $\mathrm{s}$ & .16 & .17 & .08 & has white flesh & $\mathrm{s}$ & .11 & .33 & .10 \\
\hline has white flesh & $\mathrm{s}$ & .11 & .33 & .10 & is thin & s & .11 & .17 & .06 \\
\hline is small & $\mathrm{s}$ & .11 & .50 & .02 & is edible & $\mathrm{f}$ & .74 & 1.00 & .10 \\
\hline is edible & $\mathrm{f}$ & .84 & 1.00 & .10 & can be cooked & $\mathrm{f}$ & .47 & .83 & .17 \\
\hline be cooked & $\mathrm{f}$ & .68 & .83 & .17 & can ripen & f & .26 & .50 & .13 \\
\hline can fall & $\mathrm{f}$ & .32 & .33 & .10 & is found in tropics & $\mathrm{e}$ & .37 & .17 & .06 \\
\hline can be picked & $\mathrm{f}$ & .16 & .67 & .15 & is found in salads & $\mathrm{e}$ & .11 & .17 & .06 \\
\hline can ripen & $\mathrm{f}$ & .16 & .50 & .13 & is found on trees & $\mathrm{e}$ & .11 & .50 & .11 \\
\hline can rot & $\mathrm{f}$ & .16 & .17 & .08 & & & & & \\
\hline can be bought & $\mathrm{f}$ & .11 & .17 & .08 & Barrel & & & & \\
\hline can be sold & $\mathrm{f}$ & .11 & .17 & .08 & is a container & c & .75 & .44 & \\
\hline can grow & $\mathrm{e}$ & .53 & .50 & .13 & is made of wood & $\mathrm{s}$ & .65 & .31 & .01 \\
\hline is found on trees & $\mathrm{e}$ & .21 & .50 & .11 & is round & $\mathrm{s}$ & .65 & .44 & .03 \\
\hline can be preserved & $\mathrm{e}$ & .11 & .17 & .08 & has lid & $\mathrm{s}$ & .60 & .31 & .12 \\
\hline \multirow[t]{2}{*}{ has maggots } & $\mathrm{e}$ & .11 & .17 & .08 & has bands & $\mathrm{s}$ & .55 & .06 & .02 \\
\hline & & & & & has tap & $\mathrm{s}$ & .55 & .06 & .02 \\
\hline Axe & & & & & is made of metal & $\mathrm{s}$ & .55 & .56 & .04 \\
\hline is a implement & $\mathrm{c}$ & .11 & .13 & & has base & $\mathrm{s}$ & .50 & .38 & .14 \\
\hline is a tool & c & .84 & 1.00 & & has staves & $\mathrm{s}$ & .35 & .06 & .02 \\
\hline has handle & s & .89 & .88 & .03 & has sides & $\mathrm{s}$ & .25 & .06 & .02 \\
\hline is sharp & $\mathrm{s}$ & .79 & .50 & .06 & is heavy & $\mathrm{s}$ & .25 & .19 & .01 \\
\hline is made of metal & s & .74 & .88 & .04 & is large & $\mathrm{s}$ & .15 & .31 & .07 \\
\hline has blade & $\mathrm{s}$ & .63 & .50 & .06 & can hold liquid & $\mathrm{f}$ & .50 & .12 & .06 \\
\hline has head & $\mathrm{s}$ & .63 & .38 & .14 & can roll & $\mathrm{f}$ & .40 & .12 & .04 \\
\hline is heavy & $\mathrm{s}$ & .63 & .38 & .01 & & & & & \\
\hline is made of wood & $\mathrm{s}$ & .26 & .63 & .01 & & & & & \\
\hline can cut & $\mathrm{f}$ & .61 & .50 & .09 & & & & & \\
\hline can fell trees & $\mathrm{f}$ & .37 & .13 & .02 & & & & & \\
\hline can split & $\mathrm{f}$ & .21 & .13 & .02 & & & & & \\
\hline can be thrown & $\mathrm{f}$ & .16 & .13 & .02 & & & & & \\
\hline can be sharpened & $\mathrm{f}$ & .11 & .38 & .06 & & & & & \\
\hline is dangerous & $\mathrm{e}$ & .47 & .50 & .11 & & & & & \\
\hline
\end{tabular}




\begin{tabular}{|c|c|c|c|c|}
\hline & $\begin{array}{c}\text { Feature } \\
\text { type }\end{array}$ & $\begin{array}{c}\text { Domi- } \\
\text { nance }\end{array}$ & $\begin{array}{l}\text { Distinc- } \\
\text { tiveness }\end{array}$ & $\begin{array}{l}\text { Proportion } \\
\text { all inter- } \\
\text { correlation } \\
\text { significan }\end{array}$ \\
\hline \multicolumn{5}{|l|}{ Basket } \\
\hline is a container & c & .37 & .44 & \\
\hline is a household item & c & .37 & .75 & \\
\hline has handle & s & 1.00 & .50 & .03 \\
\hline is made of cane & s & .79 & .06 & .03 \\
\hline is woven & s & .47 & .06 & .03 \\
\hline is hollow & s & .26 & .25 & .11 \\
\hline has base & s & .21 & .38 & .14 \\
\hline has body & s & .21 & .25 & .20 \\
\hline has lid & s & .21 & .31 & .12 \\
\hline is light & s & .21 & .44 & .02 \\
\hline is made of plastic & s & .21 & .50 & .03 \\
\hline is small & s & .21 & .69 & .03 \\
\hline is made of wood & s & .16 & .31 & .01 \\
\hline has wheel & $\mathrm{s}$ & .11 & .19 & .09 \\
\hline is large & s & .11 & .31 & .07 \\
\hline is made of fabric & s & .11 & .12 & .09 \\
\hline is round & s & .11 & .44 & .03 \\
\hline can be filled & $\mathrm{f}$ & .84 & .25 & .11 \\
\hline can be carried & $\mathrm{f}$ & .42 & .56 & .04 \\
\hline can hold shopping & $\mathrm{f}$ & .32 & .06 & .03 \\
\hline is useful & $\mathrm{f}$ & .32 & .75 & .01 \\
\hline can be emptied & $\mathrm{f}$ & .16 & .19 & .09 \\
\hline has pocket & $\mathrm{e}$ & .11 & .12 & .09 \\
\hline
\end{tabular}

Proportion of all inter-

Feature Domi- Distinc- correlations type nance tiveness significant

Bicycle

is a vehicle

has wheel

has seat

is made of metal

has handlebar

has pedal

has light

has tyre

has chain

is fast

has frame

is light

is unstable

has spokes

is coloured

can be ridden

has brakes

can be pushed

is manoeuvrable

can be raced

can move

is powered by rider

is useful

can be bought

can carry passengers

can freewheel

is non-polluting

has gears

Brush

is a household item

is a tool

has bristles

has handle

has head

is hard

is made of wood

is long and/or thin

is soft

is made of plastic

is small

can sweep

can clean

can smooth hair

can apply paint

is hand held

is useful

is found in the garden $\mathrm{e}$
$1.00 \quad 1.00$

$.94 \quad .75$

$.72 \quad .88$

$.67 \quad .88$

$.56 \quad .25$

$.50 \quad .25$

$.39 \quad .38$

$.33 \quad .25$

$.28 \quad .12$

$.28 \quad .88$

.22

.12

.12

.38

.12

.38

.25

.38

.12

.12

.12

.75

.12

.75

.12

.12

.12

.12

.38

.09

.06

.04

.09

.09

.12

.09

.05

.08

.09

.02

.12

.05

.04

.09

.12

.05

.05

.05

.23

.05

.01

.01

.05

.05

.05

.12 


\begin{tabular}{|c|c|c|c|c|c|c|c|c|c|}
\hline & $\begin{array}{c}\text { Feature } \\
\text { type }\end{array}$ & $\begin{array}{c}\text { Domi- } \\
\text { nance }\end{array}$ & $\begin{array}{l}\text { I } \\
\text { Distinc- } \\
\text { tiveness }\end{array}$ & $\begin{array}{l}\text { Proportion of } \\
\text { all inter- } \\
\text { correlations } \\
\text { significant }\end{array}$ & & $\begin{array}{c}\text { Feature } \\
\text { type }\end{array}$ & $\begin{array}{c}\text { Domi- } \\
\text { nance }\end{array}$ & $\begin{array}{l}\quad \\
\text { Distinc- } \\
\text { tiveness }\end{array}$ & $\begin{array}{c}\text { Proportion } \\
\text { all inter- } \\
\text { correlation } \\
\text { significan }\end{array}$ \\
\hline \multicolumn{10}{|l|}{ Bus } \\
\hline is a vehicle & c & 1.00 & 1.00 & & is a mammal & c & .11 & .50 & \\
\hline has wheel & $\mathrm{s}$ & .79 & .75 & .09 & is a vehicle & c & .16 & .06 & \\
\hline has seat & $\mathrm{s}$ & .74 & .88 & .06 & is a animal & c & .95 & .88 & \\
\hline is large & s & .58 & .62 & .07 & has humps & s & .79 & .06 & .08 \\
\hline is made of metal & s & .37 & .88 & .04 & has legs & s & .68 & .88 & .12 \\
\hline has decks & s & .32 & .12 & .07 & has four legs & s & .53 & .94 & .13 \\
\hline has window & s & .32 & .50 & .19 & is large & s & .53 & .62 & .06 \\
\hline is coloured & s & .32 & .38 & .04 & has tail & s & .42 & .81 & .11 \\
\hline is roomy & s & .16 & .12 & .07 & has fur & s & .37 & .69 & .11 \\
\hline is fast & $\mathrm{s}$ & .11 & .88 & .08 & has hooves & $\mathrm{s}$ & .26 & .19 & .11 \\
\hline can make a noise & $\mathrm{s}$ & .11 & .75 & .08 & has ears & $\mathrm{s}$ & .21 & .69 & .09 \\
\hline has body & s & .11 & .25 & .20 & has long neck & $\mathrm{s}$ & .21 & .06 & .07 \\
\hline has cab & s & .11 & .25 & .11 & has neck & s & .21 & .06 & .07 \\
\hline has door & s & .11 & .25 & .11 & has eyes & s & .16 & 1.00 & .13 \\
\hline can carry passengers & $\mathrm{f}$ & .78 & .50 & .17 & has large mouth & s & .16 & .12 & .08 \\
\hline can move & $\mathrm{f}$ & .37 & .75 & .23 & has mouth & s & .16 & .19 & .11 \\
\hline can stop & $\mathrm{f}$ & .32 & .38 & .13 & has small tail & $\mathrm{s}$ & .16 & .25 & .14 \\
\hline can break down & $\mathrm{f}$ & .17 & .12 & .07 & has smell & s & .16 & .12 & .06 \\
\hline can reverse & $\mathrm{f}$ & .16 & .38 & .14 & is brown & s & .16 & .50 & .05 \\
\hline can run on roads & $\mathrm{f}$ & .16 & .12 & .07 & is fast & s & .11 & .62 & .08 \\
\hline can follow a route & $\mathrm{f}$ & .11 & .12 & .07 & can be ridden & $\mathrm{f}$ & .58 & .19 & .12 \\
\hline can start & $f$ & .11 & .12 & .07 & can carry & $\mathrm{f}$ & .58 & .19 & .14 \\
\hline is powerful & $f$ & .11 & .38 & .15 & can run & $\mathrm{f}$ & .47 & .88 & .12 \\
\hline has driver & e & .74 & .38 & .14 & can walk & $\mathrm{f}$ & .47 & .75 & .08 \\
\hline has engine & $\mathrm{e}$ & .63 & .75 & .24 & can spit & $\mathrm{f}$ & .26 & .06 & .08 \\
\hline has conductor & $\mathrm{e}$ & .26 & .12 & .07 & can eat & $\mathrm{f}$ & .21 & .94 & .11 \\
\hline has stairs & $\mathrm{e}$ & .26 & .12 & .07 & can kneel & $\mathrm{f}$ & .21 & .06 & .08 \\
\hline has brakes & $\mathrm{e}$ & .16 & .25 & .11 & can bite & $\mathrm{f}$ & .20 & .31 & .17 \\
\hline has fare & $\mathrm{e}$ & .11 & .12 & .07 & can sit & $\mathrm{f}$ & .16 & .06 & .08 \\
\hline is polluting & $\mathrm{e}$ & .11 & .25 & .11 & is useful & $\mathrm{f}$ & .16 & .12 & .07 \\
\hline is powered by diesel & $\mathrm{e}$ & .11 & .38 & .14 & can drink & $\mathrm{f}$ & .11 & .12 & .10 \\
\hline is powered by petrol & $\mathrm{e}$ & .11 & .38 & .13 & can store water & $\mathrm{e}$ & .58 & .06 & .08 \\
\hline \multirow[t]{8}{*}{ is public } & e & .11 & .12 & .07 & is found in desert & e & .47 & .06 & .08 \\
\hline & & & & & is bad temepered & $\mathrm{e}$ & .37 & .06 & .08 \\
\hline & & & & & is herbivorous & e & .16 & .25 & .15 \\
\hline & & & & & is domesticated & $\mathrm{e}$ & .11 & .38 & .05 \\
\hline & & & & & is found in Africa & $\mathrm{e}$ & .11 & .19 & .11 \\
\hline & & & & & is found in Australia & e & .11 & .12 & .06 \\
\hline & & & & & is strong & $\mathrm{e}$ & .11 & .31 & .21 \\
\hline & & & & & is wild & $\mathrm{e}$ & .11 & .75 & .09 \\
\hline
\end{tabular}




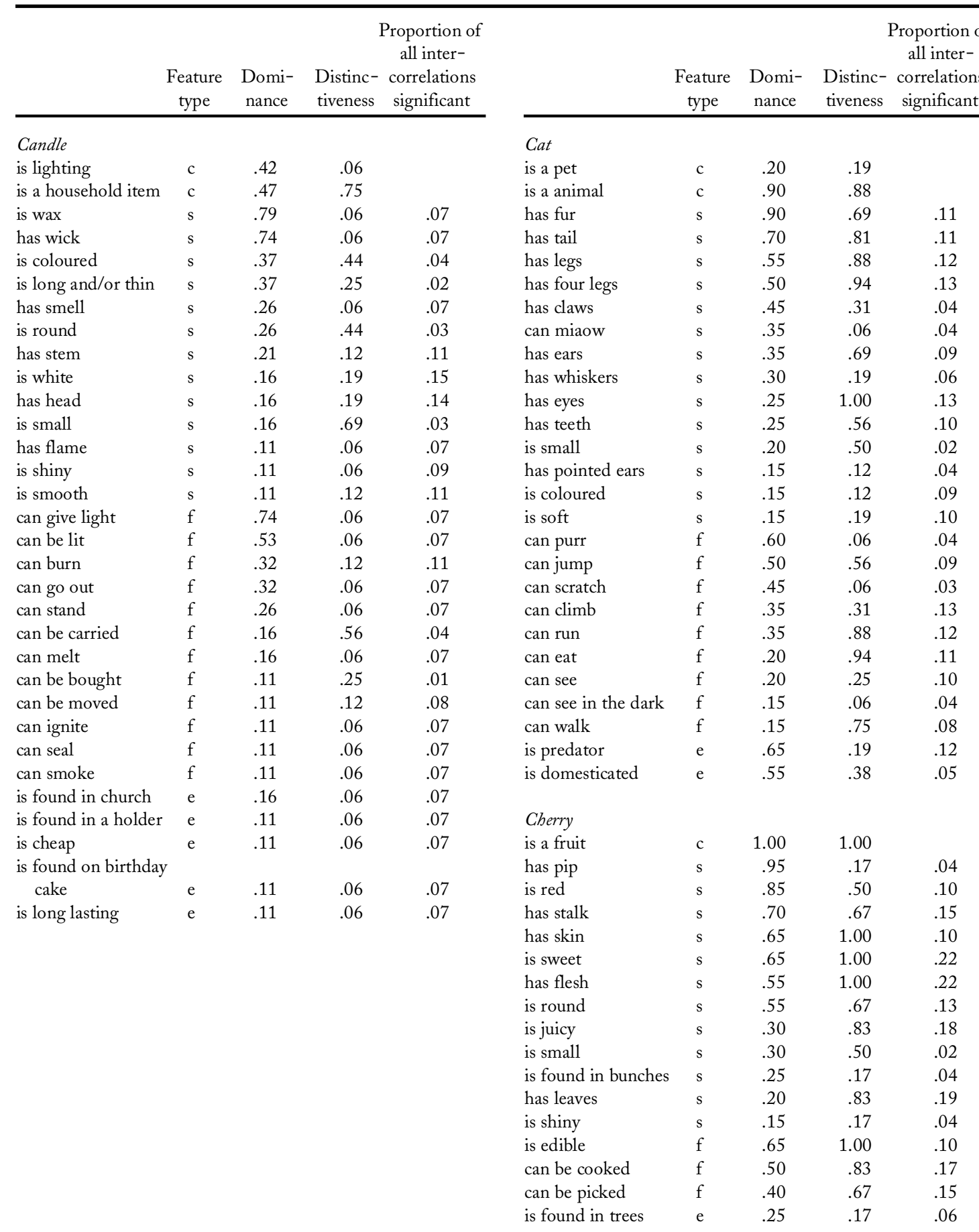




\begin{tabular}{|c|c|c|c|c|c|c|c|c|c|}
\hline & $\begin{array}{c}\text { Feature } \\
\text { type }\end{array}$ & $\begin{array}{l}\text { Domi- } \\
\text { nance }\end{array}$ & $\begin{array}{l}\text { Distinc- } \\
\text { tiveness }\end{array}$ & $\begin{array}{l}\text { Proportion of } \\
\text { all inter- } \\
\text { correlations } \\
\text { significant }\end{array}$ & & $\begin{array}{c}\text { Feature } \\
\text { type }\end{array}$ & $\begin{array}{l}\text { Domi- } \\
\text { nance }\end{array}$ & $\begin{array}{l}\text { Distinc- } \\
\text { tiveness }\end{array}$ & $\begin{array}{l}\text { Proportion of } \\
\text { all inter- } \\
\text { correlations } \\
\text { significant }\end{array}$ \\
\hline \multicolumn{5}{|l|}{ Chicken } & \multicolumn{5}{|l|}{ Cow } \\
\hline is a animal & c & .15 & .50 & & is a mammal & c & .16 & .50 & \\
\hline is a bird & $\mathrm{c}$ & .90 & 1.00 & & is a ruminant & c & .26 & .06 & \\
\hline has feathers & s & .80 & 1.00 & .07 & is a animal & c & 1.00 & .88 & \\
\hline has beak & $\mathrm{s}$ & .55 & 1.00 & .07 & has udder & $\mathrm{s}$ & .74 & .06 & .04 \\
\hline has legs & s & .55 & .75 & .12 & has four legs & s & .47 & .94 & .13 \\
\hline has wings & s & .35 & 1.00 & .07 & can moo & $\mathrm{s}$ & .37 & .06 & .04 \\
\hline has two legs & $\mathrm{s}$ & .35 & .62 & .13 & is large & $\mathrm{s}$ & .37 & .62 & .06 \\
\hline is small & s & .35 & .38 & .02 & has eyes & $\mathrm{s}$ & .26 & 1.00 & .13 \\
\hline has crest & $\mathrm{s}$ & .30 & .25 & .05 & has cloven hooves & $\mathrm{s}$ & .16 & .06 & .04 \\
\hline can make a noise & $\mathrm{s}$ & .20 & .62 & .03 & has ears & $\mathrm{s}$ & .16 & .69 & .09 \\
\hline has eyes & $\mathrm{s}$ & .20 & .75 & .13 & has fur & $\mathrm{s}$ & .16 & .69 & .11 \\
\hline has feet & $\mathrm{s}$ & .20 & .75 & .06 & is black & s & .16 & .06 & .06 \\
\hline has scaley legs & $\mathrm{s}$ & .15 & .12 & .02 & is brown & $\mathrm{s}$ & .16 & .50 & .05 \\
\hline is brown & $\mathrm{s}$ & .15 & .25 & .05 & has teats & $\mathrm{s}$ & .11 & .06 & .04 \\
\hline can lay eggs & $\mathrm{f}$ & .80 & 1.00 & .05 & has tongue & $\mathrm{s}$ & .11 & .12 & .06 \\
\hline is edible & $\mathrm{f}$ & .65 & .38 & .10 & can be milked & $\mathrm{f}$ & .84 & .06 & .04 \\
\hline can cluck & $\mathrm{f}$ & .30 & .12 & .02 & is edible & $\mathrm{f}$ & .37 & .31 & .10 \\
\hline can eat & $\mathrm{f}$ & .30 & .62 & .11 & can breed & $\mathrm{f}$ & .26 & .56 & .07 \\
\hline can fly & $\mathrm{f}$ & .30 & .75 & .14 & can chew & $\mathrm{f}$ & .26 & .19 & .07 \\
\hline can scratch & $\mathrm{f}$ & .20 & .12 & .03 & can eat & $\mathrm{f}$ & .26 & .94 & .11 \\
\hline can peck & $\mathrm{f}$ & .15 & .12 & .02 & can walk & $\mathrm{f}$ & .26 & .75 & .08 \\
\hline can run & $\mathrm{f}$ & .15 & .38 & .12 & is useful & $\mathrm{f}$ & .21 & .12 & .07 \\
\hline is domesticated & $\mathrm{e}$ & .55 & .25 & .05 & can run & $\mathrm{f}$ & .16 & .88 & .12 \\
\hline \multirow[t]{2}{*}{ is found on farms } & $\mathrm{e}$ & .30 & .25 & .05 & is found on farms & $\mathrm{e}$ & .47 & .06 & .05 \\
\hline & & & & & can eat grass & $\mathrm{e}$ & .26 & .12 & .07 \\
\hline Comb & & & & & is docile & $\mathrm{e}$ & .26 & .12 & .07 \\
\hline is a household item & c & .25 & .75 & & is domesticated & $\mathrm{e}$ & .26 & .38 & .05 \\
\hline is a toiletry & $\mathrm{c}$ & .30 & .12 & & has valuable skin & $\mathrm{e}$ & .11 & .06 & .04 \\
\hline is a tool & c & .35 & .50 & & & & & & \\
\hline has teeth & $\mathrm{s}$ & 1.00 & .12 & .06 & & & & & \\
\hline is made of plastic & s & .65 & .50 & .03 & & & & & \\
\hline is small & $\mathrm{s}$ & .30 & .69 & .03 & & & & & \\
\hline has back & s & .25 & .12 & .06 & & & & & \\
\hline is made of metal & $\mathrm{s}$ & .25 & .56 & .04 & & & & & \\
\hline has handle & s & .20 & .50 & .03 & & & & & \\
\hline is coloured & $\mathrm{s}$ & .20 & .44 & .04 & & & & & \\
\hline is hard & $\mathrm{s}$ & .15 & .44 & .02 & & & & & \\
\hline is long and/or thin & $\mathrm{s}$ & .15 & .25 & .02 & & & & & \\
\hline can tidy hair & $\mathrm{f}$ & .80 & .06 & .01 & & & & & \\
\hline is useful & $\mathrm{f}$ & .30 & .75 & .01 & & & & & \\
\hline can be put in pocket & $\mathrm{f}$ & .20 & .06 & .01 & & & & & \\
\hline can be broken & $\mathrm{f}$ & .15 & .19 & .09 & & & & & \\
\hline can be carried & $\mathrm{f}$ & .15 & .56 & .04 & & & & & \\
\hline can be played & $\mathrm{f}$ & .15 & .12 & .07 & & & & & \\
\hline
\end{tabular}




\begin{tabular}{|c|c|c|c|c|c|c|c|c|c|}
\hline & $\begin{array}{c}\text { Feature } \\
\text { type }\end{array}$ & $\begin{array}{l}\text { Domi- } \\
\text { nance }\end{array}$ & $\begin{array}{l}\text { Distinc- } \\
\text { tiveness }\end{array}$ & $\begin{array}{l}\text { Proportion of } \\
\text { all inter- } \\
\text { correlations } \\
\text { significant }\end{array}$ & & $\begin{array}{c}\text { Feature } \\
\text { type }\end{array}$ & $\begin{array}{c}\text { Domi- } \\
\text { nance }\end{array}$ & $\begin{array}{l}\text { Distinc- } \\
\text { tiveness }\end{array}$ & $\begin{array}{l}\text { Proportion } \\
\text { all inter- } \\
\text { correlatior } \\
\text { significan }\end{array}$ \\
\hline Dog & & & & & Duck & & & & \\
\hline is a mammal & $\mathrm{c}$ & .16 & .50 & & is a bird & c & .90 & 1.00 & \\
\hline is a pet & $\mathrm{c}$ & .84 & .19 & & has feathers & $\mathrm{s}$ & .85 & 1.00 & .07 \\
\hline is a animal & c & 1.00 & .88 & & has beak & $\mathrm{s}$ & .70 & 1.00 & .07 \\
\hline has legs & s & .79 & .88 & .12 & has feet & $\mathrm{s}$ & .70 & .75 & .06 \\
\hline has four legs & $\mathrm{s}$ & .68 & .94 & .13 & has webbed feet & $\mathrm{s}$ & .65 & .38 & .10 \\
\hline has tail & $\mathrm{s}$ & .68 & .81 & .11 & has wings & $\mathrm{s}$ & .60 & 1.00 & .07 \\
\hline can bark & $\mathrm{s}$ & .58 & .06 & .08 & can quack & $\mathrm{s}$ & .40 & .12 & .02 \\
\hline has ears & $\mathrm{s}$ & .47 & .69 & .09 & has legs & $\mathrm{s}$ & .35 & .75 & .12 \\
\hline has teeth & s & .32 & .56 & .10 & is coloured & $\mathrm{s}$ & .35 & .25 & .09 \\
\hline has eyes & $\mathrm{s}$ & .26 & 1.00 & .13 & has tail & $\mathrm{s}$ & .20 & .38 & .11 \\
\hline has fur & s & .26 & .69 & .11 & can make a noise & $\mathrm{s}$ & .15 & .62 & .03 \\
\hline can make a noise & $\mathrm{s}$ & .21 & .19 & .03 & has eyes & $\mathrm{s}$ & .15 & .75 & .13 \\
\hline has head & $\mathrm{s}$ & .21 & .38 & .04 & is small & $\mathrm{s}$ & .15 & .38 & .02 \\
\hline has nose & $\mathrm{s}$ & .16 & .12 & .09 & can swim & $\mathrm{f}$ & .90 & .38 & .04 \\
\hline has sharp teeth & $\mathrm{s}$ & .16 & .38 & .19 & can fly & $\mathrm{f}$ & .85 & .75 & .14 \\
\hline has mouth & $\mathrm{s}$ & .11 & .19 & .11 & is edible & $\mathrm{f}$ & .63 & .38 & .10 \\
\hline has wet nose & $\mathrm{s}$ & .11 & .06 & .08 & can dive & f & .60 & .38 & .10 \\
\hline is coloured & s & .11 & .12 & .09 & can lay eggs & $f$ & .40 & 1.00 & .05 \\
\hline is fast & $\mathrm{s}$ & .11 & .62 & .08 & can walk & $\mathrm{f}$ & .25 & .75 & .08 \\
\hline is in different sizes & s & .11 & .06 & .08 & is found near water & $\mathrm{e}$ & .45 & .38 & .04 \\
\hline is large & $\mathrm{s}$ & .11 & .62 & .06 & is wild & $\mathrm{e}$ & .25 & .62 & .09 \\
\hline is small & $\mathrm{s}$ & .11 & .50 & .02 & is domestic & $\mathrm{e}$ & .15 & .12 & .02 \\
\hline can eat & $\mathrm{f}$ & .74 & .94 & .11 & & & & & \\
\hline can run & $\mathrm{f}$ & .58 & .88 & .12 & Dustbin & & & & \\
\hline can bite & $\mathrm{f}$ & .47 & .31 & .17 & is a container & $\mathrm{c}$ & .50 & .44 & \\
\hline can jump & $\mathrm{f}$ & .32 & .56 & .09 & is a household item & $\mathrm{c}$ & .55 & .75 & \\
\hline can be trained & f & .26 & .25 & .17 & has lid & $\mathrm{s}$ & .95 & .31 & .12 \\
\hline can wag tail & $\mathrm{f}$ & .26 & .06 & .08 & is made of metal & $\mathrm{s}$ & .75 & .56 & .04 \\
\hline can guard & $\mathrm{f}$ & .21 & .06 & .08 & has handle & $\mathrm{s}$ & .70 & .50 & .03 \\
\hline can guide & $\mathrm{f}$ & .21 & .06 & .08 & is made of plastic & $\mathrm{s}$ & .65 & .50 & .03 \\
\hline can walk & $\mathrm{f}$ & .21 & .75 & .08 & is round & $\mathrm{s}$ & .40 & .44 & .03 \\
\hline can be bought & $\mathrm{f}$ & .11 & .06 & .08 & has wheel & $\mathrm{s}$ & .35 & .19 & .09 \\
\hline can beg & $\mathrm{f}$ & .11 & .06 & .08 & is large & $\mathrm{s}$ & .25 & .31 & .07 \\
\hline can drink & $\mathrm{f}$ & .11 & .12 & .10 & is hollow & $\mathrm{s}$ & .20 & .25 & .11 \\
\hline can play & $\mathrm{f}$ & .11 & .06 & .08 & has base & $\mathrm{s}$ & .15 & .38 & .14 \\
\hline can pull & $\mathrm{f}$ & .11 & .19 & .12 & can hold rubbish & f & .60 & .06 & .02 \\
\hline can sleep & $\mathrm{f}$ & .11 & .06 & .08 & can be filled & $\mathrm{f}$ & .50 & .25 & .11 \\
\hline is domesticated & $\mathrm{e}$ & .47 & .38 & .05 & can be emptied & $f$ & .45 & .19 & .09 \\
\hline is friendly & $\mathrm{e}$ & .47 & .12 & .11 & is useful & $\mathrm{f}$ & .30 & .75 & .01 \\
\hline has good sense of & & & & & can be carried & $\mathrm{f}$ & .25 & .56 & .04 \\
\hline smell & $\mathrm{e}$ & .16 & .06 & .08 & can be moved & $f$ & .20 & .12 & .08 \\
\hline is carnivorous & $\mathrm{e}$ & .11 & .19 & .14 & can roll & $\mathrm{f}$ & .15 & .12 & .04 \\
\hline is intelligent & $\mathrm{e}$ & .11 & .12 & .10 & has lining & $\mathrm{e}$ & .15 & .06 & .02 \\
\hline is predator & $\mathrm{e}$ & .11 & .19 & .12 & & & & & \\
\hline is wild & $\mathrm{e}$ & .11 & .75 & .09 & & & & & \\
\hline
\end{tabular}




\begin{tabular}{|c|c|c|c|c|c|c|c|c|c|}
\hline & $\begin{array}{c}\text { Feature } \\
\text { type }\end{array}$ & $\begin{array}{c}\text { Domi- } \\
\text { nance }\end{array}$ & $\begin{array}{l}\text { Distinc- } \\
\text { tiveness }\end{array}$ & $\begin{array}{l}\text { Proportion of } \\
\text { all inter- } \\
\text { correlations } \\
\text { significant }\end{array}$ & & $\begin{array}{c}\text { Feature } \\
\text { type }\end{array}$ & $\begin{array}{c}\text { Domi- } \\
\text { nance }\end{array}$ & $\begin{array}{c}\text { Distinc- } \\
\text { tiveness }\end{array}$ & $\begin{array}{c}\text { Proportion o } \\
\text { all inter- } \\
\text { correlations } \\
\text { significant }\end{array}$ \\
\hline \multicolumn{10}{|c|}{ Elephant } \\
\hline is a bird & c & 1.00 & 1.00 & & is a mammal & c & .15 & .50 & \\
\hline has claws & s & .89 & .25 & .04 & is a animal & c & 1.00 & .88 & \\
\hline has wings & $\mathrm{s}$ & .89 & 1.00 & .07 & has trunk & $\mathrm{s}$ & .90 & .06 & .08 \\
\hline has beak & $\mathrm{s}$ & .78 & 1.00 & .07 & is large & s & .90 & .62 & .06 \\
\hline has feathers & $\mathrm{s}$ & .67 & 1.00 & .07 & has ears & $\mathrm{s}$ & .60 & .69 & .09 \\
\hline is large & $\mathrm{s}$ & .44 & .62 & .06 & has tusks & $\mathrm{s}$ & .60 & .06 & .08 \\
\hline has legs & $\mathrm{s}$ & .32 & .75 & .12 & is grey & $\mathrm{s}$ & .60 & .19 & .09 \\
\hline has large wings & $\mathrm{s}$ & .28 & .25 & .07 & has large ears & $\mathrm{s}$ & .55 & .12 & .09 \\
\hline has feet & $\mathrm{s}$ & .22 & .75 & .06 & has legs & $\mathrm{s}$ & .45 & .88 & .12 \\
\hline has two legs & $\mathrm{s}$ & .22 & .62 & .13 & has feet & $\mathrm{s}$ & .40 & .44 & .06 \\
\hline has eyes & $\mathrm{s}$ & .17 & .75 & .13 & has skin & $\mathrm{s}$ & .40 & .44 & .10 \\
\hline has hooked beak & $\mathrm{s}$ & .17 & .12 & .06 & has tail & $\mathrm{s}$ & .40 & .81 & .11 \\
\hline is golden & $\mathrm{s}$ & .16 & .12 & .06 & has four legs & $\mathrm{s}$ & .35 & .94 & .13 \\
\hline is grey & $\mathrm{s}$ & .11 & .12 & .09 & has thick skin & $\mathrm{s}$ & .30 & .12 & .08 \\
\hline can fly & $\mathrm{f}$ & .89 & .75 & .14 & has large feet & $\mathrm{s}$ & .30 & .06 & .08 \\
\hline can swoop & f & .39 & .25 & .08 & is heavy & $\mathrm{s}$ & .30 & .25 & .15 \\
\hline can lay eggs & $\mathrm{f}$ & .28 & 1.00 & .05 & has eyes & $\mathrm{s}$ & .20 & 1.00 & .13 \\
\hline can hover & $\mathrm{f}$ & .22 & .12 & .06 & has small tail & $\mathrm{s}$ & .20 & .25 & .14 \\
\hline can reproduce & $\mathrm{f}$ & .22 & .25 & .07 & is slow & $\mathrm{s}$ & .20 & .12 & .08 \\
\hline can carry & $\mathrm{f}$ & .17 & .12 & .14 & has ivory tusks & $\mathrm{s}$ & .15 & .06 & .08 \\
\hline can walk & $\mathrm{f}$ & .11 & .75 & .08 & can trumpet & $\mathrm{f}$ & .45 & .06 & .08 \\
\hline is predator & e & .89 & .25 & .12 & can be ridden & f & .35 & .19 & .12 \\
\hline is carnivorous & e & .78 & .25 & .14 & can pull & $\mathrm{f}$ & .35 & .19 & .12 \\
\hline has good eyesight & $\mathrm{e}$ & .67 & .25 & .10 & can be trained & $\mathrm{f}$ & .25 & .25 & .17 \\
\hline is dangerous & $\mathrm{e}$ & .33 & .50 & .05 & can carry & $\mathrm{f}$ & .25 & .19 & .14 \\
\hline has nest & e & .28 & .38 & .12 & can spray & $\mathrm{f}$ & .25 & .06 & .08 \\
\hline is wild & $\mathrm{e}$ & .28 & .62 & .09 & can breed & $\mathrm{f}$ & .20 & .56 & .07 \\
\hline is found in mountain & ns e & .22 & .12 & .06 & can trample & $\mathrm{f}$ & .20 & .06 & .08 \\
\hline is rare & $\mathrm{e}$ & .22 & .12 & .08 & can walk & $\mathrm{f}$ & .20 & .75 & .08 \\
\hline is protected & e & .11 & .12 & .06 & can pick things up & $\mathrm{f}$ & .15 & .06 & .08 \\
\hline \multirow[t]{10}{*}{ is strong } & $\mathrm{e}$ & .11 & .12 & .21 & can run & $\mathrm{f}$ & .15 & .88 & .12 \\
\hline & & & & & is strong & $\mathrm{e}$ & .50 & .31 & .21 \\
\hline & & & & & is wild & $\mathrm{e}$ & .35 & .75 & .09 \\
\hline & & & & & is vegetarian & e & .25 & .50 & .09 \\
\hline & & & & & is found India & $\mathrm{e}$ & .20 & .06 & .08 \\
\hline & & & & & is dangerous & $\mathrm{e}$ & .15 & .25 & .05 \\
\hline & & & & & is found in a zoo & $\mathrm{e}$ & .15 & .19 & .08 \\
\hline & & & & & is found in Africa & $\mathrm{e}$ & .15 & .19 & .11 \\
\hline & & & & & is gregarious & $\mathrm{e}$ & .15 & .12 & .09 \\
\hline & & & & & is herbivorous & $\mathrm{e}$ & .15 & .25 & .15 \\
\hline
\end{tabular}




\begin{tabular}{|c|c|c|c|c|c|c|c|c|c|}
\hline & $\begin{array}{c}\text { Feature } \\
\text { type }\end{array}$ & $\begin{array}{c}\text { Domi- } \\
\text { nance }\end{array}$ & $\begin{array}{l}\text { D } \\
\text { Distinc- } \\
\text { tiveness }\end{array}$ & $\begin{array}{l}\text { Proportion of } \\
\text { all inter- } \\
\text { correlations } \\
\text { significant }\end{array}$ & & $\begin{array}{c}\text { Feature } \\
\text { type }\end{array}$ & $\begin{array}{l}\text { Domi- } \\
\text { nance }\end{array}$ & $\begin{array}{l}\text { Distinc- } \\
\text { tiveness }\end{array}$ & $\begin{array}{l}\text { Proportion } \\
\text { all inter- } \\
\text { correlation } \\
\text { significan }\end{array}$ \\
\hline \multicolumn{5}{|l|}{ Envelope } & \multicolumn{5}{|l|}{ Glass } \\
\hline is a container & c & .15 & .44 & & is a tool & $\mathrm{c}$ & .12 & .50 & \\
\hline is stationery & $\mathrm{c}$ & .20 & .06 & & is a container & $\mathrm{c}$ & .35 & .44 & \\
\hline has gummed edge & $\mathrm{s}$ & .80 & .06 & .05 & is a household item & $\mathrm{c}$ & .47 & .75 & \\
\hline has flap & $\mathrm{s}$ & .70 & .06 & .09 & is transparent & $\mathrm{s}$ & .76 & .06 & .04 \\
\hline is made of paper & $\mathrm{s}$ & .65 & .06 & .05 & has base & $\mathrm{s}$ & .65 & .38 & .14 \\
\hline is square & s & .30 & .31 & .16 & has bowl & $\mathrm{s}$ & .41 & .06 & .04 \\
\hline is in different sizes & $\mathrm{s}$ & .25 & .12 & .10 & has stem & $\mathrm{s}$ & .41 & .12 & .11 \\
\hline is white & $\mathrm{s}$ & .25 & .19 & .15 & is round & $\mathrm{s}$ & .24 & .44 & .03 \\
\hline has front & $\mathrm{s}$ & .20 & .06 & .05 & is small & $\mathrm{s}$ & .24 & .69 & .03 \\
\hline is brown & s & .20 & .12 & .09 & has rim & $\mathrm{s}$ & .18 & .06 & .04 \\
\hline is flat & s & .20 & .06 & .05 & is different shapes & $\mathrm{s}$ & .18 & .06 & .04 \\
\hline has back & $\mathrm{s}$ & .15 & .12 & .06 & is hard & $\mathrm{s}$ & .18 & .44 & .02 \\
\hline has fold & $\mathrm{s}$ & .15 & .06 & .05 & is open-topped & $\mathrm{s}$ & .18 & .06 & .04 \\
\hline has window & $\mathrm{s}$ & .15 & .06 & .19 & is smooth & $\mathrm{s}$ & .18 & .12 & .11 \\
\hline is light & $\mathrm{s}$ & .15 & .44 & .02 & is coloured & $\mathrm{s}$ & .12 & .44 & .04 \\
\hline can hold a letter & $\mathrm{f}$ & .85 & .06 & .05 & is decorative & $\mathrm{s}$ & .12 & .06 & .04 \\
\hline can be posted & $\mathrm{f}$ & .60 & .06 & .05 & is light & $\mathrm{s}$ & .12 & .44 & .02 \\
\hline can be stamped & $\mathrm{f}$ & .55 & .06 & .05 & can be broken & $\mathrm{f}$ & .65 & .19 & .09 \\
\hline can be addressed & $\mathrm{f}$ & .45 & .06 & .05 & can hold liquid & $\mathrm{f}$ & .59 & .12 & .06 \\
\hline can be stuck down & $\mathrm{f}$ & .25 & .06 & .05 & can be drunk from & f & .53 & .06 & .04 \\
\hline is useful & $\mathrm{f}$ & .20 & .75 & .01 & can be bought & $\mathrm{f}$ & .12 & .25 & .01 \\
\hline \multirow[t]{2}{*}{ can be delivered } & $\mathrm{f}$ & .15 & .06 & .05 & can be cut & f & .12 & .12 & .08 \\
\hline & & & & & can be washed & f & .12 & .12 & .07 \\
\hline Frog & & & & & can cut & $\mathrm{f}$ & .12 & .06 & .09 \\
\hline is a reptile & $\mathrm{c}$ & .15 & .19 & & is useful & $\mathrm{f}$ & .12 & .75 & .01 \\
\hline is an animal & c & .50 & .12 & & & & & & \\
\hline is an amphibian & $\mathrm{c}$ & .55 & .06 & & Hammer & & & & \\
\hline has eyes & $\mathrm{s}$ & .55 & 1.00 & .13 & is a tool & c & .95 & 1.00 & \\
\hline has skin & $\mathrm{s}$ & .50 & .44 & .10 & has handle & $\mathrm{s}$ & .95 & .88 & .03 \\
\hline is green & $\mathrm{s}$ & .40 & .06 & .11 & has head & $\mathrm{s}$ & .95 & .38 & .14 \\
\hline is slimy & $\mathrm{s}$ & .40 & .06 & .03 & is made of wood & $\mathrm{s}$ & .79 & .62 & .01 \\
\hline has four legs & $\mathrm{s}$ & .35 & .94 & .13 & is made of metal & $\mathrm{s}$ & .74 & .88 & .04 \\
\hline has feet & $\mathrm{s}$ & .25 & .44 & .06 & is heavy & $\mathrm{s}$ & .53 & .38 & .01 \\
\hline has spots & $\mathrm{s}$ & .25 & .06 & .03 & has claw & $\mathrm{s}$ & .37 & .12 & .03 \\
\hline is small & $\mathrm{s}$ & .25 & .50 & .02 & can make a noise & $\mathrm{s}$ & .21 & .12 & .08 \\
\hline has tongue & $\mathrm{s}$ & .20 & .12 & .06 & is hard & $\mathrm{s}$ & .21 & .38 & .02 \\
\hline has webbed feet & $\mathrm{s}$ & .20 & .06 & .10 & has face & $\mathrm{s}$ & .16 & .12 & .03 \\
\hline has bulging eyes & $\mathrm{s}$ & .15 & .06 & .03 & is long and/or thin & $\mathrm{s}$ & .11 & .38 & .02 \\
\hline can jump & $\mathrm{f}$ & 1.00 & .56 & .09 & can knock in nails & $\mathrm{f}$ & .89 & .12 & .03 \\
\hline can swim & $\mathrm{f}$ & .80 & .25 & .04 & can pull nails & $\mathrm{f}$ & .47 & .12 & .03 \\
\hline can eat & f & .45 & .94 & .11 & can flatten surfaces & $\mathrm{f}$ & .26 & .12 & .03 \\
\hline can croak & $\mathrm{f}$ & .40 & .06 & .03 & is handheld & $\mathrm{f}$ & .26 & .88 & .03 \\
\hline can spawn & $\mathrm{f}$ & .30 & .06 & .03 & can break things & $\mathrm{f}$ & .16 & .12 & .03 \\
\hline can breed & $\mathrm{f}$ & .20 & .56 & .07 & is dangerous & $\mathrm{e}$ & .16 & .50 & .11 \\
\hline is edible & $\mathrm{f}$ & .20 & .31 & .10 & is found in the house & $\mathrm{e}$ & .16 & .12 & .03 \\
\hline can lay eggs & f & .15 & .19 & .05 & is found in the & & & & \\
\hline can eat insects & $\mathrm{e}$ & .50 & .06 & .03 & workshop & $\mathrm{e}$ & .11 & .12 & .03 \\
\hline is found in gardens & $\mathrm{e}$ & .20 & .06 & .03 & & & & & \\
\hline is found near water & $\mathrm{e}$ & .20 & .25 & .04 & & & & & \\
\hline
\end{tabular}




\begin{tabular}{|c|c|c|c|c|c|c|c|c|c|}
\hline & $\begin{array}{c}\text { Feature } \\
\text { type }\end{array}$ & $\begin{array}{c}\text { Domi- } \\
\text { nance }\end{array}$ & $\begin{array}{l}\text { Distinc- } \\
\text { tiveness }\end{array}$ & $\begin{array}{l}\text { Proportion of } \\
\text { all inter- } \\
\text { correlations } \\
\text { significant }\end{array}$ & & $\begin{array}{c}\text { Feature } \\
\text { type }\end{array}$ & $\begin{array}{c}\text { Domi- } \\
\text { nance }\end{array}$ & $\begin{array}{l}\text { Distinc- } \\
\text { tiveness }\end{array}$ & $\begin{array}{l}\text { Proportion o } \\
\text { all inter- } \\
\text { - correlation } \\
\text { significant }\end{array}$ \\
\hline \multicolumn{10}{|l|}{ Helicopter } \\
\hline is a machine & c & .17 & .12 & & is a mammal & c & .16 & .50 & \\
\hline is a aircraft & c & .44 & .25 & & is a animal & c & 1.00 & .88 & \\
\hline is a vehicle & c & .50 & 1.00 & & has legs & $\mathrm{s}$ & .79 & .88 & .12 \\
\hline has rotor & s & 1.00 & .12 & .05 & has four legs & $\mathrm{s}$ & .74 & .94 & .13 \\
\hline can make a noise & s & .50 & .75 & .08 & has tail & $\mathrm{s}$ & .68 & .81 & .11 \\
\hline has cockpit & $\mathrm{s}$ & .28 & .25 & .09 & has mane & $\mathrm{s}$ & .47 & .06 & .07 \\
\hline has wheel & $\mathrm{s}$ & .28 & .75 & .09 & is large & $\mathrm{s}$ & .47 & .62 & .06 \\
\hline has skids & $\mathrm{s}$ & .22 & .12 & .05 & has hooves & $\mathrm{s}$ & .32 & .19 & .11 \\
\hline is made of metal & s & .22 & .88 & .04 & has teeth & $\mathrm{s}$ & .32 & .56 & .10 \\
\hline has fuselage & $\mathrm{s}$ & .17 & .25 & .09 & has eyes & $\mathrm{s}$ & .26 & 1.00 & .13 \\
\hline has seat & $\mathrm{s}$ & .17 & .88 & .06 & has fur & $\mathrm{s}$ & .26 & .69 & .11 \\
\hline has window & $\mathrm{s}$ & .17 & .50 & .19 & has ears & $\mathrm{s}$ & .21 & .69 & .09 \\
\hline is large & $\mathrm{s}$ & .17 & .62 & .07 & has head & $\mathrm{s}$ & .21 & .38 & .04 \\
\hline has controls & $\mathrm{s}$ & .11 & .25 & .12 & is brown & $\mathrm{s}$ & .21 & .50 & .05 \\
\hline can fly & $\mathrm{f}$ & .83 & .25 & .09 & is fast & $\mathrm{s}$ & .21 & .62 & .08 \\
\hline can hover & f & .67 & .12 & .05 & is heavy & $\mathrm{s}$ & .21 & .25 & .15 \\
\hline can carry passengers & $\mathrm{f}$ & .33 & .50 & .17 & has body & $\mathrm{s}$ & .16 & .31 & .14 \\
\hline can land & $\mathrm{f}$ & .22 & .25 & .09 & can neigh & $\mathrm{s}$ & .11 & .06 & $\begin{array}{l}.17 \\
.07\end{array}$ \\
\hline \multicolumn{5}{|l|}{ can take off / land } & has skin & $\mathrm{s}$ & $\begin{array}{l}.11 \\
.11\end{array}$ & .00 & .10 \\
\hline vertical & $\mathrm{f}$ & .22 & .12 & .05 & is dappled & $\mathrm{s}$ & $\begin{array}{l}.11 \\
.11\end{array}$ & .06 & .07 \\
\hline can lower & $\mathrm{f}$ & .11 & .12 & .05 & is white & s & .11 & .06 & .06 \\
\hline can rise & $\mathrm{f}$ & .11 & .12 & .05 & can pull & $\mathrm{f}$ & .58 & .19 & .12 \\
\hline is useful & $\mathrm{f}$ & .11 & .75 & .01 & can be ridden & $\mathrm{f}$ & .42 & .19 & .12 \\
\hline has engine & $\mathrm{e}$ & .50 & .75 & .24 & can jump & $\mathrm{f}$ & .37 & .56 & .09 \\
\hline has pilot & $\mathrm{e}$ & .28 & .25 & .09 & can be raced & $\mathrm{f}$ & .32 & .06 & .07 \\
\hline can be used by forces & es $\mathrm{e}$ & .17 & .12 & .05 & can trot & $\mathrm{f}$ & .32 & .06 & .07 \\
\hline \multirow{16}{*}{$\begin{array}{l}\text { can be used for } \\
\text { observation }\end{array}$} & & & & & can walk & $\mathrm{f}$ & .32 & .75 & .08 \\
\hline & $\mathrm{e}$ & .11 & .12 & .05 & can gallop & $\mathrm{f}$ & .26 & .06 & .07 \\
\hline & & & & & can run & $\mathrm{f}$ & .26 & .88 & .12 \\
\hline & & & & & can be trained & $\mathrm{f}$ & .16 & .25 & .17 \\
\hline & & & & & can bite & $\mathrm{f}$ & .16 & .31 & .17 \\
\hline & & & & & can eat & $\mathrm{f}$ & .16 & .94 & .11 \\
\hline & & & & & can be shod & $\mathrm{f}$ & .11 & .06 & .07 \\
\hline & & & & & can carry & $\mathrm{f}$ & .11 & .19 & .14 \\
\hline & & & & & can kick & $\mathrm{f}$ & .11 & .06 & .06 \\
\hline & & & & & is herbivorous & $\mathrm{e}$ & .32 & .25 & .15 \\
\hline & & & & & is vegetarian & $\mathrm{e}$ & .26 & .50 & .09 \\
\hline & & & & & is domesticated & e & .21 & .38 & .05 \\
\hline & & & & & is strong & $\mathrm{e}$ & .16 & .31 & .21 \\
\hline & & & & & can eat grass & $\mathrm{e}$ & .11 & .12 & .07 \\
\hline & & & & & has strong teeth & e & .11 & .12 & .07 \\
\hline & & & & & is friendly & $\mathrm{e}$ & .11 & .12 & .11 \\
\hline
\end{tabular}




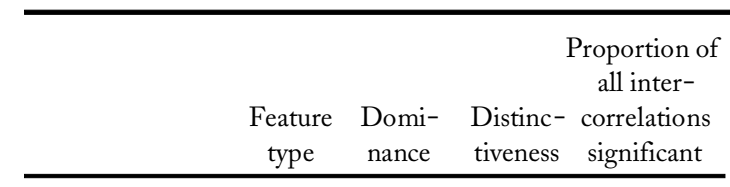

\section{Kangaroo}

is a marsupial

is a animal

has legs

has large hind legs

has pouch

has fur

is brown/grey

has small front legs

is large

has ears

has tail

is fast

has feet

has powerful tail

is upright

has eyes

has four legs

has head

has large feet

can jump

can eat

can carry young

is edible

can breed

can run

can see

is found in Australia

is vegetarian

is wild

is found in a zoo

$.60 \quad .06$

$.90 \quad .88$

$.85 \quad .88$

$.60 \quad .12$

.12

$.60 \quad .06$

$.50 \quad .69$

$.45 \quad .06$

$.40 \quad .06$

$.40 \quad .62$

.35

.25

.25

.20

.20

.20

.15

.15

.15

.15

.70

.30

.25

.20

.15

.15

.15

.50

.40

.40

.30
.07

.04

.11

.04

.04

.06

.09

.11

.08

.06

.07

.04

.13

.13

.04

.04

.09

.11

.04

.10

.07

.12

.10

.06

.09

.09

.08
Proportion of all inter-

Feature Domi- Distinc- correlations

type nance tiveness significant

Key

$\begin{array}{llll}\text { is a household item } & \text { c } & .35 & .75\end{array}$

$\begin{array}{llll}\text { is a tool } & \mathrm{c} & .45 & .50\end{array}$

$\begin{array}{llll}\text { is made of metal } & \mathrm{s} & .90 & .56\end{array}$

$\begin{array}{llll}\text { has teeth } & \mathrm{s} & .55 & .12\end{array}$

.04

has handle

$.35 \quad .50$

.06

is small

.35

.03

is hard

has pattern

.69

.03

has shaft/stem

has hole

can open doors

can lock doors

can be turned

can be hung on a ring

can be inserted

can be lost

can be carried

can be copied

can be cut

can start cars

is useful

is unique

.21

.44

.02

.04

.04

.04

.04

.04

.04

.04

.08

.09

.04

.04

.08

.04

.01

.04 


\begin{tabular}{|c|c|c|c|c|c|c|c|c|c|}
\hline & $\begin{array}{c}\text { Feature } \\
\text { type }\end{array}$ & $\begin{array}{c}\text { Domi- } \\
\text { nance }\end{array}$ & $\begin{array}{l}\text { Distinc- } \\
\text { tiveness }\end{array}$ & $\begin{array}{l}\text { Proportion of } \\
\text { all inter- } \\
\text { correlations } \\
\text { significant }\end{array}$ & & $\begin{array}{c}\text { Feature } \\
\text { type }\end{array}$ & $\begin{array}{c}\text { Domi- } \\
\text { nance }\end{array}$ & $\begin{array}{l}\text { Distinc- } \\
\text { tiveness }\end{array}$ & $\begin{array}{l}\text { Proportion o } \\
\text { all inter- } \\
\text { correlation } \\
\text { significant }\end{array}$ \\
\hline \multicolumn{5}{|l|}{ Lorry } & \multicolumn{5}{|l|}{ Monkey } \\
\hline is a vehicle & c & .94 & 1.00 & & is a primate & c & .25 & .06 & \\
\hline has wheel & $\mathrm{s}$ & .89 & .75 & .09 & is a animal & c & 1.00 & .88 & \\
\hline is large & $\mathrm{s}$ & .72 & .62 & .07 & has tail & $\mathrm{s}$ & .75 & .81 & .11 \\
\hline has cab & $\mathrm{s}$ & .56 & .25 & .11 & has fur & $\mathrm{s}$ & .70 & .69 & .11 \\
\hline can make a noise & $\mathrm{s}$ & .22 & .75 & .08 & has legs & $\mathrm{s}$ & .50 & .88 & .12 \\
\hline has trailer & s & .22 & .12 & .07 & has arms & $\mathrm{s}$ & .30 & .06 & .06 \\
\hline has body & s & .17 & .25 & .20 & has teeth & $\mathrm{s}$ & .25 & .56 & .10 \\
\hline has light & s & .17 & .38 & .12 & is small & $\mathrm{s}$ & .25 & .50 & .02 \\
\hline is articulated & s & .17 & .12 & .07 & has hands & $\mathrm{s}$ & .20 & .06 & .06 \\
\hline is fast & s & .17 & .88 & .08 & has long tail & $\mathrm{s}$ & .20 & .25 & .11 \\
\hline is heavy & s & .17 & .12 & .01 & has two legs & $\mathrm{s}$ & .20 & .06 & .06 \\
\hline is made of metal & s & .17 & .88 & .04 & can make a noise & $\mathrm{s}$ & .15 & .19 & .03 \\
\hline has door & s & .11 & .25 & .11 & has eyes & $\mathrm{s}$ & .15 & 1.00 & .13 \\
\hline has platform & s & .11 & .12 & .07 & has feet & $\mathrm{s}$ & .15 & .44 & .06 \\
\hline has window & $\mathrm{s}$ & .11 & .50 & .19 & has four legs & $\mathrm{s}$ & .15 & .94 & .13 \\
\hline is hard & $\mathrm{s}$ & .11 & .12 & .02 & has long arms & $\mathrm{s}$ & .15 & .06 & .06 \\
\hline can carry goods & $\mathrm{f}$ & .94 & .38 & .12 & has sharp teeth & $\mathrm{s}$ & .15 & .38 & .19 \\
\hline can be loaded & $\mathrm{f}$ & .50 & .12 & .07 & is brown & $\mathrm{s}$ & .15 & .50 & .05 \\
\hline can move & $\mathrm{f}$ & .17 & .75 & .23 & can climb & $\mathrm{f}$ & .55 & .31 & .13 \\
\hline can reverse & $\mathrm{f}$ & .17 & .38 & .14 & can jump & $\mathrm{f}$ & .40 & .56 & .09 \\
\hline can stop & $\mathrm{f}$ & .11 & .38 & .13 & can swing & $\mathrm{f}$ & .40 & .06 & .06 \\
\hline can tip & $\mathrm{f}$ & .11 & .12 & .09 & can breed & $\mathrm{f}$ & .25 & .56 & .07 \\
\hline is useful & $\mathrm{f}$ & .11 & .75 & .01 & can chatter & $\mathrm{f}$ & .25 & .06 & .06 \\
\hline has engine & e & .72 & .75 & .24 & can run & $\mathrm{f}$ & .25 & .88 & .12 \\
\hline has driver & e & .39 & .38 & .14 & can grasp & $\mathrm{f}$ & .20 & .12 & .08 \\
\hline is powered by diesel & e & .33 & .38 & .14 & can eat & $\mathrm{f}$ & .15 & .94 & .11 \\
\hline has brakes & e & .17 & .25 & .11 & is agile & $\mathrm{f}$ & .15 & .25 & .12 \\
\hline is polluting & e & .17 & .25 & .11 & is found in trees & $\mathrm{e}$ & .40 & .12 & .06 \\
\hline has gears & $\mathrm{e}$ & .11 & .38 & .12 & is wild & e & .40 & .75 & .09 \\
\hline has license & $\mathrm{e}$ & .11 & .12 & .07 & is intelligent & $\mathrm{e}$ & .30 & .12 & .10 \\
\hline is dangerous & $\mathrm{e}$ & .11 & .12 & .11 & is vegetarian & e & .30 & .50 & .09 \\
\hline is expensive & $\mathrm{e}$ & .11 & .25 & .13 & is found in zoos & $\mathrm{e}$ & .20 & .12 & .08 \\
\hline is powered by petrol & e & .11 & .38 & .13 & is mischeivous & $\mathrm{e}$ & .20 & .06 & .06 \\
\hline is strong & e & .11 & .12 & .11 & can eat fruit & $\mathrm{e}$ & .15 & .06 & .06 \\
\hline & & & & & is gregarious & $\mathrm{e}$ & .15 & .12 & .09 \\
\hline
\end{tabular}




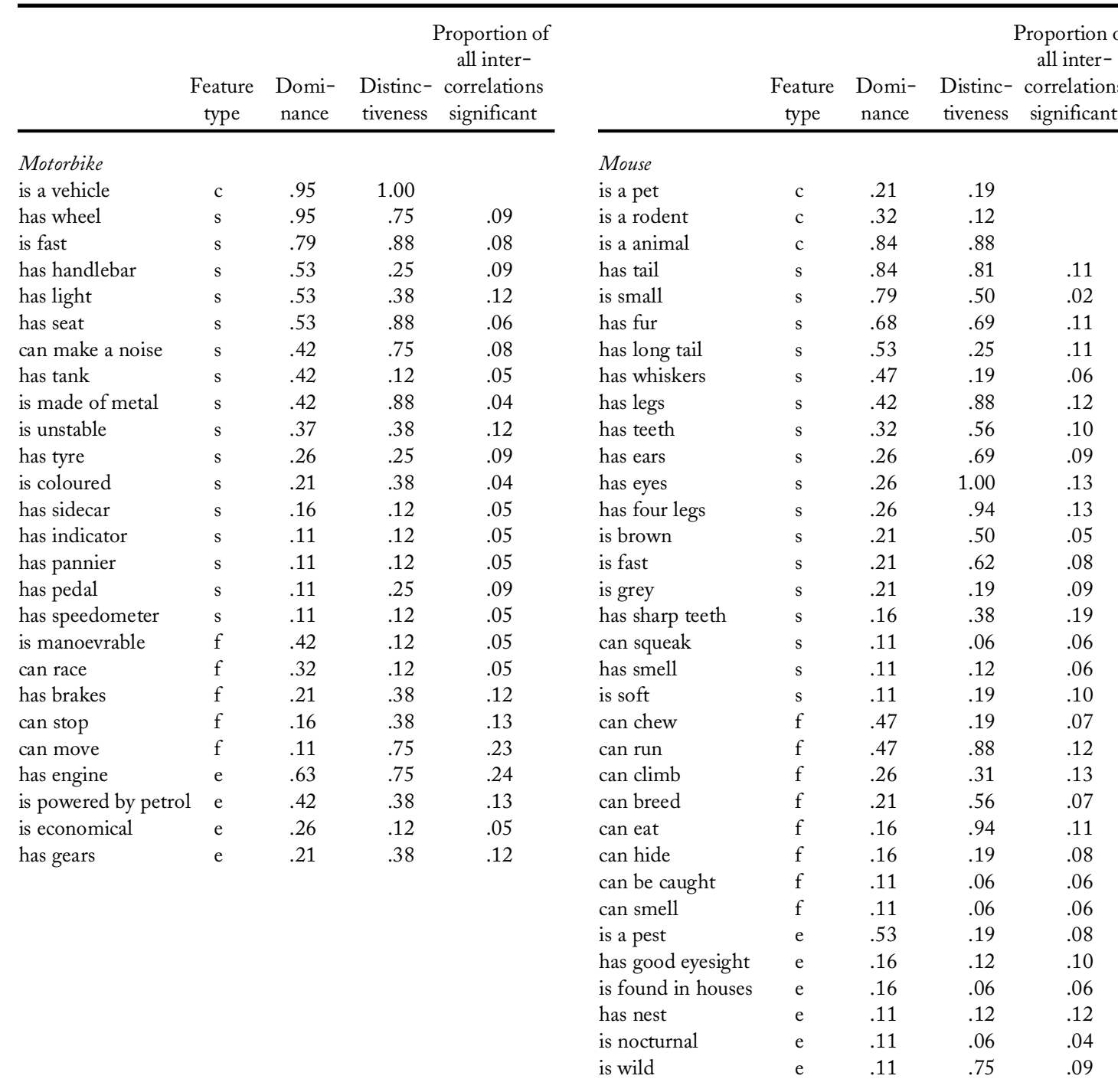




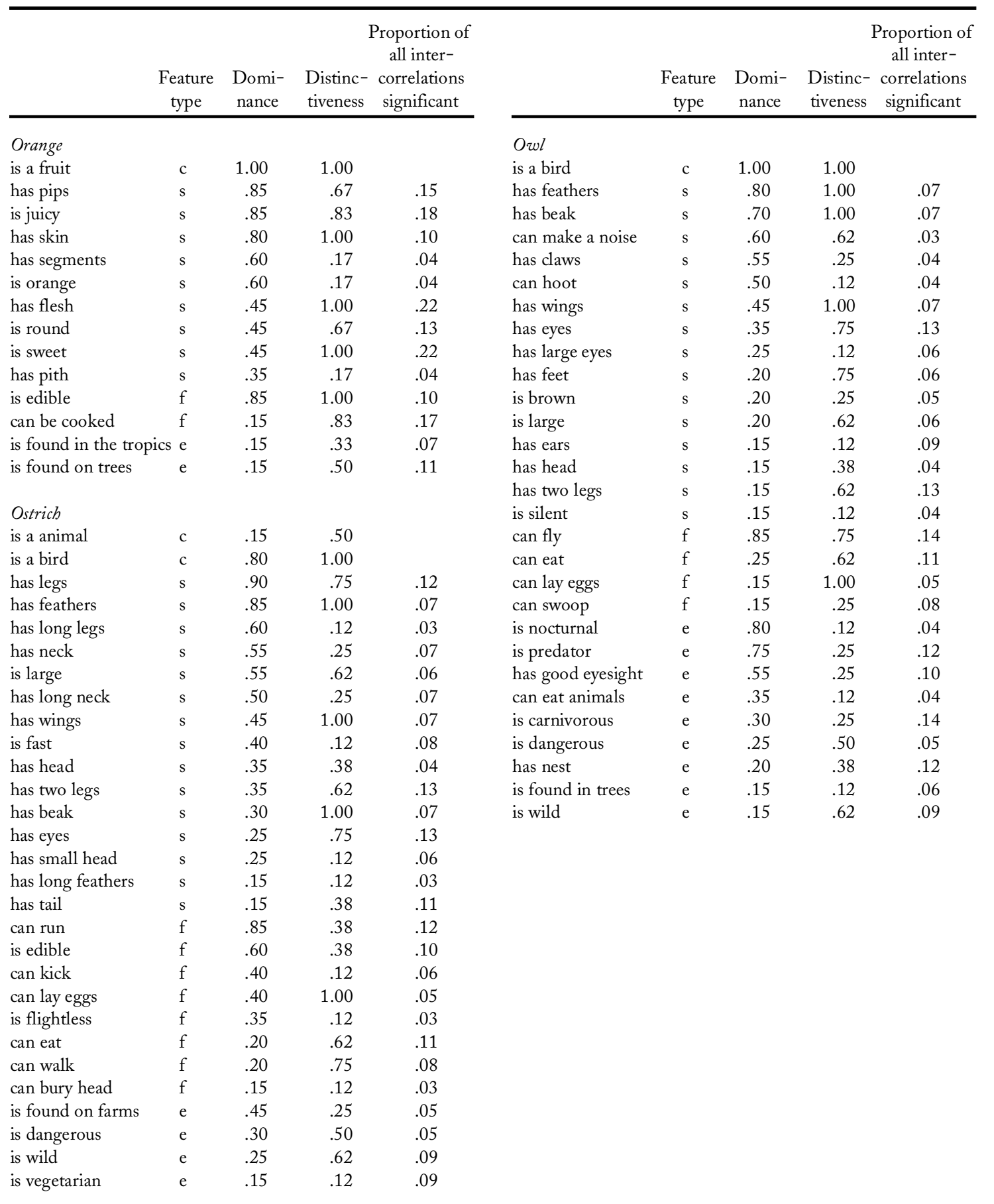




\begin{tabular}{|c|c|c|c|c|c|c|c|c|c|}
\hline & $\begin{array}{l}\text { Feature } \\
\text { type }\end{array}$ & $\begin{array}{l}\text { Domi- } \\
\text { nance }\end{array}$ & $\begin{array}{l}\text { Distinc- } \\
\text { tiveness }\end{array}$ & $\begin{array}{l}\text { Proportion of } \\
\text { all inter- } \\
\text { correlations } \\
\text { significant }\end{array}$ & & $\begin{array}{l}\text { Feature } \\
\text { type }\end{array}$ & $\begin{array}{l}\text { Domi- } \\
\text { nance }\end{array}$ & $\begin{array}{l}\text { P } \\
\text { Distinc- } \\
\text { tiveness }\end{array}$ & $\begin{array}{l}\text { Proportion } \\
\text { all inter- } \\
\text { correlation } \\
\text { significant }\end{array}$ \\
\hline \multicolumn{5}{|l|}{ Paintbrush } & \multicolumn{5}{|l|}{ Penguin } \\
\hline is a tool & $\mathrm{c}$ & .72 & 1.00 & & is a animal & c & .15 & .50 & \\
\hline has bristles & $\mathrm{s}$ & 1.00 & .12 & .07 & is a bird & c & .85 & 1.00 & \\
\hline has handle & $\mathrm{s}$ & .94 & .88 & .03 & has feet & $\mathrm{s}$ & .75 & .75 & .06 \\
\hline is made of wood & $\mathrm{s}$ & .50 & .62 & .01 & is black & $\mathrm{s}$ & .70 & .25 & .06 \\
\hline is in different sizes & $\mathrm{s}$ & .33 & .25 & .10 & has beak & $\mathrm{s}$ & .55 & 1.00 & .07 \\
\hline is soft & $\mathrm{s}$ & .22 & .12 & .09 & is white & s & .55 & .25 & .06 \\
\hline has metal band & $\mathrm{s}$ & .11 & .12 & .03 & has feathers & s & .50 & 1.00 & .07 \\
\hline is made of plastic & s & .11 & .25 & .03 & has webbed feet & $\mathrm{s}$ & .50 & .38 & .10 \\
\hline is small & $\mathrm{s}$ & .11 & .50 & .03 & is upright & $\mathrm{s}$ & .40 & .12 & .04 \\
\hline can spread paint & $\mathrm{f}$ & .67 & .12 & .03 & has flippers & $\mathrm{s}$ & .35 & .12 & .05 \\
\hline can be cleaned & $\mathrm{f}$ & .33 & .12 & .03 & has wings & $\mathrm{s}$ & .35 & 1.00 & .07 \\
\hline is handheld & $f$ & .22 & .88 & .03 & is small & $\mathrm{s}$ & .15 & .38 & .02 \\
\hline is useful & $\mathrm{f}$ & .17 & .75 & .01 & can swim & $\mathrm{f}$ & .90 & .38 & .04 \\
\hline \multicolumn{5}{|l|}{ can be used to clean } & can walk & $\mathrm{f}$ & .80 & .75 & .08 \\
\hline things & $\mathrm{f}$ & .15 & .12 & .03 & can eat & $\mathrm{f}$ & .75 & .62 & .11 \\
\hline can be bought & $\mathrm{f}$ & .11 & .25 & .01 & can lay eggs & $\mathrm{f}$ & .45 & 1.00 & .05 \\
\hline can be stored & $\mathrm{f}$ & .11 & .12 & .03 & can dive & $\mathrm{f}$ & .20 & .38 & .10 \\
\hline is used by artists & $\mathrm{e}$ & .28 & .12 & .03 & can eat fish & $\mathrm{e}$ & .70 & .12 & .06 \\
\hline is used by decorators & $\mathrm{e}$ & .22 & .12 & .03 & $\begin{array}{l}\text { is found in cold } \\
\text { climate }\end{array}$ & $\mathrm{e}$ & .55 & .12 & .03 \\
\hline \multicolumn{5}{|l|}{ Peacock } & is found near water & $\mathrm{e}$ & .30 & .38 & .04 \\
\hline is a bird & c & .95 & 1.00 & & is found in groups & $\mathrm{e}$ & .15 & .12 & .03 \\
\hline is domesticated & $\mathrm{e}$ & .15 & .25 & .05 & & & & & \\
\hline can lay eggs & $\mathrm{f}$ & .25 & 1.00 & .05 & \multicolumn{5}{|l|}{ Piano } \\
\hline can run & $\mathrm{f}$ & .30 & .38 & .12 & \multicolumn{5}{|l|}{ is a musical } \\
\hline can walk & $\mathrm{f}$ & .30 & .75 & .08 & instrument & c & .84 & \multicolumn{2}{|l|}{.06} \\
\hline can fly & $\mathrm{f}$ & .50 & .75 & .14 & \multicolumn{2}{|l|}{ has keys } & .79 & .06 & .05 \\
\hline has head & $\mathrm{s}$ & .15 & .38 & .04 & \multicolumn{2}{|l|}{ has pedals } & .68 & .06 & .05 \\
\hline \multirow{2}{*}{$\begin{array}{l}\text { has crest } \\
\text { has large tail }\end{array}$} & $\mathrm{s}$ & .20 & .25 & .05 & has lid & $\mathrm{s}$ & .58 & .31 & .12 \\
\hline & $\mathrm{s}$ & .25 & .12 & .02 & is made of wood & $\mathrm{s}$ & .58 & .31 & .01 \\
\hline has wings & s & .25 & 1.00 & .07 & is large & s & .47 & .31 & .07 \\
\hline has two legs & $\mathrm{s}$ & .30 & .12 & .06 & can make a noise & $\mathrm{s}$ & .32 & .06 & .08 \\
\hline has beak & $\mathrm{s}$ & .35 & 1.00 & .07 & has legs & $\mathrm{s}$ & .32 & .12 & .07 \\
\hline is large & $\mathrm{s}$ & .35 & .62 & .06 & has black keys & $\mathrm{s}$ & .26 & .06 & .05 \\
\hline can screech & $\mathrm{s}$ & .40 & .12 & .02 & is grand & s & .26 & .06 & .05 \\
\hline has tail & $\mathrm{s}$ & .50 & .38 & .11 & is made of ivory & $\mathrm{s}$ & .26 & .06 & .05 \\
\hline is coloured & $\mathrm{s}$ & .50 & .25 & .09 & has frame & $\mathrm{s}$ & .21 & .06 & .09 \\
\hline can fan tail & $\mathrm{s}$ & .55 & .12 & .02 & is heavy & $\mathrm{s}$ & .21 & .19 & .01 \\
\hline has legs & $\mathrm{s}$ & .55 & .75 & .12 & is upright & $\mathrm{s}$ & .21 & .06 & .05 \\
\hline is decorative & $\mathrm{s}$ & .55 & .12 & .02 & has case & s & .16 & .06 & .05 \\
\hline has feathers & $\mathrm{s}$ & .60 & 1.00 & .07 & has feet & $\mathrm{s}$ & .11 & .06 & .05 \\
\hline can make a noise & $\mathrm{s}$ & .90 & .62 & .03 & has music-stand & $\mathrm{s}$ & .11 & .06 & .05 \\
\hline & & & & & is made of metal & $\mathrm{s}$ & .11 & .56 & .04 \\
\hline & & & & & is soft & $\mathrm{s}$ & .11 & .19 & .09 \\
\hline & & & & & can be played & $\mathrm{f}$ & .84 & .12 & .07 \\
\hline & & & & & can be tuned & $\mathrm{f}$ & .37 & .06 & .05 \\
\hline & & & & & can be polished & $\mathrm{f}$ & .16 & .12 & .07 \\
\hline & & & & & has hammer & $\mathrm{e}$ & .21 & .06 & .05 \\
\hline & & & & & is expensive & $\mathrm{e}$ & .21 & .06 & .13 \\
\hline
\end{tabular}




\begin{tabular}{|c|c|c|c|c|c|c|c|c|c|}
\hline \multicolumn{5}{|l|}{ Pineapple } & \multicolumn{5}{|l|}{ Plug } \\
\hline is a fruit & c & 1.00 & 1.00 & & is a appliance & $\mathrm{c}$ & .11 & .06 & \\
\hline is sweet & s & .70 & 1.00 & .22 & is a tool & $\mathrm{c}$ & .21 & .50 & \\
\hline has leaves & s & .65 & .83 & .19 & is a electrical item & c & .68 & .12 & \\
\hline has flesh & s & .60 & 1.00 & .22 & has pin & $\mathrm{s}$ & .95 & .06 & .05 \\
\hline is juicy & s & .60 & .83 & .18 & is made of plastic & $\mathrm{s}$ & .63 & .50 & .03 \\
\hline has rough skin & $\mathrm{s}$ & .40 & .17 & .06 & has fuse & s & .58 & .06 & .05 \\
\hline is oval/round & s & .25 & .17 & .06 & has cover & $\mathrm{s}$ & .26 & .06 & .05 \\
\hline has yellow flesh & $\mathrm{s}$ & .20 & .17 & .06 & has screws & $\mathrm{s}$ & .26 & .06 & .05 \\
\hline has spikey leaves & s & .15 & .17 & .06 & is white & $\mathrm{s}$ & .21 & .19 & .15 \\
\hline is large & s & .15 & .17 & .06 & has terminals & $\mathrm{s}$ & .16 & .06 & .05 \\
\hline is edible & $\mathrm{f}$ & .85 & 1.00 & .10 & has cable grip & s & .11 & .06 & .05 \\
\hline can be cut & f & .40 & .17 & .06 & is coloured & $\mathrm{s}$ & .11 & .44 & .04 \\
\hline can be peeled & $\mathrm{f}$ & .25 & .17 & .06 & is square & $\mathrm{s}$ & .11 & .31 & .16 \\
\hline can be picked & $\mathrm{f}$ & .15 & .67 & .15 & can conduct electr & city $\mathrm{f}$ & .53 & .06 & .05 \\
\hline is found in the tropics & cs e & .40 & .33 & .07 & can be inserted & $\mathrm{f}$ & .42 & .12 & .08 \\
\hline can grow & $\mathrm{e}$ & .35 & .50 & .13 & can earth & $\mathrm{f}$ & .28 & .06 & .05 \\
\hline has hinge & s & .37 & .25 & .06 & & & & & \\
\hline is hard & $\mathrm{s}$ & .32 & .38 & .02 & & & & & \\
\hline has notch & s & .21 & .12 & .03 & & & & & \\
\hline is small & $\mathrm{s}$ & .11 & .50 & .03 & & & & & \\
\hline can grip & $\mathrm{f}$ & .63 & .12 & .03 & & & & & \\
\hline can pull & $\mathrm{f}$ & .47 & .12 & .08 & & & & & \\
\hline can cut & $\mathrm{f}$ & .37 & .50 & .09 & & & & & \\
\hline can squeeze & $f$ & .32 & .12 & .03 & & & & & \\
\hline can turn & $\mathrm{f}$ & .32 & .25 & .05 & & & & & \\
\hline is handheld & $\mathrm{f}$ & .21 & .88 & .03 & & & & & \\
\hline can bend & $\mathrm{f}$ & .16 & .12 & .03 & & & & & \\
\hline can open and close & $\mathrm{f}$ & .16 & .12 & .07 & & & & & \\
\hline is useful & $\mathrm{f}$ & .16 & .75 & .01 & & & & & \\
\hline is used in metalwork & $\mathrm{e}$ & .21 & .25 & .05 & & & & & \\
\hline is found in a toolbox & $\mathrm{e}$ & .16 & .12 & .03 & & & & & \\
\hline
\end{tabular}




\begin{tabular}{|c|c|c|c|c|c|c|c|c|c|}
\hline & $\begin{array}{c}\text { Feature } \\
\text { type }\end{array}$ & $\begin{array}{c}\text { Domi- } \\
\text { nance }\end{array}$ & $\begin{array}{r}\text { P } \\
\text { Distinc- } \\
\text { tiveness }\end{array}$ & $\begin{array}{l}\text { Proportion of } \\
\text { all inter- } \\
\text { correlations } \\
\text { significant }\end{array}$ & & $\begin{array}{c}\text { Feature } \\
\text { type }\end{array}$ & $\begin{array}{l}\text { Domi- } \\
\text { nance }\end{array}$ & $\begin{array}{r}\mathrm{P} \\
\text { Distinc- } \\
\text { tiveness }\end{array}$ & $\begin{array}{l}\text { Proportion } \\
\text { all inter- } \\
\text { correlatior } \\
\text { significan }\end{array}$ \\
\hline Rabbit & & & & & Rhinoceros & & & & \\
\hline is a mammal & $\mathrm{c}$ & .11 & .50 & & is an animal & c & .95 & .12 & \\
\hline is a animal & $\mathrm{c}$ & .95 & .88 & & has horn & $\mathrm{s}$ & .95 & .06 & .05 \\
\hline has long ears & $\mathrm{s}$ & 1.00 & .06 & .07 & has legs & $\mathrm{s}$ & .58 & .88 & .12 \\
\hline has fur & $\mathrm{s}$ & .79 & .69 & .11 & has skin & $\mathrm{s}$ & .58 & .44 & .10 \\
\hline has tail & $\mathrm{s}$ & .79 & .81 & .11 & is heavy & $\mathrm{s}$ & .53 & .25 & .15 \\
\hline has large ears & $\mathrm{s}$ & .68 & .12 & .09 & is large & $\mathrm{s}$ & .53 & .62 & .06 \\
\hline has legs & $\mathrm{s}$ & .68 & .88 & .12 & has four legs & s & .47 & .94 & .13 \\
\hline has small tail & $\mathrm{s}$ & .53 & .25 & .14 & has eyes & $\mathrm{s}$ & .26 & 1.00 & .13 \\
\hline has four legs & s & .47 & .94 & .13 & has tail & s & .26 & .81 & .11 \\
\hline has eyes & $\mathrm{s}$ & .37 & 1.00 & .13 & has small tail & $\mathrm{s}$ & .21 & .25 & .14 \\
\hline is small & $\mathrm{s}$ & .37 & .50 & .02 & is grey/black & $\mathrm{s}$ & .21 & .06 & .05 \\
\hline is fast & $\mathrm{s}$ & .26 & .62 & .08 & has ears & s & .16 & .69 & .09 \\
\hline has whiskers & $\mathrm{s}$ & .16 & .19 & .06 & has hooves & s & .16 & .19 & .11 \\
\hline has white tail & $\mathrm{s}$ & .16 & .06 & .07 & has small eyes & s & .16 & .06 & .05 \\
\hline is brown & $\mathrm{s}$ & .16 & .50 & .05 & can make a noise & $\mathrm{s}$ & .11 & .19 & .03 \\
\hline can squeal & $\mathrm{s}$ & .11 & .06 & .07 & has body & s & .11 & .31 & .14 \\
\hline has body & $\mathrm{s}$ & .11 & .31 & .14 & has head & $\mathrm{s}$ & .11 & .38 & .04 \\
\hline has claws & s & .11 & .31 & .04 & has large legs & s & .11 & .06 & .05 \\
\hline has large eyes & $\mathrm{s}$ & .11 & .06 & .06 & has teeth & $\mathrm{s}$ & .11 & .56 & .10 \\
\hline has large hind legs & $\mathrm{s}$ & .11 & .12 & .07 & has cloven hooves & $\mathrm{s}$ & .11 & .06 & .05 \\
\hline has nose & $\mathrm{s}$ & .11 & .12 & .09 & is fast & $\mathrm{s}$ & .11 & .62 & .08 \\
\hline is soft & $\mathrm{s}$ & .11 & .19 & .10 & is ungainly & $\mathrm{s}$ & .11 & .06 & .05 \\
\hline can jump & $\mathrm{f}$ & .74 & .56 & .09 & can charge & f & .53 & .06 & .05 \\
\hline can dig & $\mathrm{f}$ & .63 & .19 & .06 & can run & $\mathrm{f}$ & .47 & .88 & .12 \\
\hline can run & $\mathrm{f}$ & .58 & .88 & .12 & can walk & $\mathrm{f}$ & .16 & .75 & .08 \\
\hline can breed & $\mathrm{f}$ & .37 & .56 & .07 & can breed & $\mathrm{f}$ & .11 & .56 & .07 \\
\hline is edible & $\mathrm{f}$ & .37 & .31 & .10 & can eat & $\mathrm{f}$ & .11 & .94 & .11 \\
\hline can eat & $\mathrm{f}$ & .16 & .94 & .11 & can see & $\mathrm{f}$ & .11 & .25 & .10 \\
\hline can hear & $\mathrm{f}$ & .11 & .06 & .07 & can swim & $\mathrm{f}$ & .11 & .25 & .04 \\
\hline can hide & $\mathrm{f}$ & .11 & .19 & .08 & is dangerous & $\mathrm{e}$ & .79 & .25 & .05 \\
\hline can see & $\mathrm{f}$ & .11 & .25 & .10 & is wild & $\mathrm{e}$ & .68 & .75 & .09 \\
\hline can walk & $\mathrm{f}$ & .11 & .75 & .08 & has tough skin & $\mathrm{e}$ & .42 & .12 & .09 \\
\hline is agile & $\mathrm{f}$ & .11 & .25 & .12 & is found near water & $\mathrm{e}$ & .21 & .25 & .04 \\
\hline is vegetarian & $\mathrm{e}$ & .47 & .50 & .09 & is found in Africa & $\mathrm{e}$ & .16 & .19 & .11 \\
\hline is wild & $\mathrm{e}$ & .32 & .75 & .09 & is vegetarian & $\mathrm{e}$ & .16 & .50 & .09 \\
\hline is docile & $\mathrm{e}$ & .26 & .12 & .07 & is found in zoos & $\mathrm{e}$ & .11 & .12 & .08 \\
\hline is a pest & $\mathrm{e}$ & .16 & .19 & .08 & is rare & $\mathrm{e}$ & .11 & .12 & .08 \\
\hline is domesticated & $\mathrm{e}$ & .16 & .38 & .05 & & & & & \\
\hline is timid & $\mathrm{e}$ & .16 & .06 & .07 & & & & & \\
\hline is herbivorous & $\mathrm{e}$ & .11 & .25 & .15 & & & & & \\
\hline
\end{tabular}




\begin{tabular}{|c|c|c|c|c|c|c|c|c|c|}
\hline & $\begin{array}{c}\text { Feature } \\
\text { type }\end{array}$ & $\begin{array}{c}\text { Domi- } \\
\text { nance }\end{array}$ & $\begin{array}{l}\text { Distinc- } \\
\text { tiveness }\end{array}$ & $\begin{array}{l}\text { Proportion of } \\
\text { all inter- } \\
\text { correlations } \\
\text { significant }\end{array}$ & & $\begin{array}{c}\text { Feature } \\
\text { type }\end{array}$ & $\begin{array}{l}\text { Domi- } \\
\text { nance }\end{array}$ & $\begin{array}{l}\text { Distinc- } \\
\text { tiveness }\end{array}$ & $\begin{array}{c}\text { Proportion o } \\
\text { all inter- } \\
\text { - correlations } \\
\text { significant }\end{array}$ \\
\hline \multicolumn{5}{|l|}{ Saw } & \multicolumn{5}{|l|}{ Screwdriver } \\
\hline has handle & s & .95 & .88 & .03 & has handle & s & .90 & .88 & .03 \\
\hline has teeth & $\mathrm{s}$ & .95 & .12 & .06 & is made of metal & s & .70 & .88 & .04 \\
\hline is made of metal & s & .68 & .88 & .04 & has blade & s & .45 & .50 & .06 \\
\hline has blade & s & .63 & .50 & .06 & has square/flat end & s & .40 & .12 & .02 \\
\hline is sharp & s & .58 & .50 & .06 & has shaft & s & .35 & .12 & .02 \\
\hline is long and/or thin & s & .32 & .38 & .02 & is made of wood & s & .35 & .62 & .01 \\
\hline is flexible & s & .26 & .12 & .03 & is sharp & s & .35 & .50 & .06 \\
\hline is made of wood & s & .26 & .62 & .01 & is small & s & .30 & .50 & .03 \\
\hline can cut & $\mathrm{f}$ & .84 & .50 & .09 & is long and/or thin & s & .20 & .38 & .02 \\
\hline can be sharpened & $\mathrm{f}$ & .26 & .38 & .06 & can turn screws & $\mathrm{f}$ & .90 & .12 & .02 \\
\hline can be played & $\mathrm{f}$ & .21 & .12 & .07 & can be used as a lever & $\mathrm{r} f$ & .45 & .12 & .02 \\
\hline is useful & $\mathrm{f}$ & .16 & .75 & .01 & is useful & $\mathrm{f}$ & .25 & .75 & .01 \\
\hline is handheld & $\mathrm{f}$ & .11 & .88 & .03 & is handheld & $\mathrm{f}$ & .20 & .88 & .03 \\
\hline is dangerous & $\mathrm{e}$ & .16 & .50 & .11 & is powered & $\mathrm{e}$ & .25 & .25 & .04 \\
\hline is powered & $\mathrm{e}$ & .16 & .25 & .04 & & & & & \\
\hline is used in metalwork & $\mathrm{k} \quad \mathrm{e}$ & .16 & .25 & .05 & Sledge & & & & \\
\hline \multirow[t]{2}{*}{ is used in woodwork } & $\mathrm{e}$ & .11 & .12 & .03 & is a toy & c & .33 & .12 & \\
\hline & & & & & is a vehicle & c & .89 & 1.00 & \\
\hline Scissors & & & & & has runner & s & .94 & .12 & .04 \\
\hline is a household item & c & .37 & .12 & & is made of wood & s & .72 & .12 & .01 \\
\hline is a tool & c & .79 & 1.00 & & has seat & s & .61 & .88 & .06 \\
\hline has blade & s & 1.00 & .50 & .06 & is made of metal & s & .44 & .88 & .04 \\
\hline has finger hole & s & .84 & .12 & .03 & has rope & s & .22 & .12 & .04 \\
\hline is sharp & s & .79 & .50 & .06 & is fast & $\mathrm{s}$ & .17 & .88 & .08 \\
\hline is made of metal & $\mathrm{s}$ & .58 & .88 & .04 & is unstable & $\mathrm{s}$ & .17 & .38 & .12 \\
\hline has hinge & s & .37 & .25 & .06 & has handle & s & .12 & .12 & .03 \\
\hline is serrated & $\mathrm{s}$ & .21 & .12 & .03 & is low & $\mathrm{s}$ & .11 & .12 & .04 \\
\hline is made of plastic & $\mathrm{s}$ & .16 & .25 & .03 & is made of plastic & s & .11 & .12 & .03 \\
\hline is pointed & s & .16 & .12 & .03 & can slide over & & & & \\
\hline is small & s & .16 & .50 & .03 & snow/ice & $\mathrm{f}$ & .83 & .12 & .04 \\
\hline is large & s & .11 & .12 & .07 & can be pulled & $\mathrm{f}$ & .67 & .12 & .09 \\
\hline is shiny & s & .11 & .12 & .09 & can be ridden & $\mathrm{f}$ & .39 & .25 & .09 \\
\hline can cut & $\mathrm{f}$ & 1.00 & .50 & .09 & can carry goods & $\mathrm{f}$ & .28 & .38 & .12 \\
\hline is handheld & $\mathrm{f}$ & .32 & .88 & .03 & can be steered & $\mathrm{f}$ & .22 & .12 & .04 \\
\hline can pierce & $\mathrm{f}$ & .26 & .12 & .03 & is useful & $\mathrm{f}$ & .22 & .75 & .01 \\
\hline can be bought & $\mathrm{f}$ & .11 & .25 & .01 & can be carried & $\mathrm{f}$ & .11 & .12 & .04 \\
\hline can be sharpened & $\mathrm{f}$ & .11 & .38 & .06 & can be made & $\mathrm{f}$ & .11 & .12 & .04 \\
\hline is useful & $\mathrm{f}$ & .11 & .75 & .01 & can move & $\mathrm{f}$ & .11 & .75 & .23 \\
\hline is used in sewing & $\mathrm{e}$ & .37 & .12 & .03 & can travel downhill & $\mathrm{f}$ & .11 & .12 & .04 \\
\hline \multirow[t]{3}{*}{ is used in cooking } & $\mathrm{e}$ & .11 & .12 & .03 & can be pulled by dogs & $r \mathrm{se}$ & .39 & .12 & .04 \\
\hline & & & & & is used in the Arctic & $\mathrm{e}$ & .17 & .12 & .04 \\
\hline & & & & & is motorised & e & .11 & .12 & .04 \\
\hline
\end{tabular}




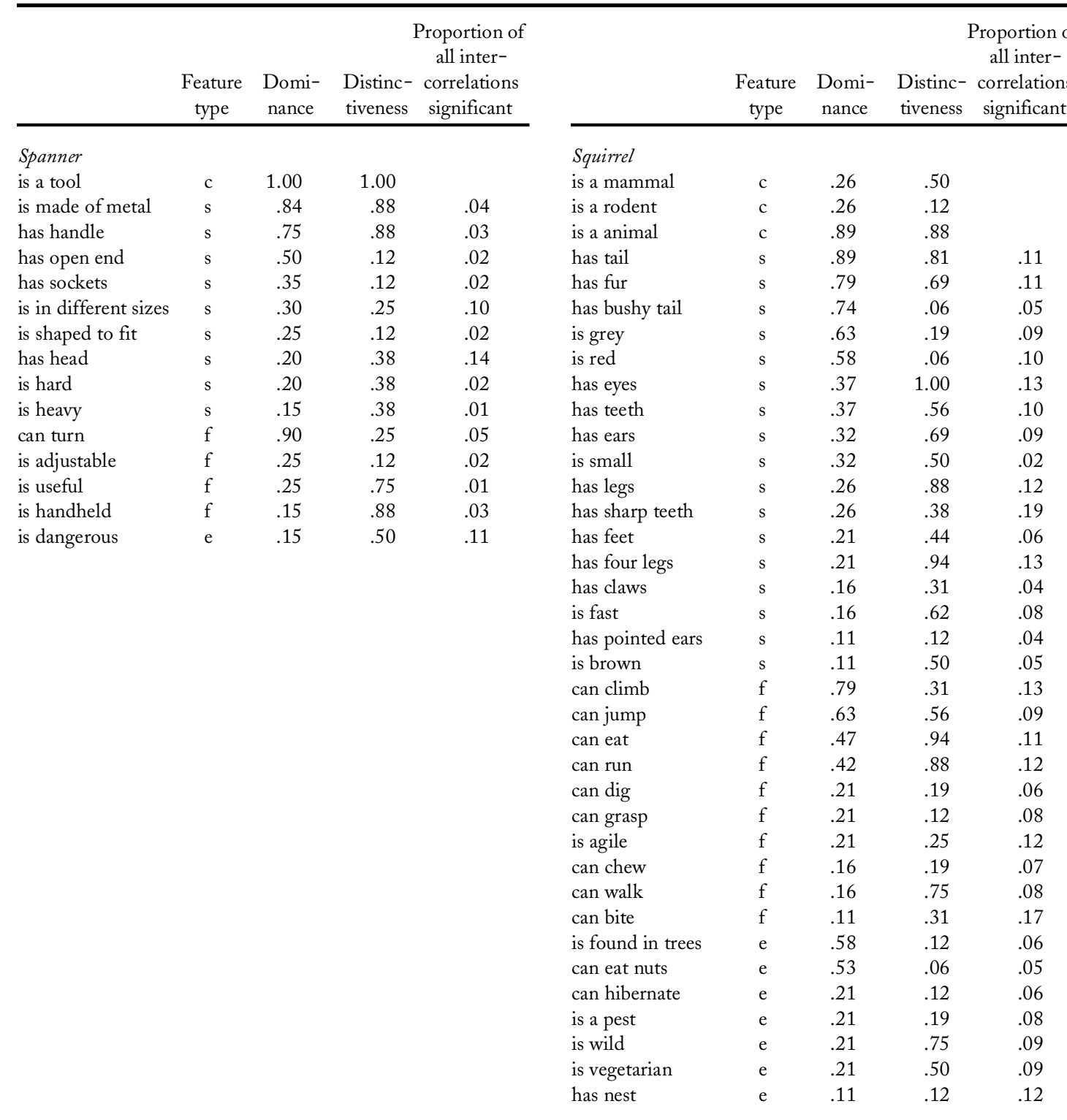




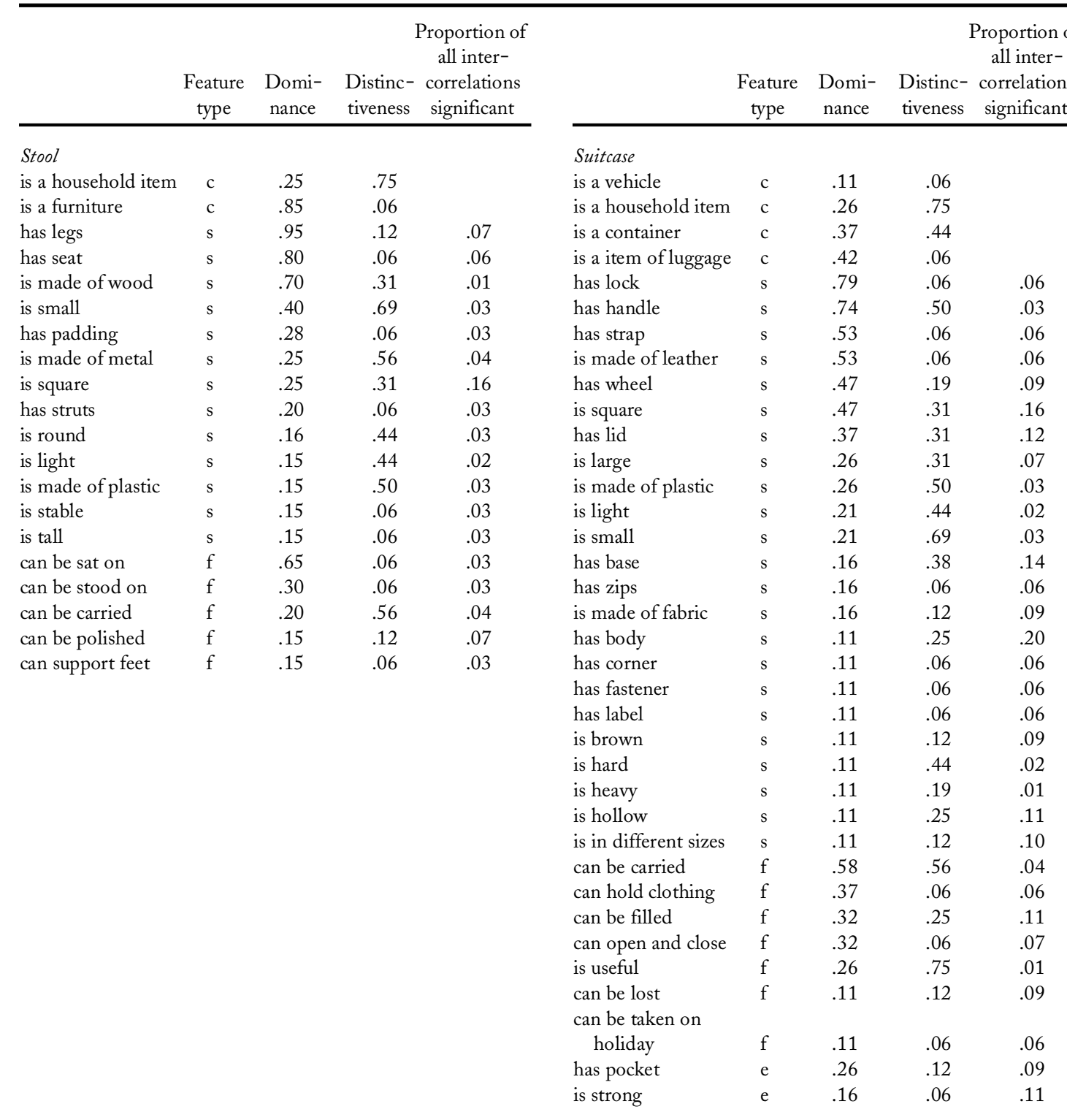




\begin{tabular}{|c|c|c|c|c|c|c|c|c|c|}
\hline & $\begin{array}{c}\text { Feature } \\
\text { type }\end{array}$ & $\begin{array}{l}\text { Domi- } \\
\text { nance }\end{array}$ & $\begin{array}{l}\text { P } \\
\text { Distinc- } \\
\text { tiveness }\end{array}$ & $\begin{array}{l}\text { Proportion of } \\
\text { all inter- } \\
\text { correlations } \\
\text { significant }\end{array}$ & & $\begin{array}{c}\text { Feature } \\
\text { type }\end{array}$ & $\begin{array}{l}\text { Domi- } \\
\text { nance }\end{array}$ & $\begin{array}{l}\text { Distinc- } \\
\text { tiveness }\end{array}$ & $\begin{array}{l}\text { Proportion } \\
\text { all inter- } \\
\text { correlation } \\
\text { significant }\end{array}$ \\
\hline \multicolumn{10}{|l|}{ Swan } \\
\hline is a animal & c & .16 & .50 & & is a cat & c & .16 & .06 & \\
\hline is a bird & $c$ & .84 & 1.00 & & is a mammal & $c$ & .16 & .50 & \\
\hline is white & $\mathrm{s}$ & .84 & .25 & .06 & is a animal & $\mathrm{c}$ & .95 & .88 & \\
\hline has feet & s & .74 & .75 & .06 & has stripes & s & .84 & .06 & .06 \\
\hline has beak & s & .68 & 1.00 & .07 & has fur & s & .63 & .69 & .11 \\
\hline has feathers & s & .68 & 1.00 & .07 & has tail & $\mathrm{s}$ & .63 & .81 & .11 \\
\hline has webbed feet & s & .68 & .38 & .10 & has teeth & $\mathrm{s}$ & .63 & .56 & .10 \\
\hline has neck & s & .58 & .25 & .07 & has legs & $\mathrm{s}$ & .47 & .88 & .12 \\
\hline has long neck & s & .53 & .25 & .07 & is fast & s & .47 & .62 & .08 \\
\hline has wings & s & .53 & 1.00 & .07 & has claws & s & .42 & .31 & .04 \\
\hline is large & s & .32 & .62 & .06 & has four legs & $\mathrm{s}$ & .37 & .94 & .13 \\
\hline has two legs & s & .21 & .62 & .13 & is large & s & .32 & .62 & .06 \\
\hline is black & s & .21 & .25 & .06 & has long tail & s & .21 & .25 & .11 \\
\hline can make a noise & s & .16 & .62 & .03 & can growl & s & .16 & .06 & .06 \\
\hline has large beak & s & .16 & .12 & .06 & has ears & $\mathrm{s}$ & .16 & .69 & .09 \\
\hline has large wings & s & .16 & .25 & .07 & has sharp teeth & $\mathrm{s}$ & .16 & .38 & .19 \\
\hline has legs & s & .16 & .75 & .12 & has skin & s & .16 & .44 & .10 \\
\hline has yellow beak & $\mathrm{s}$ & .16 & .12 & .06 & has body & $\mathrm{s}$ & .11 & .31 & .14 \\
\hline is elegant & s & .16 & .12 & .06 & has eyes & s & .11 & 1.00 & .13 \\
\hline has eyes & $\mathrm{s}$ & .11 & .75 & .13 & is quiet & $\mathrm{s}$ & .11 & .06 & .06 \\
\hline can fly & $\mathrm{f}$ & .89 & .75 & .14 & can run & $\mathrm{f}$ & .63 & .88 & .12 \\
\hline can swim & $f$ & .84 & .38 & .04 & can jump & $f$ & .32 & .56 & .09 \\
\hline can lay eggs & f & .42 & 1.00 & .05 & can breed & $\mathrm{f}$ & .26 & .56 & .07 \\
\hline can walk & $\mathrm{f}$ & .26 & .75 & .08 & can climb & f & .26 & .31 & .13 \\
\hline can reproduce & $\mathrm{f}$ & .21 & .25 & .07 & can roar & $\mathrm{f}$ & .16 & .06 & .06 \\
\hline can dive & $\mathrm{f}$ & .16 & .38 & .10 & can be trained & f & .11 & .25 & .17 \\
\hline can eat & $\mathrm{f}$ & .16 & .62 & .11 & can eat & $\mathrm{f}$ & .11 & .94 & .11 \\
\hline is found near water & $\mathrm{e}$ & .53 & .38 & .04 & can walk & $\mathrm{f}$ & .11 & .75 & .08 \\
\hline is dangerous & $\mathrm{e}$ & .37 & .50 & .05 & is agile & $f$ & .11 & .25 & .12 \\
\hline is royal & $\mathrm{e}$ & .26 & .12 & .06 & is dangerous & $\mathrm{e}$ & .68 & .25 & .05 \\
\hline is monogamous & $\mathrm{e}$ & .21 & .12 & .06 & is predator & $\mathrm{e}$ & .63 & .19 & .12 \\
\hline is wild & $\mathrm{e}$ & .21 & .62 & .09 & is wild & $\mathrm{e}$ & .47 & .75 & .09 \\
\hline can eat weeds & $\mathrm{e}$ & .16 & .12 & .06 & is carnivorous & $\mathrm{e}$ & .32 & .19 & .14 \\
\hline \multirow[t]{6}{*}{ has nest } & $\mathrm{e}$ & .16 & .38 & .12 & has good eyesight & $\mathrm{e}$ & .11 & .12 & .10 \\
\hline & & & & & has strong teeth & $\mathrm{e}$ & .11 & .12 & .07 \\
\hline & & & & & is found in a zoo & $\mathrm{e}$ & .11 & .19 & .08 \\
\hline & & & & & is found in jungles & $\mathrm{e}$ & .11 & .06 & .06 \\
\hline & & & & & is rare & $\mathrm{e}$ & .11 & .12 & .08 \\
\hline & & & & & is strong & $\mathrm{e}$ & .11 & .31 & .21 \\
\hline
\end{tabular}




\begin{tabular}{|c|c|c|c|c|}
\hline & $\begin{array}{c}\text { Feature } \\
\text { type }\end{array}$ & $\begin{array}{l}\text { Domi- } \\
\text { nance }\end{array}$ & $\begin{array}{l}\text { Distinc- } \\
\text { tiveness }\end{array}$ & $\begin{array}{l}\text { Proportion } \\
\text { all inter- } \\
\text { correlation } \\
\text { significant }\end{array}$ \\
\hline \multicolumn{5}{|l|}{ Toaster } \\
\hline is a tool & c & .32 & .50 & \\
\hline is a household item & c & .47 & .75 & \\
\hline is a electrical item & c & .58 & .12 & \\
\hline has a element & s & .74 & .06 & .05 \\
\hline is made of metal & s & .68 & .56 & .04 \\
\hline has plug & $\mathrm{s}$ & .63 & .06 & .05 \\
\hline has switch & s & .53 & .06 & .05 \\
\hline has lead & $\mathrm{s}$ & .37 & .06 & .05 \\
\hline has casing & s & .32 & .06 & .05 \\
\hline has controls & $\mathrm{s}$ & .32 & .06 & .12 \\
\hline is hot & s & .32 & .06 & .05 \\
\hline has body & s & .16 & .25 & .20 \\
\hline has slot & $\mathrm{s}$ & .16 & .06 & .05 \\
\hline has wires & s & .11 & .12 & .09 \\
\hline is coloured & s & .11 & .44 & .04 \\
\hline is hard & $\mathrm{s}$ & .11 & .44 & .02 \\
\hline is light & s & .11 & .44 & .02 \\
\hline is square & s & .11 & .31 & .16 \\
\hline can make toast & f & .79 & .06 & .05 \\
\hline can burn & $\mathrm{f}$ & .37 & .12 & .11 \\
\hline can be carried & $\mathrm{f}$ & .26 & .56 & .04 \\
\hline can be damaged & $\mathrm{f}$ & .11 & .06 & .05 \\
\hline can pop up & $\mathrm{f}$ & .11 & .06 & .05 \\
\hline is useful & $\mathrm{f}$ & .11 & .75 & .01 \\
\hline is found in kitchen & $\mathrm{e}$ & .47 & .06 & .05 \\
\hline has crumb tray & $\mathrm{e}$ & .11 & .06 & .05 \\
\hline
\end{tabular}

Proportion of all inter-

Feature Domi- Distinc- correlations type nance tiveness significant

Tomato

$\begin{array}{llll}\text { is a vegetable } & c & .40 & .17\end{array}$

$\begin{array}{llll}\text { is a fruit } & c & .70 & 1.00\end{array}$

$\begin{array}{llll}\text { has skin } & \mathrm{s} & 1.00 & 1.00\end{array}$

.10

is red

$.95 \quad .50$

.10

has pips

.85

.67

.15

is round

.65

.67

.13

has flesh

.60

1.00

.22

has leaves

is juicy

has stalk

is soft

is small

is sweet

is edible

can be cooked

.40

.83

.19

.40

.83

.67

.18

.35

.33

.15

.20

.50

.10

.15

1.00

.02

.15

1.00

.22

.70

83

.10

can be eaten raw

can ripen

can be picked

can fall

can grow

is found in salad

is found in tins

is common

.50

.17

.17

.06

.13

.15

.10

.13

.06

.08

.33

.17

Toothbrush

is a toiletry

is a household item

is a tool

has bristles

has handle

is long and/or thin

is coloured

is hard

is soft

has head

is light

is small

can clean teeth

is useful

can be washed

can clean

can hold toothpaste

is handheld

can scrub

is made of plastic

is hygienic

is found in a case

67

.33

.50

.06
.12

.75

.50

.12

.07

1.00

.50

.25

.44

.44

.19

.19

.44

.69

.06

.75

.12

.12

.06

.06

.06

.06

.06

.06 


\begin{tabular}{|c|c|c|c|c|c|c|c|c|c|}
\hline & $\begin{array}{l}\text { Feature } \\
\text { type }\end{array}$ & $\begin{array}{l}\text { Domi- } \\
\text { nance }\end{array}$ & $\begin{array}{l}\text { Distinc- } \\
\text { tiveness }\end{array}$ & $\begin{array}{l}\text { Proportion of } \\
\text { all inter- } \\
\text { correlations } \\
\text { significant }\end{array}$ & & $\begin{array}{l}\text { Feature } \\
\text { type }\end{array}$ & $\begin{array}{l}\text { Domi- } \\
\text { nance }\end{array}$ & $\begin{array}{l}\text { P } \\
\text { Distinc- } \\
\text { tiveness }\end{array}$ & $\begin{array}{r}\text { Proportion } \\
\text { all inter- } \\
\text { correlation } \\
\text { significan }\end{array}$ \\
\hline \multicolumn{5}{|l|}{ Train } & \multicolumn{5}{|l|}{ Turtle } \\
\hline is a vehicle & c & .95 & 1.00 & & is a reptile & $\mathrm{c}$ & .26 & \multicolumn{2}{|l|}{.19} \\
\hline & $\mathrm{s}$ & .89 & .12 & .06 & is a animal & c & .53 & \multicolumn{2}{|l|}{.88} \\
\hline & $\mathrm{s}$ & .89 & .75 & .09 & is a amphibian & c & .58 & \multicolumn{2}{|l|}{.12} \\
\hline & s & .47 & .62 & .07 & has shell & s & .95 & .06 & .04 \\
\hline is fast & $\mathrm{s}$ & .47 & .88 & .08 & has legs & $\mathrm{s}$ & .58 & .88 & .12 \\
\hline can make a noise & $\mathrm{s}$ & .26 & .75 & .08 & has four legs & s & .58 & .12 & .08 \\
\hline \multirow{2}{*}{$\begin{array}{l}\text { has seat } \\
\text { has wagon }\end{array}$} & $\mathrm{s}$ & .21 & .88 & .06 & has four legs & s & .56 & \multirow{2}{*}{$\begin{array}{l}.94 \\
.12\end{array}$} & .13 \\
\hline & $\mathrm{s}$ & .21 & .12 & .06 & is slow & $\mathrm{s}$ & .37 & & .08 \\
\hline has window & s & .16 & .50 & .19 & has skin & s & .32 & .44 & .10 \\
\hline has funnel & $\mathrm{s}$ & .11 & .12 & .06 & is hard & $\mathrm{s}$ & .32 & .06 & .09 \\
\hline \multirow{2}{*}{$\begin{array}{l}\text { can carry passengers } \\
\text { can run on rails }\end{array}$} & $f$ & .74 & .50 & .17 & has feet & $\mathrm{s}$ & .26 & .44 & .06 \\
\hline & $\mathrm{f}$ & .47 & .12 & .06 & has head & $\mathrm{s}$ & .26 & .38 & .04 \\
\hline can carry goods & $\mathrm{f}$ & .37 & .38 & .12 & is large & $\mathrm{s}$ & .21 & .62 & .06 \\
\hline can move & $\mathrm{f}$ & .32 & .75 & .23 & has eyes & $\mathrm{s}$ & .21 & 1.00 & .13 \\
\hline has whistle & $\mathrm{f}$ & .26 & .12 & .06 & has small head & $\mathrm{s}$ & .16 & .06 & .06 \\
\hline can pull & $\mathrm{f}$ & .21 & .12 & .08 & is brown & s & .16 & .50 & .05 \\
\hline has brakes & $\mathrm{f}$ & .21 & .38 & .12 & has claws & $\mathrm{s}$ & .11 & .31 & .04 \\
\hline can reverse & $\mathrm{f}$ & .16 & .38 & .14 & has flippers & s & .11 & .06 & .05 \\
\hline can stop at stations & $\mathrm{f}$ & .16 & .12 & .06 & has four feet & $\mathrm{s}$ & .11 & .06 & .04 \\
\hline can run underground & $\mathrm{f}$ & .11 & .12 & .06 & has thick skin & $\mathrm{s}$ & .11 & .12 & .08 \\
\hline is comfortable & $\mathrm{f}$ & .11 & .12 & .06 & is heavy & s & .11 & .25 & .15 \\
\hline is powerful & $\mathrm{f}$ & .11 & .38 & .15 & is small & $\mathrm{s}$ & .11 & .50 & .02 \\
\hline is useful & $\mathrm{f}$ & .11 & .75 & .01 & can swim & $\mathrm{f}$ & .89 & .25 & .04 \\
\hline has engine & $\mathrm{e}$ & .74 & .75 & .24 & can lay eggs & $\mathrm{f}$ & .68 & .19 & .05 \\
\hline is powered by & & & & & can walk & $f$ & .53 & .75 & .08 \\
\hline electricity & $\mathrm{e}$ & .37 & .12 & .06 & is edible & $\mathrm{f}$ & .42 & .31 & .10 \\
\hline has driver & $\mathrm{e}$ & .32 & .38 & .14 & can retract head & $f$ & .16 & .06 & .04 \\
\hline is powered by diesel & $\mathrm{e}$ & .26 & .38 & .14 & can dig & $\mathrm{f}$ & .11 & .19 & .06 \\
\hline is powered by steam & $\mathrm{e}$ & .22 & .12 & .06 & can eat & $\mathrm{f}$ & .11 & .94 & .11 \\
\hline is pollutory & $\mathrm{e}$ & .11 & .12 & .06 & is found near water & $\mathrm{e}$ & .42 & .25 & .04 \\
\hline & & & & & can hibernate & $\mathrm{e}$ & .21 & .12 & .06 \\
\hline & & & & & is vegetarian & $\mathrm{e}$ & .21 & .50 & .09 \\
\hline & & & & & is wild & $\mathrm{e}$ & .16 & .75 & .09 \\
\hline & & & & & is long-lived & $\mathrm{e}$ & .11 & .06 & .04 \\
\hline
\end{tabular}


Proportion of all inter-

Feature Domi- Distinc- correlations

type nance tiveness significant

\begin{tabular}{lcccc}
\hline Watering can & & & & \\
is a container & $\mathrm{c}$ & .16 & .44 & \\
is a tool & $\mathrm{c}$ & .63 & .50 & \\
has handle & $\mathrm{s}$ & .95 & .50 & .03 \\
has rose & $\mathrm{s}$ & .95 & .06 & .05 \\
has spout & $\mathrm{s}$ & .95 & .06 & .05 \\
is made of metal & $\mathrm{s}$ & .89 & .56 & .04 \\
is made of plastic & $\mathrm{s}$ & .68 & .50 & .03 \\
has body & $\mathrm{s}$ & .21 & .25 & .20 \\
is coloured & $\mathrm{s}$ & .21 & .44 & .04 \\
is open & $\mathrm{s}$ & .21 & .06 & .05 \\
has base & $\mathrm{s}$ & .11 & .38 & .14 \\
is hollow & $\mathrm{s}$ & .11 & .25 & .11 \\
is round & $\mathrm{s}$ & .11 & .44 & .03 \\
is small & $\mathrm{s}$ & .11 & .69 & .03 \\
can be filled & $\mathrm{f}$ & .53 & .25 & .11 \\
can sprinkle & $\mathrm{f}$ & .53 & .06 & .05 \\
can water plants & $\mathrm{f}$ & .42 & .06 & .05 \\
can be carried & $\mathrm{f}$ & .26 & .56 & .04 \\
can hold water & $\mathrm{f}$ & .26 & .06 & .05 \\
can be emptied & $\mathrm{f}$ & .21 & .19 & .09 \\
is useful & $\mathrm{f}$ & .21 & .75 & .01 \\
can be bought & $\mathrm{f}$ & .11 & .25 & .01 \\
can pour & $\mathrm{f}$ & .11 & .06 & .05 \\
can tip & $\mathrm{f}$ & .11 & .06 & .09 \\
is found in the garden $\mathrm{e}$ & .68 & .12 & .06 \\
is waterproof & $\mathrm{e}$ & .16 & .06 & .05 \\
can leak & $\mathrm{e}$ & .11 & .06 & .05 \\
can measure & $\mathrm{e}$ & .11 & .06 & .05 \\
\hline
\end{tabular}

Feature types: $\mathrm{c}=$ categorising; $\mathrm{e}=$ encyclopaedic; $\mathrm{f}=$ functional; $\mathrm{s}=$ sensory. 